\title{
A Distributed Multifactorial Particle Swarm Optimization Approach
}

This paper was downloaded from TechRxiv (https://www.techrxiv.org).

LICENSE

CC BY 4.0

SUBMISSION DATE / POSTED DATE

$17-12-2021 / 22-12-2021$

\section{CITATION}

Aboud, Ahlem; Rokbani, Nizar; Mirjalili, Seyedali; Qahtani, Abdulrahman M.; Almutiry, Omar; dhahri, habib; et al. (2021): A Distributed Multifactorial Particle Swarm Optimization Approach. TechRxiv. Preprint. https://doi.org/10.36227/techrxiv.17260040.v1

$\mathrm{DOI}$

10.36227/techrxiv.17260040.v1 


\title{
A Distributed Multifactorial Particle Swarm Optimization Approach
}

\author{
Ahlem Aboud $^{\mathrm{a}, \mathrm{b}, *}$, Nizar Rokbani ${ }^{\mathrm{b}, \mathrm{c}}$, Seyedali Mirjalilie,f, Abdulrahman M. Qahtani ${ }^{\mathrm{g}}$, Omar Almutiry ${ }^{\mathrm{h}}$, \\ Habib Dhahri ${ }^{\text {h }}$, and Adel M. Alimi ${ }^{\text {b,d }}$ \\ ${ }^{a}$ University of Sousse, ISITCom, 4011, Sousse, Tunisia. \\ ${ }^{b}$ REGIM Lab: REsearch Groups in Intelligent Machines, University of Sfax, National Engineering School of Sfax (ENIS), BP \\ 1173, Sfax, 3038, Tunisia. \\ ${ }^{c}$ High Institute of Applied Science and technolgy of Sousse, University of Sousse, Tunisia. \\ ${ }^{d}$ Department of Electrical and Electronic Engineering Science, Faculty of Engineering and the Built Environment, University \\ of Johannesburg, South Africa. \\ ${ }^{e}$ Centre for Artificial Intelligence Research and Optimisation, Torrens University Australia, Brisbane, Australia. \\ ${ }^{f}$ Yonsei Frontier Lab, Yonsei University, South Korea. \\ ${ }^{g}$ Department of Computer Science, College of Computers and Information Technology, Taif University, P.O.Box. 11099, Taif \\ 21944, Saudi Arabia. \\ ${ }^{h}$ College of Applied Computer Science, King Saud University, Riyadh, Saudi Arabia.
}

\begin{abstract}
Multifactorial Optimization (MFO) and Evolutionary Transfer Optimization (ETO) are new optimization challenging paradigms for which the multi-Objective Particle Swarm Optimization system (MOPSO) may be interesting despite limitations. MOPSO has been widely used in static/dynamic multi-objective optimization problems, while its potentials for multi-task optimization are not completely unveiled. This paper proposes a new Distributed Multifactorial Particle Swarm Optimization algorithm (DMFPSO) for multi-task optimization. This new system has a distributed architecture on a set of sub-swarms that are dynamically constructed based on the number of optimization tasks affected by each particle skill factor. DMFPSO is designed to deal with the issues of handling convergence and diversity concepts separately. DMFPSO uses Beta function to provide two optimized profiles with a dynamic switching behaviour. The first profile, Beta-1, is used for the exploration which aims to explore the search space toward potential solutions, while the second Beta-2 function is used for convergence enhancement. This new system is tested on 36 benchmarks provided by the CEC'2021 Evolutionary Transfer Multi-Objective Optimization Competition. Comparatives with the state-of-the-art methods are done using the Inverted General Distance (IGD) and Mean Inverted General Distance (MIGD) metrics. Based on the MSS metric, this proposal has the best results on most tested problems.
\end{abstract}

Keywords: Dynamic Multi-Objective Particle Swarm Optimization, Distributed Algorithm, Evolutionary Transfer Optimization, Large Scale Problem, Multitasking Optimization, Many Objective Optimization Problem.

${ }^{*}$ Corresponding author. E-mail address: ahlem.aboud@ regim.usf.tn (A. Aboud).

Contributing authors: Email addresses: nizar.rokbani@ieee.org (N. Rokbani), ali.mirjalili@torrens.edu.au (S. Mirjalili), amqahtani@tu.edu.sa (A. M. Qahtani), oalmutiry@ksu.edu.sa (O. Almutiry), hdhahri@ksu.edu.sa (H. Dhahri), adel.alimi@ieee.org (A. M. Alimi). 


\section{Introduction}

Multifactorial optimization (MFO) for multi-task optimization is a new paradigm in the domain of optimization [1], [2]. Since 2016, the field of evolutionary computing has undergone major evolutions of several complex problems, which are characterized by a large number of decision variables (more than 100) with more than three objective functions performed in multiple tasks. Unlike using Swarm Intelligence (SI) methods [3], [4] and Evolutionary Algorithms (EA) [5], [6] to solve a single task from scratch, the main challenge of Multi-Objective Evolutionary Algorithms (MOEAs) is to optimize multiple independent tasks simultaneously where a task may stand for a static single/multi-objective problem (SOP, MOP) or a Many-Objective Optimization Problem (MaOP) or a dynamic multi-objective problem (DMOP) [7]-[11]. In [1], Gupta et al. introduced MFO for multi-task optimization, which is also known as Multi-Objective Multitasking Optimization (MTO). A multi-task optimization problem (MTOP) may be expressed as in Equation (1), where each task $k$ is defined as a minimization problem (MOP, DMOP or MaOP).

$$
\text { Minimize: }\left\{\begin{array}{c}
\mathrm{F}_{1}\left(\mathrm{x}_{1}\right)=\left(\mathrm{f}_{1}^{1}\left(\mathrm{x}_{1}\right), \ldots, \mathrm{f}_{1}^{\mathrm{m}_{1}}\left(\mathrm{x}_{1}\right)\right) \\
\mathrm{F}_{2}\left(\mathrm{x}_{2}\right)=\left(\mathrm{f}_{2}^{1}\left(\mathrm{x}_{2}\right), \ldots, \mathrm{f}_{2}^{\mathrm{m}_{2}}\left(\mathrm{x}_{2}\right)\right) \\
\ldots \ldots \\
\mathrm{F}_{\mathrm{k}}\left(\mathrm{x}_{\mathrm{k}}\right)=\left(\mathrm{f}_{\mathrm{k}}^{1}\left(\mathrm{x}_{\mathrm{k}}\right), \ldots, \mathrm{f}_{\mathrm{k}}^{\mathrm{m}_{\mathrm{k}}}\left(\mathrm{x}_{\mathrm{k}}\right)\right)
\end{array}\right.
$$

$$
\text { Subject to: } \mathrm{x}_{\mathrm{i}} \in \prod_{\mathrm{s}=1}^{\mathrm{n}_{\mathrm{i}}}\left[\mathrm{a}_{\mathrm{i}}^{\mathrm{s}}, \mathrm{b}_{\mathrm{i}}^{\mathrm{s}}\right], \mathrm{i}=1, \ldots, \mathrm{k}
$$

where $F_{k}$ stands for the $k^{\text {th }}$ multi-objective optimization task, $\prod_{s=1}^{n_{k}}\left[a_{k}^{s}, b_{k}^{s}\right]$ represents the decision space, $n_{k}$ is the dimension of the decision space, and $f_{k}^{1}\left(x_{k}\right), \ldots, f_{k}^{m_{k}}\left(x_{k}\right)$, presents the objective space of the $k^{t h}$ task.

Multi-Factorial Optimization, MFO, was introduced in bi-level programming [12], where an implicit genetic transfer across multiple tasks was used to reduce time-processing challenges and enhance convergence. It is characterized by multiple concurrent search spaces corresponding to dependent or independent tasks with different objective spaces. Evolutionary multitasking considers the $K$ tasks to optimize as independent. Each task $T_{j}, \forall j=1, \ldots, K$ is considered independently in its search space $X_{j}$. However, the main goal of MFO is not to find the best trade-off between consecutive objective functions $f_{j}$, but to optimize multiple tasks at the same time.

Four main challenges rise when using MOEA for MFO [13]: reducing the intensity of negative transfer knowledge, allocating the necessary resources for each problem, establishing acceptable mapping between tasks, and managing the complexity of transferred knowledge when needed. As mentioned above, the most known MFO method was first proposed by Gupta et al. [1], denoted by Multifactorial Evolutionary Algorithm, (MFEA). MFEA is a parallel population-based search method which solves a set of MTOPs using a single fitness function. Transferring positive knowledge among tasks is the main important step of evolutionary multitasking optimization. However, many improved MFEA variants have been proposed. In [14], the Generalized Multifactorial Evolutionary Algorithm (G-MFEA) was proposed to optimize multiple tasks with different dimensions and separate objective space.

Evolutionary multitasking based Effective Knowledge Transfer approach (EMT/ET) [13] was integrated with a set of nondominated solutions as a positive transferred knowledge across tasks. A Multi-Objective-Multifactorial Evolutionary Algorithm (MO-MFEA) [15] and a Permutation-based MFEA [16] are used for MOP and combinatorial optimization problems, respectively. Evolutionary Transfer Optimization (ETO) [17] used evolutionary algorithm (EA), for multi-task optimization and for transferring useful information across tasks as presented in the explicit multi-population evolutionary framework (MPEF) [18]. ETO aims to make a learnable EA to speed up the computation time and automatically solving related tasks using only positive knowledge. ETO can use several transfer learning tools to improve the efficiency of evolutionary algorithms, such as prediction of new solutions, reuse of previous experience, sharing of similar knowledge and consider non-dominant solutions between related tasks. 
The main components of ETO system are presented in Figure 1. They appear through the combination of classic EA and knowledge learning process, when all positive solution is preserved and transferred between related tasks in the same problem or domain. For the EA proposed in [13], only non-dominated solutions are considered in the sharing step between target tasks. Since 2010, the term Transfer Learning (TL) or knowledge transfer [19] has been widely used in a variety of Machine Learning (ML) methods for classification, clustering, regression and deep learning training models. This mechanism has considered to improve the performance of the learner by avoiding much expensive data-labelling efforts taking into consideration the difference between feature space representation and the data distribution. Many TL techniques [20] are used to construct and enhance ML models, such a matrix knowledge, tree knowledge and neural knowledge [21] for face recognition, deep learning, speech recognition and natural language processing applications.

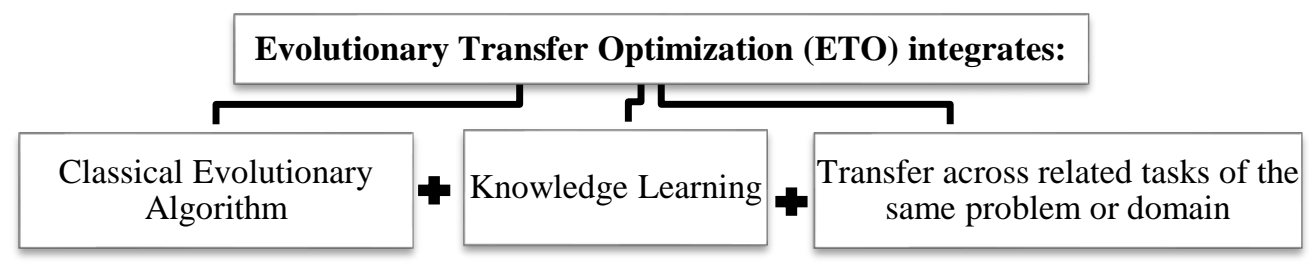

Fig. 1. Evolutionary Transfer Optimization Components.

Furthermore, two requirements are needed to build an efficient learnable EA, so it includes data representation and a transfer learning mechanism across multiple tasks. Different transfer learning (TL) tools have been integrated with EA to solve multiobjective optimization problems with multiple related tasks. These mechanisms are detailed in the next section and resumed in Table 1. The main motivation for this study is the importance of the recent field of MTO in terms of the complexity of the problem. To the best of our knowledge, there is no proposed method based on the PSO system to solve the new set of 36 benchmarks provided by CEC'2021 Evolutionary Transfer Multi -Objective Optimization Competition.

This paper proposes a new Distributed Multifactorial Particle Swarm Optimization (DMFPSO) algorithm for multitasking optimization problems. This new system has a distributed architecture on a set of sub-swarms that are dynamically constructed based on the number of optimization tasks affected by each particle skill factor. The novelty of the DMFPSO approach is reflected in the advantages of using a couple of Beta equation provided by Alimi [22]. Changes in the properties of the beta function can lead to different shapes, such as Gaussian, triangular and trapezoidal, which are suitable for single and multi-dimensional search spaces, and are very flexible to solve different type of optimization problems, including the diversification of data distribution.

DMFPSO method presents a dynamic switching behaviour based on two beta distribution profiles denoted by "Beta-1" and "Beta-2". The "Beta-1" profile is used for exploration to perform a normally distributed population, pushing particles to explore all search spaces in order to get closer to the best solutions over time. The second "Beta-2" profile aims to exponentially decrease the distribution of all the optimal particles in the convergence phase. The dynamic switching behaviour of each particle (from Beta 1 to Beta 2 level and vice versa) is assumed by the comparison procedure between the fitness function value and the average solution value. For each particle $p$, if the fitness value $F i t(X)$ is greater than the average $m F i t(X)$, the "Beta-1" exploration profile is considered as a mechanism to update the position. Otherwise, the "Beta-2" exploitation profile will be used. These two beta profiles are considered to deal with the issue of treating the concept of convergence and diversity separately, aiming to improve the efficiency of optimization in exploration and exploitation without any deterioration in the optimization process.

The rest of this paper is organized as follows. Section 2, outlines evolutionary multitasking and transfer learning-based approaches. Section 3, details the proposed Distributed Multifactorial Particle Swarm Optimization (DMFPSO) system. The experimental setting and discussion of all quantitative results are presented in Section 4. Finally, Section 5 summarizes the paper and suggested some prospects for future work. 


\section{State of Art of Evolutionary Multitasking and Transfer Learning-Based Approaches}

Recently, MFO and ETO have received great attention in the field of optimization. Inspired by the ability of the human brain to manage multiple tasks simultaneously. MTO has been proposed as a new paradigm, attracting the attention of several researchers in the Evolutionary Computation (EC) community. Many contributions for multi-task optimization have been published, including some useful techniques to guarantee positive knowledge transfer across related tasks or problems. Therefore, four categories of optimization problems are considered, including MOP, MaOP, Large-scale Multi-Objective problem, Many-Task Problems and DMOP with multiple related tasks. Based on the types of problems, Tan et al [17] classified ETO approaches into five categories:

- ETO for multi-task optimization,

- ETO method for optimization in uncertain environment or DMOP,

- ETO for multi/many-objective optimization,

- ETO for complex optimization,

- $\quad$ ETO for machine learning applications.

The main differences between a multiple tasks' optimization problem, MTOP, and multiple optimization problem, MOP, are the type and the dimension of the search space [2]. When a vector of the $M$ objective functions $\left\{f_{1}, \ldots, f_{M}\right\}$ of MOP are executed on a single search space, while an MTO, involves several search spaces, one for each optimization task. Based on the MFEA approach [1], several approaches are proposed to solve a set of MTOPs with a single objective function. In standard MFEA, a single population is used to perform multiple tasks. This mechanism is called implicit parallelism of population-based search. MFEA was proposed to solve k-factorial problem, when the goal is to find the minimum of the fitness function $\left\{x_{1}, \ldots, x_{k}\right\}=$ $\operatorname{argmin}\left\{f_{1}, \ldots, f_{k}\right\} ; x_{j}$ is a feasible solution in $X_{k}$. All individuals $\left\{X_{1}, \ldots, X_{k}\right\}$ are performed in a unified search space. In addition, the concept of multifactorial optimization is introduced [1] to solve the K-factorial problem. Each individual $p_{i}$ is decoded according to the task dimension $\left\{x_{1}^{i}, \ldots, x_{k}^{i}\right\}$ where; $x_{1}^{i} \in X_{1}$ and $x_{k}^{i} \in X_{k}$, and is characterized by the five properties including factorial cost, factorial rank, scalar fitness, skill factor and multifactorial optimality. The optimal set of non-dominated solutions is determined using a multifactorial optimality mechanism. A member $p^{*}$ is optimal in the multifactorial sense, if it is the nondominated solution for all the objective functions $\left\{f_{1}^{*}, \ldots, f_{k}^{*}\right\}$ for each task, where $f_{j}^{*} \leq f_{j}\left(x_{j}\right)$ for all $x_{j} \in X_{j}$.

As shown in Table 1, several MFEA variants have been adapted to MTOP, involving a variety of TL mechanisms to manage the dimensionality of decision variables [14], and positive transferred data [13], [23]. Furthermore, the uncertainty of the optimization domain or DMO can be maintained by the time variation of the decision variables and/or fitness function and the dynamic approximation to the optimal solution. In DMO, global and local solutions may change, or there may be some similarities from one instance to another. The main goal of the ETO method used for DMOP is the hybridization of transfer learning mechanisms to retain useful knowledge during dynamic optimization. Furthermore, Jiang et al. [24], developed a dynamic multiobjective evolutionary algorithm based on transfer learning (Tr-DMOEA) to manage the uncertainty in the search space. $\mathrm{Tr}$ DMOEA system is a time-varying prediction model that takes into account related and identical data distributions. Zhoulet al. [25] developed an evolutionary search paradigm with learning capabilities, which is based on structured knowledge captured form previous optimized solutions to tackle dynamic vehicle routing problem.

Improved Tr-DMOEA system [26] used a linear kernel function to combine the previous solutions and the transferred solutions to build a new population. Furthermore, the imbalanced learning-based knee point mechanism [27], manifold transfer learning [28] and kernel-based methods [26] are used to manage the uncertainty of the problem by predicting the movements of the optimal solutions. Last but not least, the hybridization of EA with ETO tools may be useful in solving multi/many objective optimization problems. Among the well-known tools used for positive knowledge transfer across related problems are: surrogate models [24], 
autoencoder [29] and non-dominated solutions [13], [30]. Taken together, several hybrid models have been proposed using EA and TL tools to solve single-objective (SO) [31] , multi-objective (MO) [32] multitask benchmarks and large-scale optimization problems [33]. However, PSO based approaches were not investigated to solve the new 36 benchmarks provided by the CEC'2021 Evolutionary Transfer Multi -Objective Optimization, which is the main motivation of this study.

Table 1. Existing Methods for MFO and ETO

\begin{tabular}{|c|c|c|c|c|}
\hline $\begin{array}{l}\text { Optimization } \\
\text { Domain }\end{array}$ & References & Proposed Approach & Transfer Learning Mechanism & Tested Benchmarks \\
\hline \multirow{6}{*}{$\begin{array}{l}\text { ETO for } \\
\text { Multitasking } \\
\text { Optimization }\end{array}$} & $\begin{array}{c}\text { Gupta et al. (2016) } \\
\text { [1] }\end{array}$ & $\begin{array}{c}\text { Multifactorial } \\
\text { Evolutionary } \\
\text { Algorithm (MFEA) }\end{array}$ & $\begin{array}{l}\text { MFEA is inspired from the multifactorial } \\
\text { inheritance models including the transmission of } \\
\text { biological and cultural building blocks from } \\
\text { parents to their offspring }\end{array}$ & $\begin{array}{c}\text { Sphere, Ackley's, Rastrigin's, Single and } \\
\text { Multiple Knapsack Problems, Quadratic } \\
\text { Assignment Problem and Capacitated } \\
\text { Vehicle Routing Problem [1]. } \\
\end{array}$ \\
\hline & $\begin{array}{c}\text { Gupta et al. (2017) } \\
{[15]}\end{array}$ & $\begin{array}{l}\text { Multi-Objective- } \\
\text { Multifactorial } \\
\text { Evolutionary } \\
\text { Algorithm (MO- } \\
\text { MFEA) } \\
\end{array}$ & $\begin{array}{c}\text { implicit transfer of genetic material between } \\
\text { candidate solutions belonging to different tasks } \\
\text { based on a random mating probability (rmp) and } \\
\text { offspring can randomly select a parental skill } \\
\text { factor for imitation }\end{array}$ & $\begin{array}{c}\text { Four variants of the ZDT4 benchmark } \\
\text { function (ZDT4-R, ZDT4-G, ZDT4-A, } \\
\text { ZDT4-RC) and a real-world } \\
\text { manufacturing process design problem } \\
\text { [15]. }\end{array}$ \\
\hline & $\begin{array}{c}\text { Yuan et al. (2017) } \\
{[16]}\end{array}$ & $\begin{array}{l}\text { Permutation-based } \\
\text { MFEA }\end{array}$ & $\begin{array}{l}\text { permutation-based MFEA for combinatorial } \\
\text { optimization problems (PCOPs) based a new } \\
\text { unified representation and a new survivor } \\
\text { selection procedure }\end{array}$ & $\begin{array}{l}\text { combinatorial optimization problems } \\
\text { including the travel salesman problem } \\
\text { (TSP), job-shop scheduling problem (JSP), } \\
\text { quadratic assignment problem (QAP) and } \\
\text { linear ordering problem (LOP) [16] }\end{array}$ \\
\hline & $\begin{array}{c}\text { Ding et al. (2019) } \\
{[14]}\end{array}$ & $\begin{array}{c}\text { Generalized } \\
\text { Multifactorial } \\
\text { Evolutionary } \\
\text { Algorithm (G-MFEA) }\end{array}$ & $\begin{array}{l}\text { improved version of MFEA is generalized over } \\
\text { two strategies. One for decision variable } \\
\text { translation and the other for decision variable } \\
\text { shuffling, to facilitate knowledge transfer } \\
\text { between optimization problems having different } \\
\text { locations of the optimums and different numbers } \\
\text { of decision variables. }\end{array}$ & Eight MFO problems F1-F8 [14] \\
\hline & Lin et al. (2020) [13] & $\begin{array}{c}\text { Evolutionary } \\
\text { multitasking based } \\
\text { Effective Knowledge } \\
\text { Transfer Approach } \\
\text { (EMT/ET) } \\
\end{array}$ & $\begin{array}{l}\text { positive knowledge transfer method using the } \\
\text { nondominated solutions of the target task. } \\
\text { Otherwise only positive neighbour is considered } \\
\text { for the transferring step. }\end{array}$ & $\begin{array}{l}\text { Nine problems, CEC } 2017 \\
\text { Evolutionary MultiTask Optimization } \\
\text { Competition benchmarks }\end{array}$ \\
\hline & $\begin{array}{c}\text { Zhou et al. (2021) } \\
\text { [23] }\end{array}$ & $\begin{array}{l}\text { A new MFEA with } \\
\text { adaptive knowledge } \\
\text { transfer (MFEA-AKT) }\end{array}$ & Adapts the crossover for knowledge transfer & $\begin{array}{c}\text { nine multitask problems (CIHS, CIMS, } \\
\text { CILS, PIHS, PIMS, PILS, NIHS, NIMS, } \\
\text { and NILS) }\end{array}$ \\
\hline \multirow{5}{*}{$\begin{array}{l}\text { ETO for } \\
\text { Dynamic } \\
\text { Multi- } \\
\text { Objective } \\
\text { Optimization }\end{array}$} & $\begin{array}{c}\text { Jiang et al. (2018) } \\
\text { [34] }\end{array}$ & $\begin{array}{l}\text { Transfer Learning- } \\
\text { Based Dynamic Multi- } \\
\text { Objective } \\
\text { Evolutionary } \\
\text { Algorithm (Tr- } \\
\text { DMOEA) }\end{array}$ & $\begin{array}{l}\text { predict the time-varying optimum taking into } \\
\text { consideration the non-independent and } \\
\text { identically data distribution }\end{array}$ & $\begin{array}{c}\text { Twelve DMOPs [34] (FDA4, FDA5, } \\
\text { FDA5iso, FDAdec, DMOP2iso, } \\
\text { DMOP2dec, DIMP2, DMOP2, DMOP3, } \\
\text { HE2, HE7 and HE9) }\end{array}$ \\
\hline & $\begin{array}{l}\text { Zhou1 et al. (2017) } \\
\text { [25] }\end{array}$ & $\begin{array}{l}\text { evolutionary search } \\
\text { paradigm with } \\
\text { learning capability for } \\
\text { solving the DVRP }\end{array}$ & $\begin{array}{c}\text { learning capability using the structured } \\
\text { knowledge captured form the previous optimized } \\
\text { solutions and reused during the evolutionary } \\
\text { search }\end{array}$ & $\begin{array}{l}\text { Dynamic Vehicle Routing Problem } \\
\text { (DVRP) }\end{array}$ \\
\hline & $\begin{array}{c}\text { Ruan et al. (2019) } \\
\text { [26] }\end{array}$ & Improved Tr-DMOEA & $\begin{array}{l}\text { A linear kernel function to combine the previous } \\
\text { solutions with the transferred solutions to } \\
\text { construct the new population. }\end{array}$ & $\begin{array}{l}\text { The IEEE CEC } 2015 \text { Benchmark problems } \\
\text { [35]. }\end{array}$ \\
\hline & $\begin{array}{c}\text { Jiang et al. (2021) } \\
\text { [27] }\end{array}$ & $\begin{array}{l}\text { knee point-based } \\
\text { transfer learning } \\
\text { method based } \\
\text { evolutionary algorithm } \\
\text { for DMOP (KT- } \\
\text { DMOEA) }\end{array}$ & $\begin{array}{c}\text { At each iteration, the initial population is } \\
\text { constructed using all estimated knee points } \\
\text { presenting the imbalance transfer learning } \\
\text { method. }\end{array}$ & DF1-DF14 benchmarks \\
\hline & $\begin{array}{c}\text { Jiang et al. }(2020) \\
{[28]}\end{array}$ & $\begin{array}{l}\text { memory-driven } \\
\text { manifold TL-based } \\
\text { evolutionary algorithm } \\
\text { for dynamic multi- } \\
\text { objective optimization } \\
\text { (MMTL-DMOEA) }\end{array}$ & $\begin{array}{l}\text { Construct the initial population based on the } \\
\text { predicted optimal solutions and the previous } \\
\text { elites of these individuals. }\end{array}$ & FDA series, dMOP series and DF series \\
\hline & $\begin{array}{c}\text { Yang et al. }(2020) \\
{[24]}\end{array}$ & $\begin{array}{l}\text { evolutionary algorithm } \\
\text { assisted by coarse and }\end{array}$ & $\begin{array}{l}\text { The coarse surrogate (CS) aims to guide the } \\
\text { algorithm to quickly find a promising subregion } \\
\text { in the search space, whereas the fine one focuses }\end{array}$ & $\begin{array}{l}\text { four DTLZ test suite and four F1-F4 } \\
\text { functions. }\end{array}$ \\
\hline
\end{tabular}




\begin{tabular}{|c|c|c|c|c|}
\hline \multirow{3}{*}{$\begin{array}{l}\text { ETO for } \\
\text { Multi/Many- } \\
\text { Objective } \\
\text { Optimization }\end{array}$} & & $\begin{array}{c}\text { fine surrogates' } \\
\text { models }\end{array}$ & $\begin{array}{l}\text { on leveraging good solutions according to the } \\
\text { knowledge transferred from the CS. }\end{array}$ & \\
\hline & $\begin{array}{l}\text { Feng et al. (2017) } \\
\qquad[29]\end{array}$ & $\begin{array}{c}\text { Autoencoding } \\
\text { Evolutionary Search } \\
\text { with Learning Across } \\
\text { Heterogeneous } \\
\text { Problems }\end{array}$ & $\begin{array}{l}\text { A novel autoencoding evolutionary search } \\
\text { paradigm with learning capability across } \\
\text { heterogeneous problems using the single layer } \\
\text { denoising autoencoder (DA) }\end{array}$ & $\begin{array}{c}12 \text { MOP benchmarks: five MOPs in ZDT } \\
\text { family and seven MOPs in DTLZ family } \\
\text { problems }\end{array}$ \\
\hline & $\begin{array}{l}\text { Liang et al. (2020) } \\
\qquad[30]\end{array}$ & $\begin{array}{c}\text { evolutionary } \\
\text { multitasking } \\
\text { optimization algorithm } \\
\text { (EMT-PD) }\end{array}$ & $\begin{array}{c}\text { Two-stage adaptive knowledge transfer method } \\
\text { by considering population distribution for both } \\
\text { multi- and many-objective optimization using } \\
\text { evolutionary multitasking }\end{array}$ & $\begin{array}{c}\text { nine multitask problems (CIHS, CIMS, } \\
\text { CILS, PIHS, PIMS, PILS, NIHS, NIMS, } \\
\text { and NILS) }\end{array}$ \\
\hline
\end{tabular}

\section{The Proposed Distributed Multifactorial Particle Swarm Optimization Approach}

The general flowchart of the proposed Distributed Multifactorial Particle Swarm Optimization (DMFPSO) system is shown in Figure 2. Compared to beta PSO [36], the new DMFPSO method aims to solve $K$ multiple tasks simultaneously based on multiple sub-swarms. Where, each task can stand for: a multi/many-objective optimization problem, a large-scale MOP or DMOP. The novelty of the DMFPSO method consists in the use of distributed architecture on a set of sub-swarms that are dynamically constructed based on the number of optimization tasks affected by each particle skill factor. In addition, DMFPSO presents a new dynamic switching behaviour over a couple of beta functions Beta-1 and Beta-2 as new equations to update the position of each particle $p_{i}$ in the swarm $S$. The overall process of DMFPSO starts after defining a set of $k$ tasks as input. According to the task $T_{j}$ assigned to each particle $p_{i}$, the population of $N$ particle is subdivided into k sub-swarms. Then, for each task $T_{j}$, only one subswarm is considered.

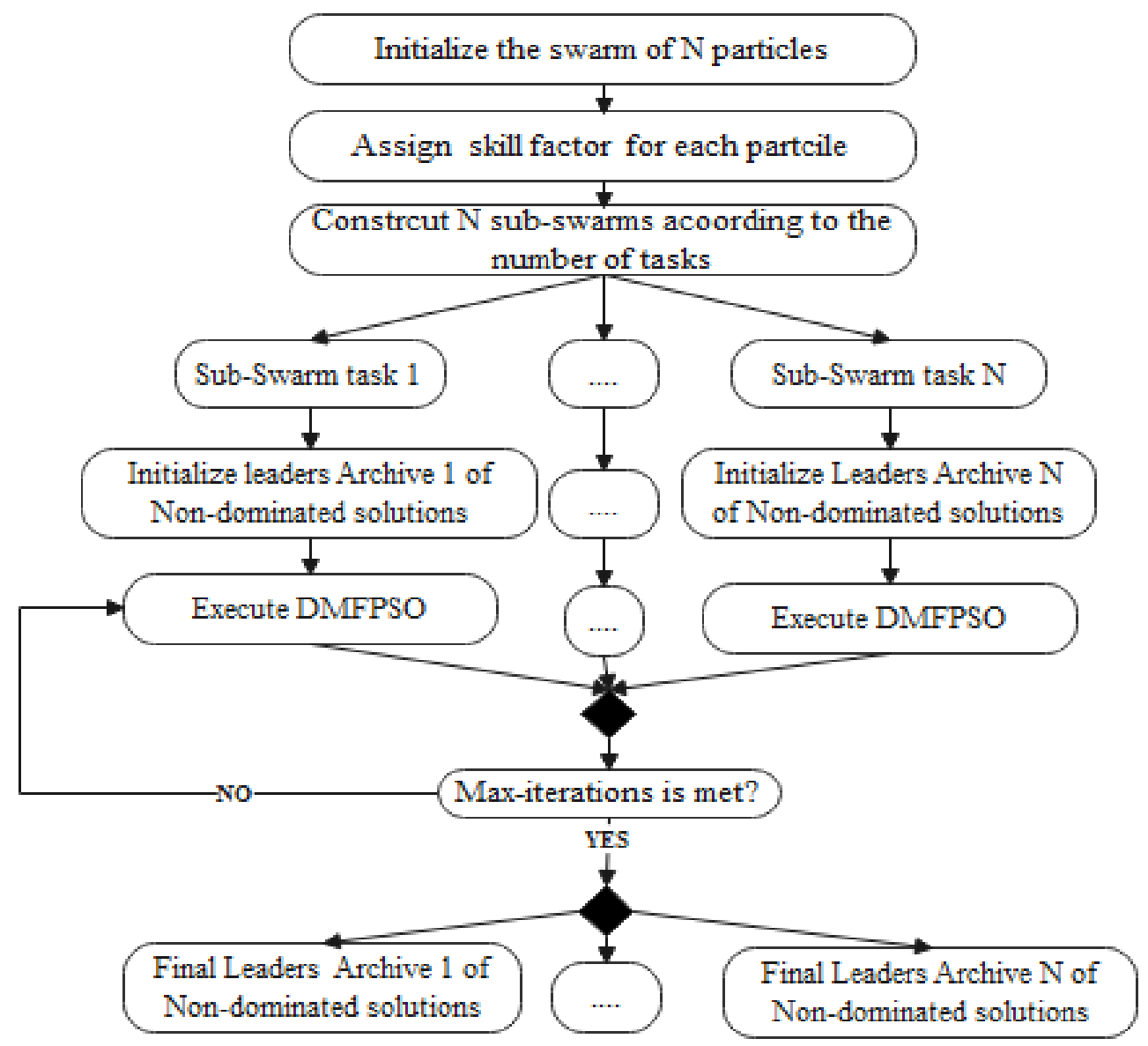

Fig. 2. The General Flowchart of the Proposed Distributed Multifactorial Particle Swarm Optimization (DMFPSO) Algorithm. 
The overall steps of the DMFPSO method are presented in Figure 3. The detailed description is as follows:

- Step 1: initialize the swarm of $\mathbf{N}$ particles

The DMFPSO algorithm starts with random initialization of the position $(X)$ of the $N$ particles $p_{i}$ in the swarm $S$; $\forall i=1 \ldots N$ in the n-dimensional search space and zero velocities.

- Step 2: assign skill factors

The term skill factor was first proposed by Gupta et al.[1]. The skill factor is to allocate a single task $\tau_{i}$ among the K tasks to each particle $p_{i}$ in the initialization step.

\section{- Step 3: build multiple sub-swarms}

After the skill factor is assigned, each particle is sorted according to the ID of each task to construct $\mathrm{N}$ sub-swarms (subSwarm_task1..., sub-swarm_taskK).

\section{- Step 4: initialize leaders archives}

For each task $K$, the global archive $A_{j} \forall j=1, \ldots, K$ is initialized to store all non-dominated solutions in the optimization process.

- Step 5: execute DMFPSO in parallel for $\mathbf{N}$ sub-swarms.

- Step 6: verify the stop criteria= maximum number of iterations.

- Step 7: determine the final set of non-dominated solutions of each task.

After constructing $\mathrm{N}$ sub-swarms, DMFPSO is performed in parallel to evaluate the fitness function $($ Fit $(\mathrm{X}(\mathrm{t})))$ of each particle until the maximum number of iterations. At each iteration $t$, the position (X) of each particle $p$ is updated using Equation (2). The update process of the velocity $V_{t+1}$ is completed using Equation (3).

$$
X_{t+1}=X_{t}+V_{t+1}
$$

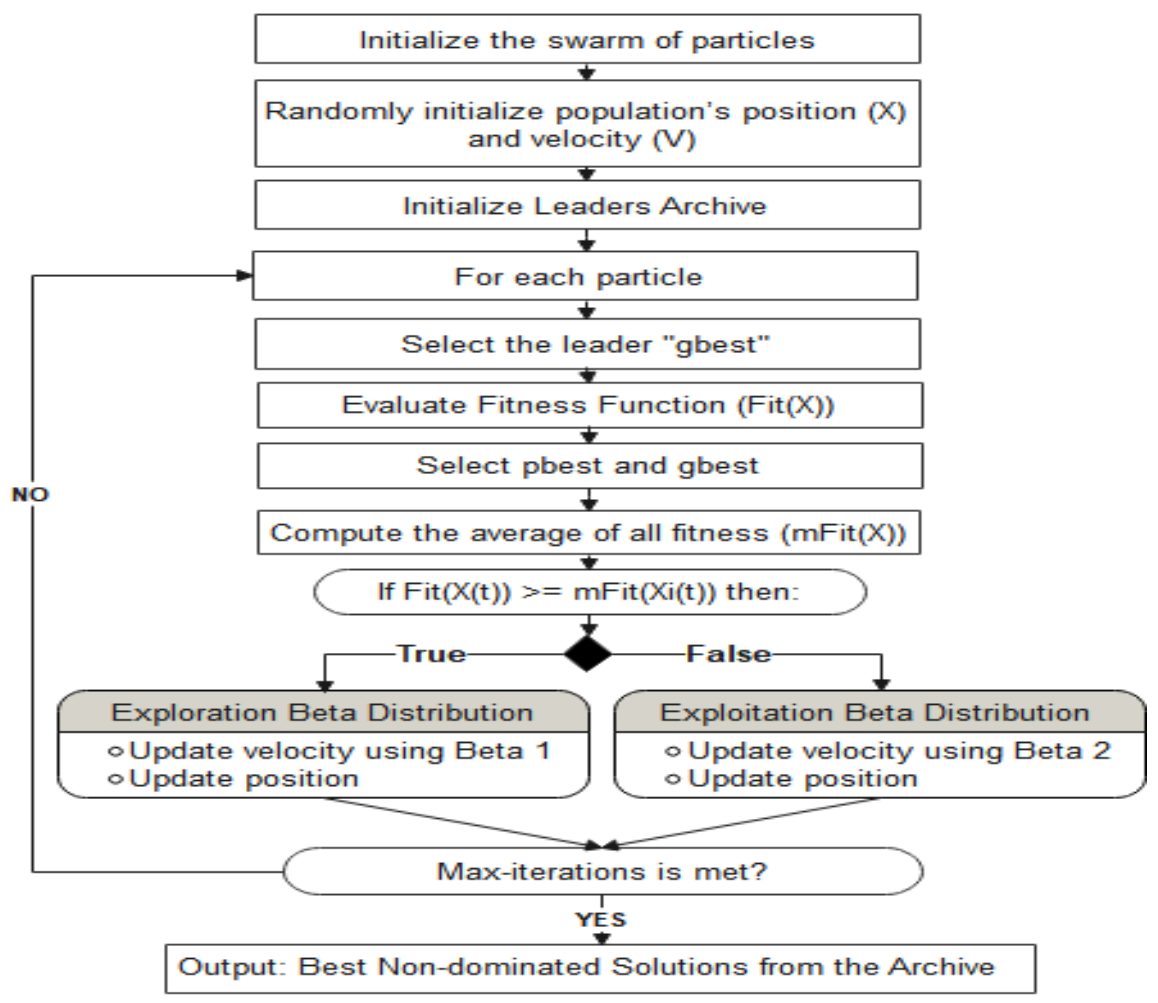

Fig. 3. The Overall Steps of the Proposal DMFPSO.

In addition, two switched beta distribution profiles were considered to ensure a dynamic balance between exploration and exploitation concepts during the optimization process. The first beta distribution profile Beta-1 is used in the exploration phase. 
The second Beta-2 profile is used in the exploitation phase. Both distribution profiles are fixed in Equation (3). For each particle $p$ the optimization stage is fixed as follows: if the fitness value aggregation $\operatorname{Fit}(X(t))$ is greater than the average fitness $m$ Fit $(X(t))$ of all particles, then optimize the particle in the exploration profile (Beta-1). Otherwise, the second beta distribution profile (Beta-2) will be considered in the exploitation phase.

$$
V_{t+1}=\left\{\begin{array}{l}
/ / \text { Exploration Profile (Beta 1) } \\
\text { if } F i t\left(X_{t}\right) \geq \text { meanFit }\left(X_{i}(t)\right) \text { then: } \\
\quad w V_{t}+c_{1} \beta_{1}(x)\left(P_{\text {best }}(t)-X_{t}\right)+c_{2} \beta_{1}(x)\left(g_{\text {best }}(t)-X_{t}\right) \\
\text { else } \\
/ / \text { Exploitation Profile (Beta 2) } \\
w V_{t}+c_{2} \beta_{2}(x)\left(g_{\text {best }}(t)-X_{t}\right)
\end{array}\right.
$$

where; $w$ is the inertia weight with a uniform random distribution in the range [0,1], $c_{1}$ and $c_{2}$ are the acceleration coefficients. The leader gbest is the global best solution for all neighbours in swarm $S$ selected from the global archive, which stores all nondominated solutions for all optimized $K$ tasks. The pbest is the best local experience of each particle. Both gbest and pbest are used to affect the updated position of each particle at each iteration $t$.

The one-dimensional Beta function $\beta(x)$ was first proposed by Alimi [22] and presented in Equation (4) aiming to highlight the different distribution forms of Beta functions based on time-varying parameters $p$ and $q$.

$$
\beta(x)=\beta\left(x_{0}, x_{1}, p, q\right)(x)=\left\{\begin{array}{l}
\text { if } x \in\left[x_{0}, x_{1}\right] \text { then: } \\
\left(\frac{x-x_{0}}{x_{c}-x_{0}}\right)^{p}\left(\frac{x_{1}-x}{x_{1}-x_{c}}\right)^{q} \\
0 \quad \text { otherwise }
\end{array}\right.
$$

where; $\mathrm{p}, \mathrm{q}, x_{0}, x_{1}$ are real numbers and $x_{c}$ is defined in the following Equation (5).

$$
x_{c}=\frac{p x_{1}+q x_{0}}{p+q}
$$

The multi-dimensional Beta function is defined in Equation (6), it is the product of $m$ one-dimensional Beta functions expressed by Equation (4).

$$
\beta(x)=\prod_{k=1}^{m} \beta\left(x_{k}, p_{k}, q_{k}, x_{0, k}, x_{1, k}\right)
$$

Figure 4 shows a couple of beta distribution profiles. The parameters of $\beta 1$ are fixed as follows; $(p=30$ and $q=0)$ and $\beta 2(p=0.1$ and $q=20)$ while $x_{0}$ and $x_{1}$ are equal to 0 and 1 respectively.
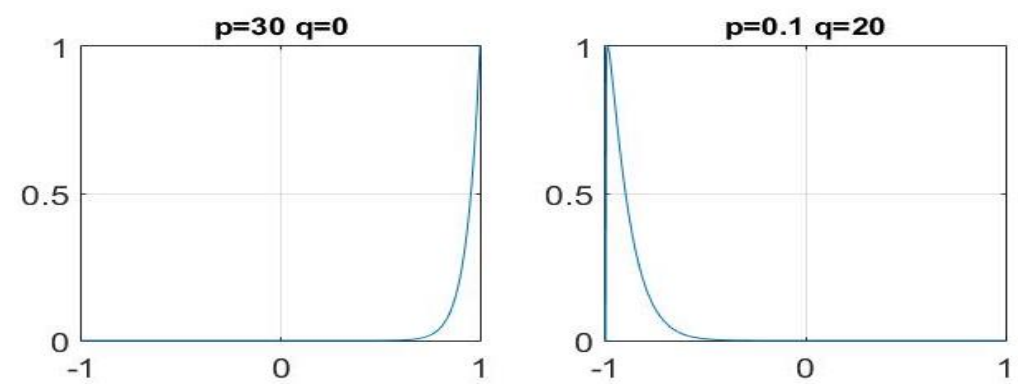

Fig. 4. Switched Beta distributions profiles: $\beta 1$ with $(\mathrm{p}=30, \mathrm{q}=0)$, and $\beta 2$ with ( $\mathrm{p}=0.1$ and $\mathrm{q}=20)$.

The optimization process of DMFPSO is executed until the maximum number of iterations is reached. Finally, all non-dominated solutions for each task are stored in the archive $A_{j}$. 
The new DMFPSO has an advantage over the use of few parameters' configurations, when the main update rules for positions and velocities are done using a flexible beta function. In addition, this new system optimizes $\mathrm{n}$ sub-swarms in parallel, which are equal to the number of optimization tasks. For each sub-swarm, DMFPSO is executed until the maximum number of iterations, the computational complexity is equal to $O(n \log (n))$. Therefore, due to the increase in the number of optimization tasks, the complexity of the new proposal has become more complicated.

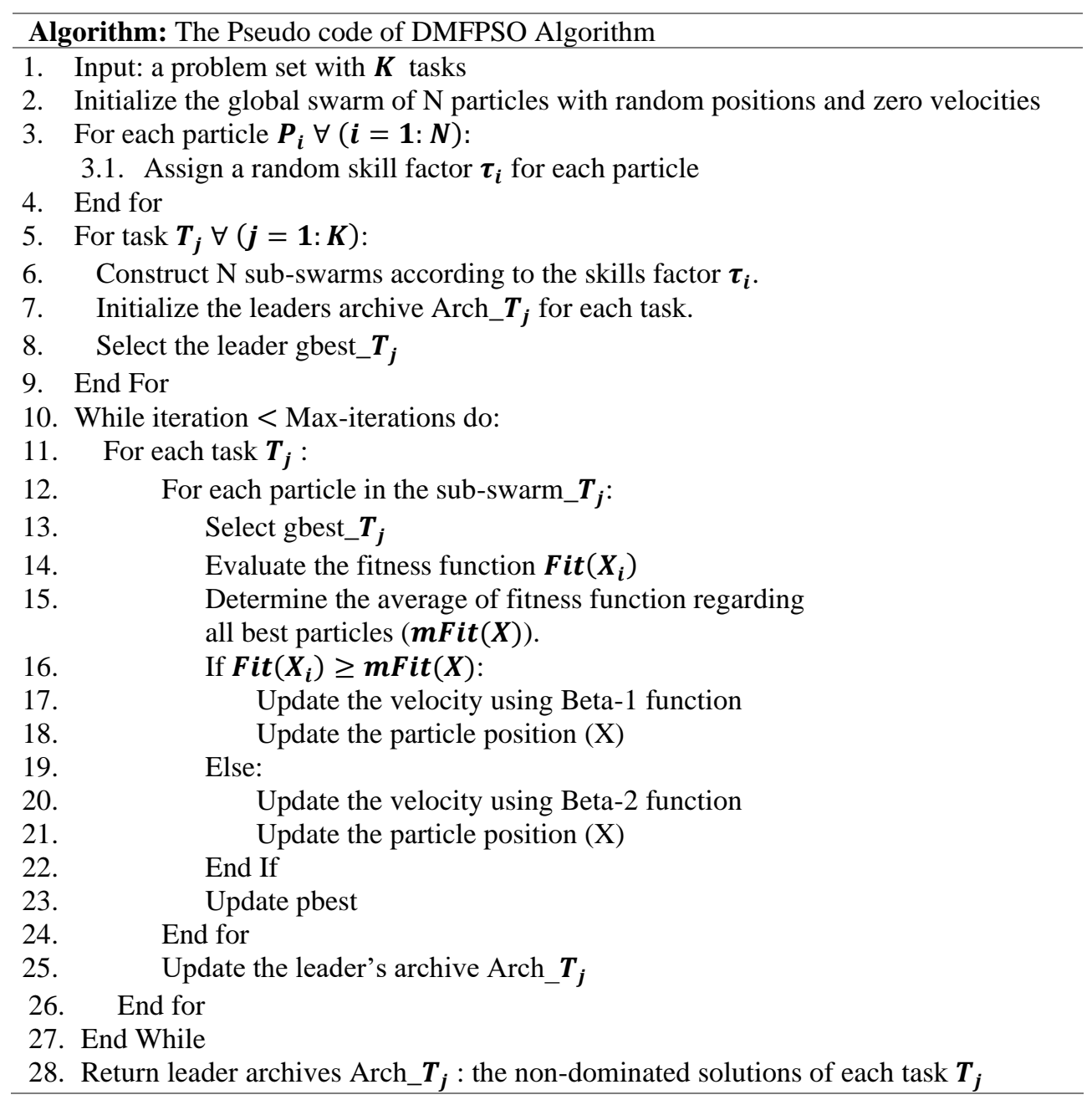

Fig. 5. The pseudo code of DMFPSO Algorithm.

\section{Experimental Study}

This experimental study is conducted using a new set of 36 benchmarks provided by the CEC'2021 Evolutionary Transfer MultiObjective Optimization Competition ${ }^{2}$, which are classified as follows:

- C1: Eight Evolutionary Transfer Multi-Objective Optimization Problems: ETMOF1 to ETMOF8.

- C2: Eight Evolutionary Transfer Many-objective Optimization Problems: ETMOF9 to ETMOF16.

- C3: Eight Evolutionary Transfer Large-scale Multi- Objective Optimization Problems: ETMOF17 to ETMOF24.

- C4: Four Evolutionary Transfer Many-task Optimization Problems: ETMOF25 to ETMOF28.

- C5: Eight Evolutionary Transfer Dynamic Multi-Objective Optimization Problems: ETMOF33 to ETMOF40.

\footnotetext{
${ }^{2}$ https://www.scholat.com/vpost.html?pid=160180
} 
The characteristics of each problem are detailed in Table 3, namely the number of tasks $T$, the number of decision variables $(n=$ $K+L)$, the Pareto Optimal Front (POF) type and the mathematical formula type.

In this case, there is no comparative study using these 36 new problems. This experimental study was conducted through a personal comparison test of the proposed DMFPSO and MO-MFEA [15] designed for SO and MO multitask benchmarks. his test was done using a personal computer equipped with 8 Go memory and i7 intel processor. The Java implementation of the proposed method is done on the jMetal framework [37].

\section{Parameters Settings}

All parameter settings are fixed in Table 2. For each single task in C1, C2, C3 and C5 (with 2 or 3 related tasks), the population size is fixed at 100 . However, for the 4 many-task optimization problems in C4 (with 5 to 20 related tasks), the population size is fixed at 10. For a single task of static MOPs, the maximum number of iterations is set to 500 function evaluations, which is the case for the benchmarks in $\mathrm{C} 1, \mathrm{C} 2, \mathrm{C} 3$ and $\mathrm{C} 4$. In addition, the maximum number of iterations of 8 DMOPs (ETMOF33 to ETMOF $40)$ in $\mathrm{C} 5$ is fixed according to the $\left(30 \times \tau_{t}\right)$ function evaluations of a single task $T_{j}$, where $\tau_{t}$ is the frequency of change fixed to 20 and 30 is the number of changes. Both comparison methods were performed during 21 independent runs.

Table 2. Parameters Settings

\begin{tabular}{|c|c|c|}
\hline Parameters & \multicolumn{2}{|c|}{ DMFPSO and MO-MFEA } \\
\hline Population size & 100: for a single task in $\mathrm{C} 1, \mathrm{C} 2, \mathrm{C} 3$ and $\mathrm{C} 5$ & 10: for a single task in $\mathrm{C} 4$ \\
\hline \multicolumn{3}{|c|}{ Archive size $=100$} \\
\hline Max-Iterations & 500 for ETMOF1 to ETMOF28 & $\left(30 \times \tau_{t}\right)$ for ETMOF33 to ETMOF 40 \\
\hline \multicolumn{2}{|c|}{ Mutation Probability $=1 /$ Number of variables } & Perturbation Index $=1.0$ \\
\hline
\end{tabular}

\section{Performance Metrics}

The Inverted General Distance (IGD) and the Mean Inverted General Distance (MIGD) are used to measure the diversity and convergence performances of each task $T_{j}$. The Mean Standard Score (MSS) is calculated to rank comparison algorithms.

- The IGD metric [38] is presented in Equation (7) and used to measure the minimum distance $d$ based on the generated POF and the true $P O F^{*}$.

$$
\operatorname{IGD}\left(\mathrm{POF} \mathrm{POF}^{*}\right)=\frac{1}{\left|\mathrm{POF}^{*}\right|} \sum_{\mathrm{x} \in \mathrm{POF}^{*}} \min _{\mathrm{y} \in \mathrm{POF}} \mathrm{d}(\mathrm{x}, \mathrm{y})
$$

- $\quad$ The MIGD metric [39] is presented in Equation (8), aims to compute the average value of the IGD metric.

$$
\operatorname{MIGD}=\frac{1}{\mathrm{~T}} \sum_{\mathrm{t}=1}^{\mathrm{T}} \operatorname{IGD}\left(\operatorname{POF}(\mathrm{t}), \operatorname{POF}^{*}(\mathrm{t})\right)
$$

where; $\mathrm{T}$ is equal to 30 presenting the number of changes in each run.

- The MSS is the overall performance metric [32] presented in Equation (9) to determine the best method taking into consideration the $\mathrm{K}$ tasks in one test problem.

$$
\operatorname{MSS}=\frac{1}{K} \sum_{j=1}^{K} \frac{I_{j}-\mu_{j}}{\sigma_{j}}
$$

where, $I_{j}$ is the IGD/MIGD value obtained by an algorithm $\mathrm{G}$ in a run for one task $T_{j} ., \mu_{j}$ and $\sigma_{j}$ are the mean and the standard deviation values obtained by an algorithm for each task $T_{j}, \forall j=1, \ldots, K$. 
Table 3. Characteristics of the Tested Benchmarks

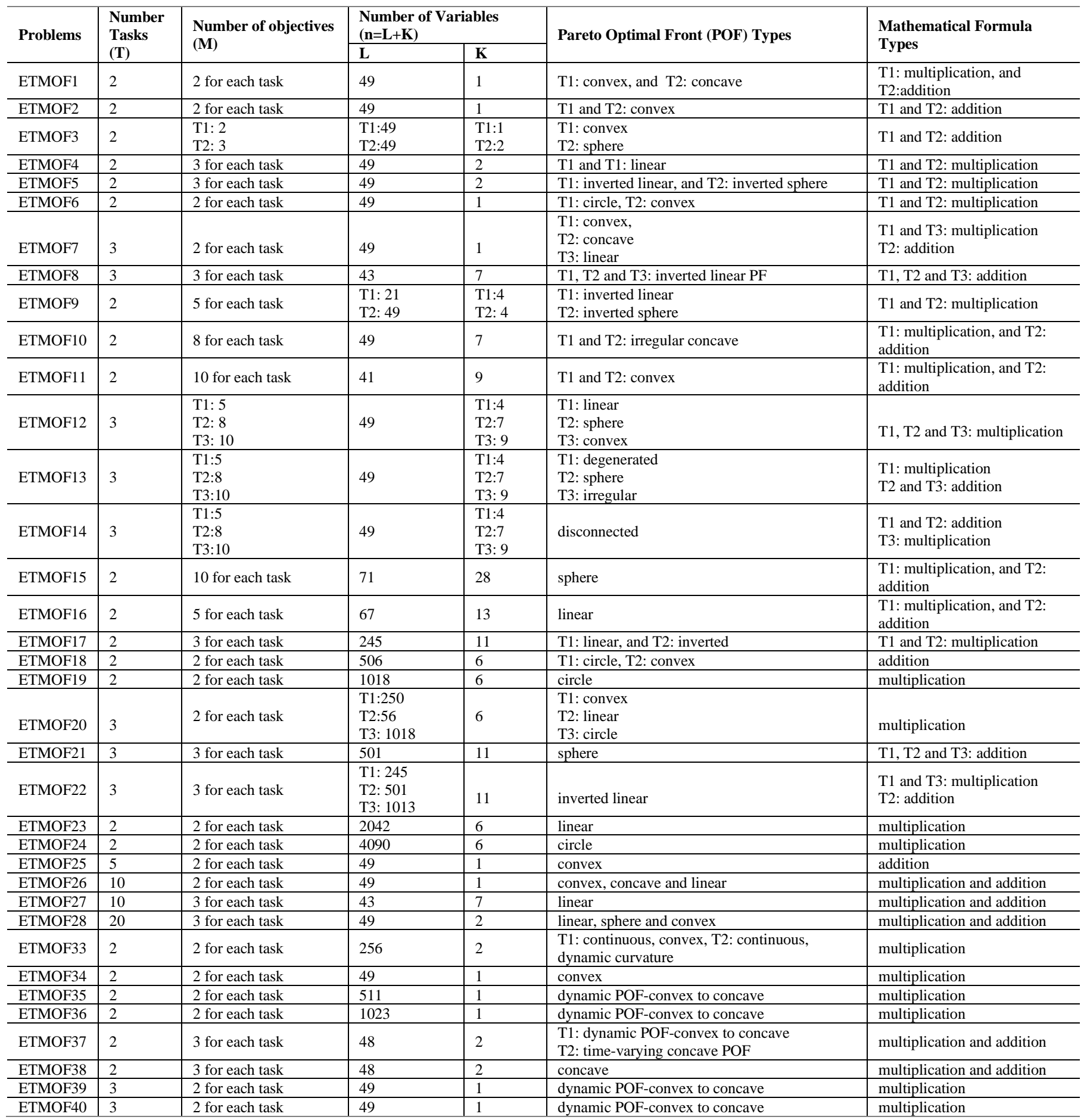

\section{Results and Discussion}

For the needs of discussions, a one-way analysis of variance (ANOVA) test [40] and a mean standard score (MSS) are used to compare the IGD/MIGD values obtained from 36 benchmarks. The smaller value of the MSS metric indicates that the overall performance of the comparison method is better on all tasks of the test problem. The proposed method is compared with the main state of art method for the used test beds, the MO-MFEA. All quantitative results are shown in the appendix (Table 6-Table 10) presenting the best, worst, mean, median, and the standard deviation of the IGD/MIGD values for each task of all ETMO problems. 
All best values are highlighted in bold. Table 6 shows the IGD and MIGD values obtained by the new DMFPSO and MO-MFEA methods for 8 ETMO functions in the first category C1 (ETMOF1- ETMOF8) with 2 or 3 tasks, each task is one Multi-Objective Optimization Problem have 2 or 3 objective functions. Based on the results of the one-way ANOVA test in the IGD metric in Figure 6, we can conclude that the DMFPSO system is the winner in solving the ETMOF problems in C1 with a p-values less than 0.05. It can be seen from Table 4 that DMFPSO is the best among the 8 functions (ETMOF1- ETMOF8) using IGD, and it only fails to solve ETMOF4 on MIGD, as shown in Table 5. Table 7 presents the IGD and MIGD quantitative results of the 8 test problems (ETMOF9- ETMOF16) in C2. It presents a set of Many-objective Optimization Problems with 2 or 3 tasks. When each task has 5,8 or 10 objective functions.

Table 4. Mean Standard Score (MSS) Obtained by DMFPSO and MO-MFEA based on IGD Metric.

\begin{tabular}{|c|c|c|c|}
\hline Prob. & MO-MFEA & DMFPSO & Best Method \\
\hline ETMOF1 & 196.69 & 114.66 & DMFPSO \\
\hline ETMOF2 & 265.45 & 28.13 & DMFPSO \\
\hline ETMOF3 & 206.37 & 66.66 & DMFPSO \\
\hline ETMOF4 & 72.65 & 45.62 & DMFPSO \\
\hline ETMOF5 & 66.85 & 54.19 & DMFPSO \\
\hline ETMOF6 & 64.93 & 71.07 & DMFPSO \\
\hline ETMOF7 & 222.66 & 95.29 & DMFPSO \\
\hline ETMOF8 & 74.53 & 49.14 & DMFPSO \\
\hline ETMOF9 & 46.17 & 17.134 & DMFPSO \\
\hline ETMOF10 & 181.99 & 229.59 & MO-MFEA \\
\hline ETMOF11 & 116.37 & 63.39 & DMFPSO \\
\hline ETMOF12 & 80.44 & 79.63 & DMFPSO \\
\hline ETMOF13 & 218.98 & 113.91 & DMFPSO \\
\hline ETMOF14 & 277.86 & 184.92 & DMFPSO \\
\hline ETMOF15 & 205.03 & 80.16 & DMFPSO \\
\hline ETMOF16 & 46.788 & 34.64 & DMFPSO \\
\hline ETMOF17 & 368.87 & 18.08 & DMFPSO \\
\hline ETMOF18 & 1205.66 & 265.29 & DMFPSO \\
\hline ETMOF19 & 355.60 & 12.13 & DMFPSO \\
\hline ETMOF20 & 723.99 & 244.68 & DMFPSO \\
\hline ETMOF21 & 55.91 & 18.39 & DMFPSO \\
\hline ETMOF22 & 194.41 & 21.35 & DMFPSO \\
\hline ETMOF23 & 478.02 & 17.97 & DMFPSO \\
\hline ETMOF24 & 405.66 & 19.77 & DMFPSO \\
\hline ETMOF25 & 227.69 & 28.22 & DMFPSO \\
\hline ETMOF26 & 178.99 & 94.82 & DMFPSO \\
\hline ETMOF27 & 310.38 & 177.27 & DMFPSO \\
\hline ETMOF28 & 341.44 & 67.09 & DMFPSO \\
\hline ETMOF33 & 795.36 & 578.14 & DMFPSO \\
\hline ETMOF34 & 186.64 & 190.85 & MO-MFEA \\
\hline ETMOF35 & 484.68 & 313.19 & DMFPSO \\
\hline ETMOF36 & 499.91 & 79.53 & DMFPSO \\
\hline ETMOF37 & 168.81 & 127.99 & DMFPSO \\
\hline ETMOF38 & 299.48 & 161.94 & DMFPSO \\
\hline ETMOF39 & 234.09 & 493.34 & MO-MFEA \\
\hline ETMOF40 & 77.02 & 222.36 & MO-MFEA \\
\hline
\end{tabular}

The MSS values in Table 4 and Table 5 show the merits of DMFPSO compared with MO-MFEA in solving different functions using IGD and MIGD indicators. Compared with MO-MFEA, DMFPSO has almost similar MSS value in the IGD for ETMOF10. It is characterized by 2 tasks; each task is a MaOP with 8 objective functions and irregular concave POF. The results of the one- 
way ANOVA test in Figure 7 suggest the relevance of the proposed system for solving almost all the problems in C2. Table 8 and Table 9 details the obtained results of the ETMO problems in C3 and C4 respectively. In C3, comparison methods were used to test eight Large-scale Multi- Objective Optimization Problems (ETMOF17- ETMOF24). These problems are characterized by a large number of decision variables (245, 506, 1018, 2042 or 4090) with 2 or 3 objective functions. In C4, four Many-task Optimization Problems (ETMOF25 to ETMOF28) are considered with 5, 10 or 20 tasks, and each task is a MOP with 2 or 3 fitness functions.

Table 5. Mean Standard Score (MSS) Obtained by DMFPSO and MO-MFEA based on MIGD Metric.

\begin{tabular}{|c|c|c|c|}
\hline Prob. & MO-MFEA & DMFPSO & Best Method \\
\hline ETMOF1 & 199.46 & 102.07 & DMFPSO \\
\hline ETMOF2 & 208.07 & 41.94 & DMFPSO \\
\hline ETMOF3 & 232.15 & 82.09 & DMFPSO \\
\hline ETMOF4 & 65.44 & 89.61 & MO-MFEA \\
\hline ETMOF5 & 82.12 & 39.27 & DMFPSO \\
\hline ETMOF6 & 63.75 & 43.35 & DMFPSO \\
\hline ETMOF7 & 186.44 & 63.73 & DMFPSO \\
\hline ETMOF8 & 76.389 & 51.07 & DMFPSO \\
\hline ETMOF9 & 44.964 & 14.49 & DMFPSO \\
\hline ETMOF10 & 226.79 & 156.31 & DMFPSO \\
\hline ETMOF11 & 145.59 & 73.25 & DMFPSO \\
\hline ETMOF12 & 106.55 & 69.06 & DMFPSO \\
\hline ETMOF13 & 234.29 & 85.24 & DMFPSO \\
\hline ETMOF14 & 254.44 & 97.54 & DMFPSO \\
\hline ETMOF15 & 238.56 & 82.71 & DMFPSO \\
\hline ETMOF16 & 59.87 & 36.59 & DMFPSO \\
\hline ETMOF17 & 301.39 & 12.05 & DMFPSO \\
\hline ETMOF18 & 728.81 & 188.65 & DMFPSO \\
\hline ETMOF19 & 315.25 & 9.13 & DMFPSO \\
\hline ETMOF20 & 629.24 & 106.05 & DMFPSO \\
\hline ETMOF21 & 69.23 & 14.74 & DMFPSO \\
\hline ETMOF22 & 191.83 & 9.38 & DMFPSO \\
\hline ETMOF23 & 409.30 & 22.32 & DMFPSO \\
\hline ETMOF24 & 438.16 & 27.86 & DMFPSO \\
\hline ETMOF25 & 227.82 & 75.23 & DMFPSO \\
\hline ETMOF26 & 207.71 & 29.98 & DMFPSO \\
\hline ETMOF27 & 361.65 & 30.84 & DMFPSO \\
\hline ETMOF28 & 254.95 & 33.29 & DMFPSO \\
\hline ETMOF33 & 865.08 & 135.89 & DMFPSO \\
\hline ETMOF34 & 214.21 & 105.24 & DMFPSO \\
\hline ETMOF35 & 456.34 & 116.19 & DMFPSO \\
\hline ETMOF36 & 648.79 & 71.27 & DMFPSO \\
\hline ETMOF37 & 207.59 & 98.42 & DMFPSO \\
\hline ETMOF38 & 254.26 & 82.24 & DMFPSO \\
\hline ETMOF39 & 203.39 & 108.86 & DMFPSO \\
\hline ETMOF40 & 126.69 & 105.92 & DMFPSO \\
\hline
\end{tabular}


One-way ANOVA Results in a Boxplot for ETMOF1

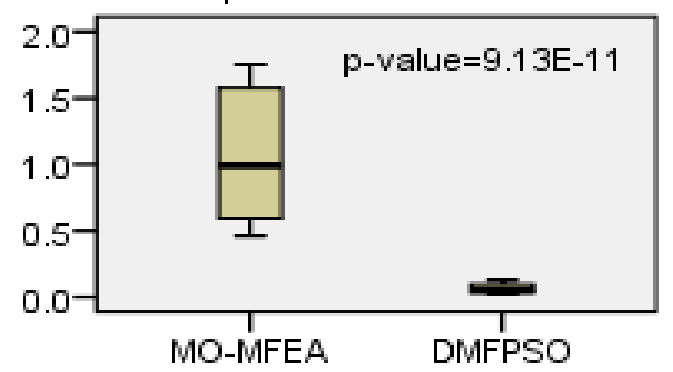

(a)

One-way ANOVA Results in a Boxplot for ETMOF3

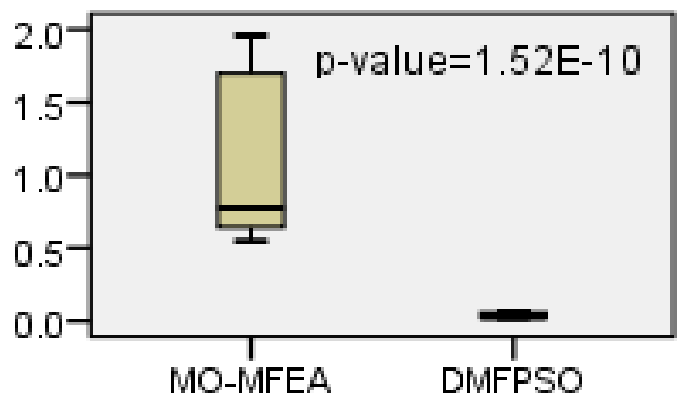

(c)

One-way ANOVA Results in a Boxplot for ETMOF5

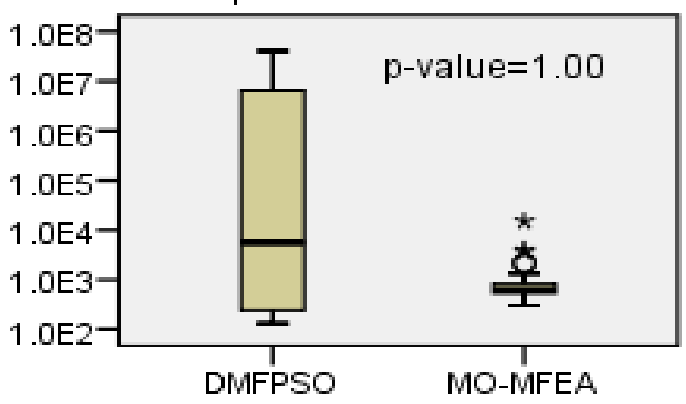

(e)

One-way ANOVA Results in a Boxplot for ETMOF6

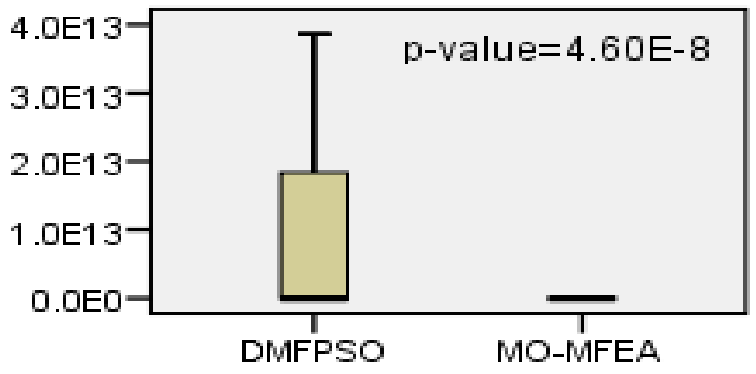

(f)
One-way ANOVA Results in a Boxplot for ETMOF2

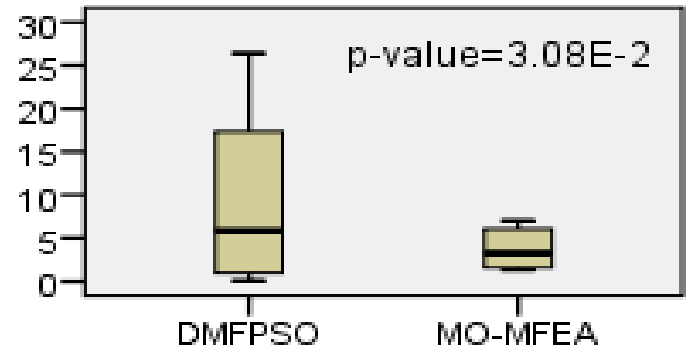

(b)

One-way ANOVA Resuts in a Boxplot for ETMOF 4

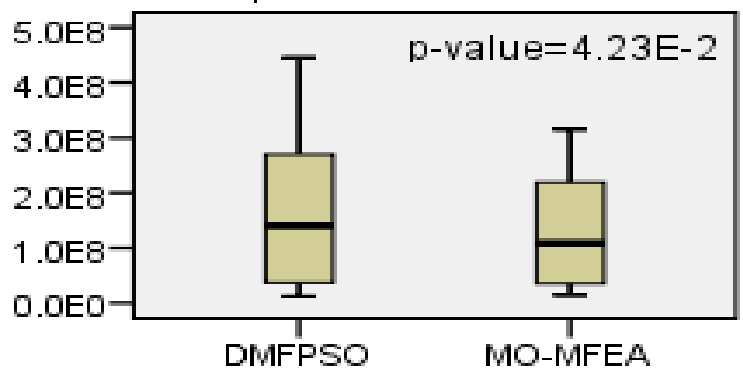

(d)

One-way ANOVA Results in a Boxplot for ETMOF7

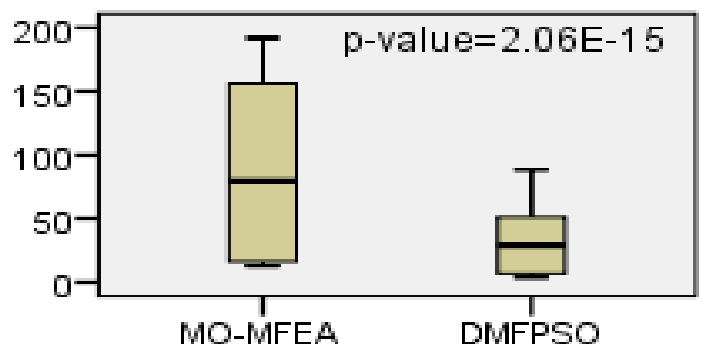

(g)

One-way ANOVA Results in a Boxplot for ETMOF8

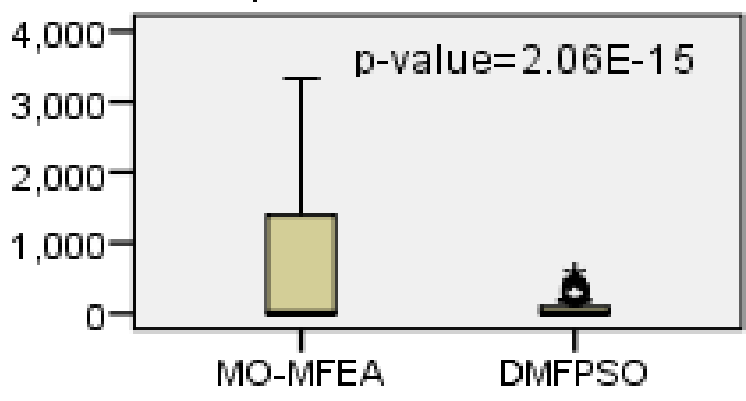

(h)

Fig. 6. One-way ANOVA Results in a Boxplot of DMFPSO and MO-MFEA over IGD of (a) ETMOF1, (b) ETMOF2, (c) ETMOF3, (d) ETMOF4, (e) ETMOF5, (f) ETMOF6, (g) ETMOF7, (h) ETMOF8. 
One-way ANOVA Results in a

Boxplot for ETMOF9

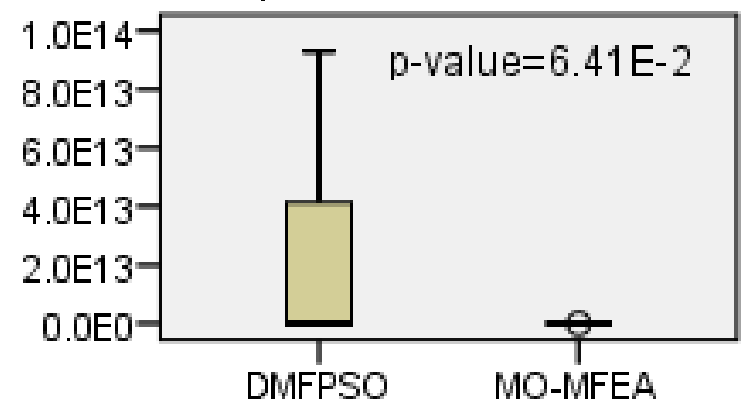

(a)

One-way ANOVA Results in a Boxplot for ETMOF10

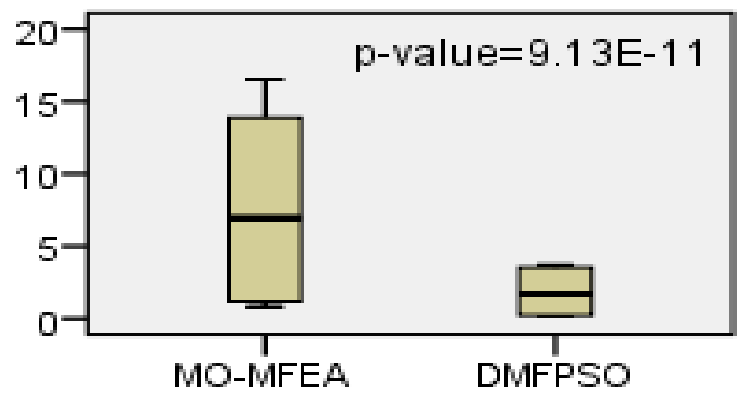

(b)

One-way ANOVA Results in a Boxplot for ETMOF13

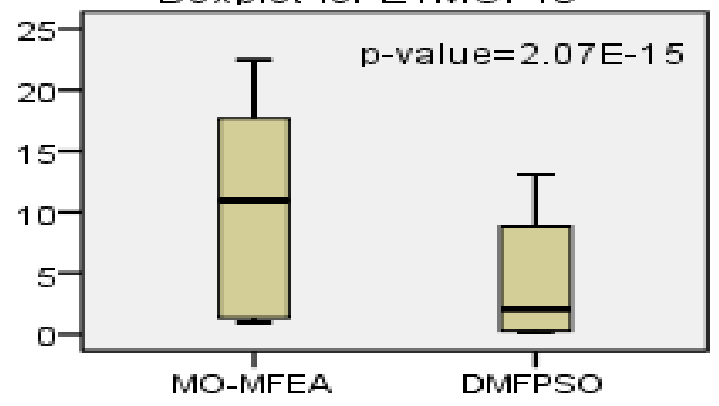

(e)

One-way ANOVA Results in a Boxplot for ETMOF14

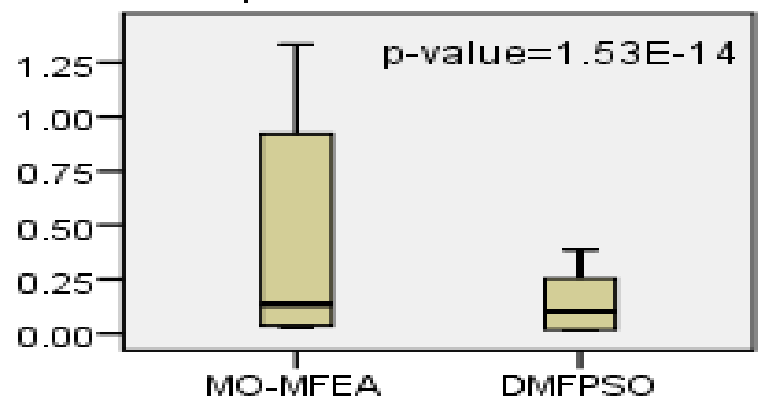

(f)
One-way ANOVA Results in a Boxplot for ETMOF11

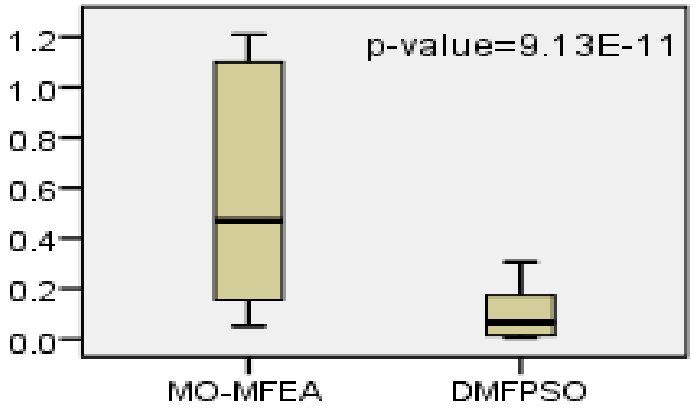

(c)

One-way ANOVA Results in a Boxplot for ETMOF 12

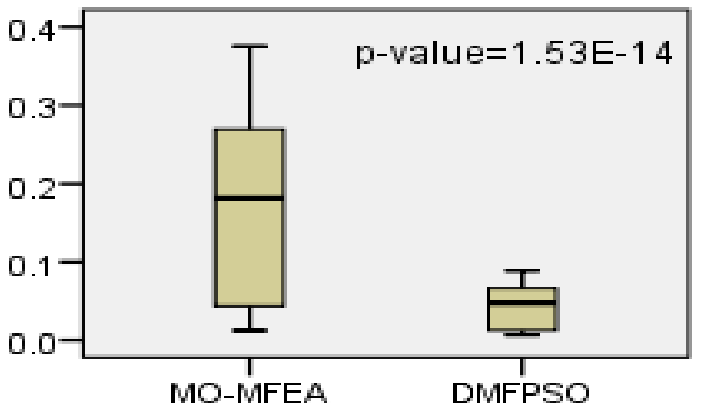

(d)

One-way ANOVA Results in a Boxplot for ETMOF15

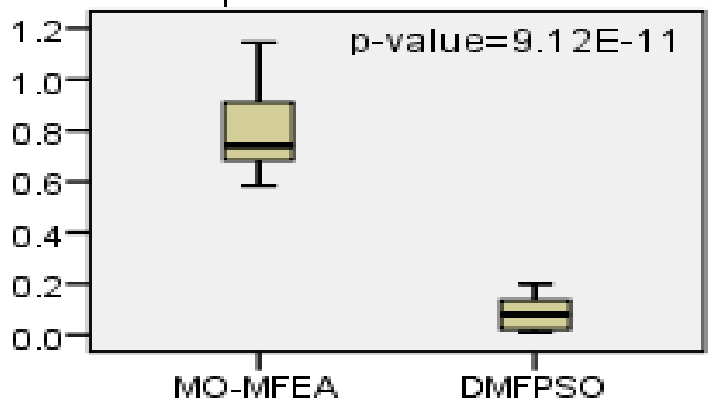

(g)

One-way ANOVA Results in a Boxplot for ETMOF 16

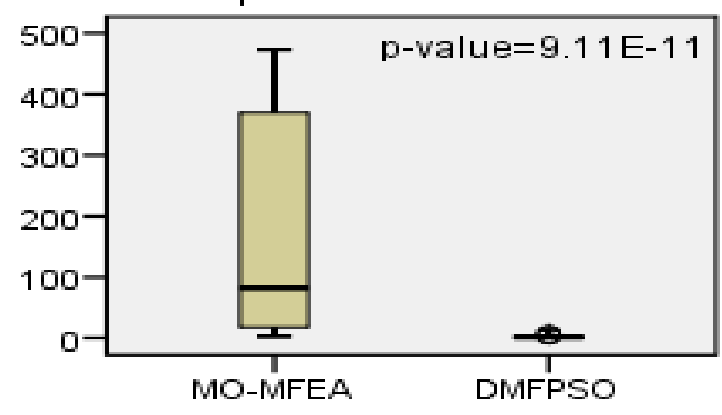

(h)

Fig. 7. One-way ANOVA Results in a Boxplot of DMFPSO and MO-MFEA over IGD of (a) ETMOF9, (b) ETMOF10, (c) ETMOF11, (d) ETMOF12, (e) ETMOF13, (f) ETMOF14, (g) ETMOF15, (h) ETMOF16. 


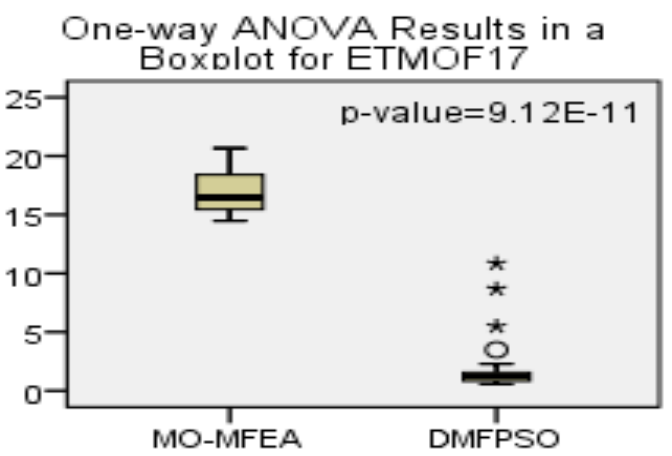

(a)

One-way ANOVA Results in a Boxplot for ETMOF18

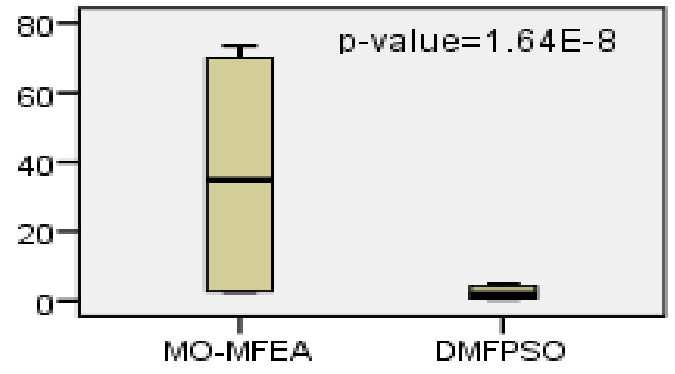

(b)

One-way ANOVA Results in a Boxplot for ETMOF21

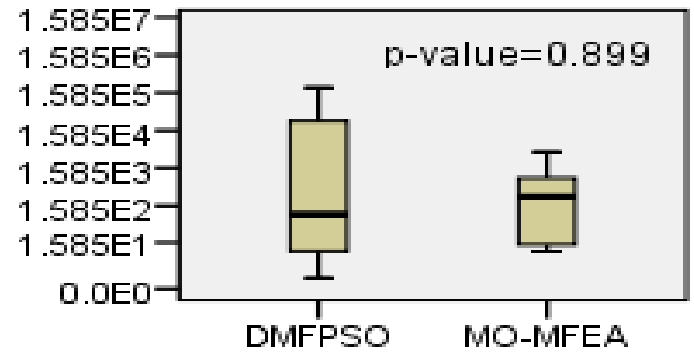

(e)

One-way ANOVA Results in a Boxplot for ETMOF22

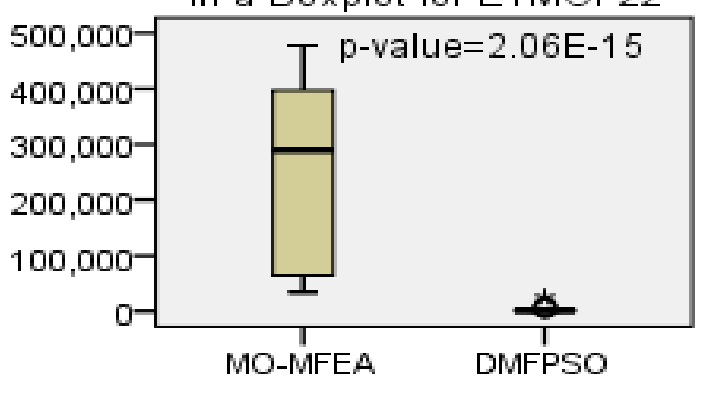

(f)

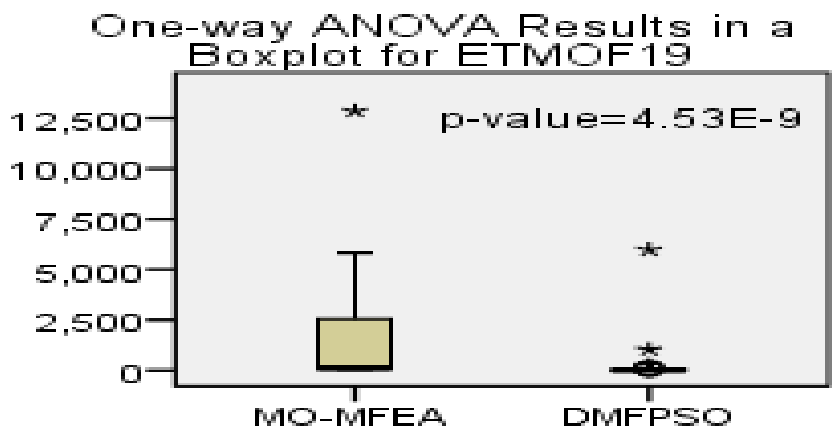

(c)

One-way ANOVA Results in a Boxplot for ETMOF2O

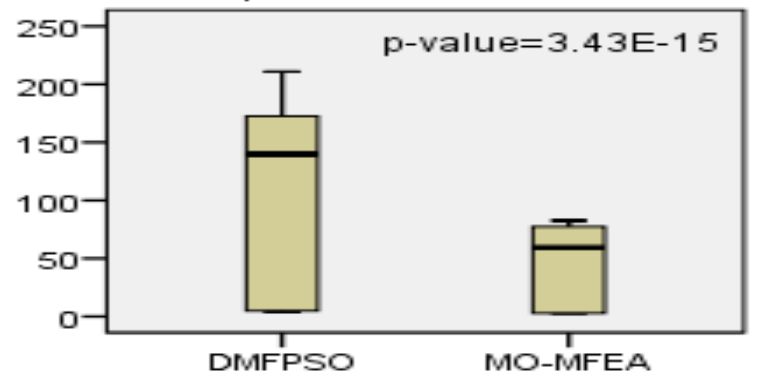

(d)

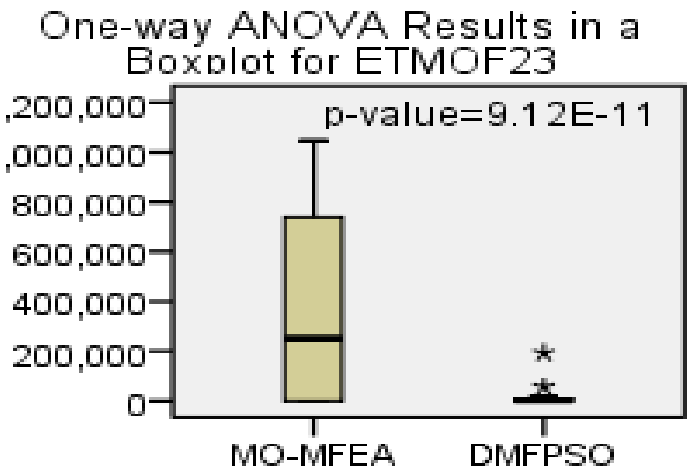

(g)

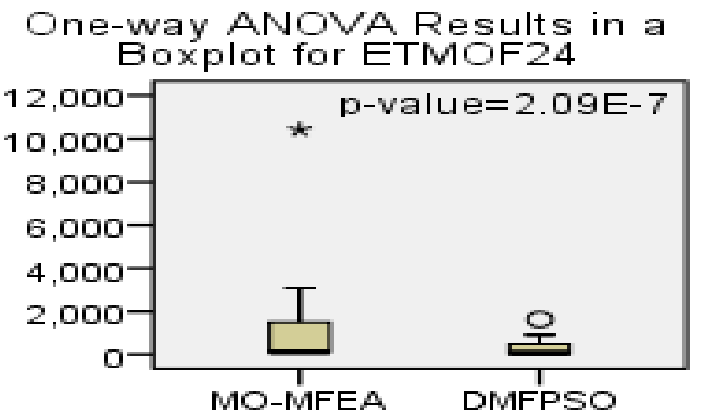

(h)

Fig. 8. One-way ANOVA Results in a Boxplot of DMFPSO and MO-MFEA over IGD of (a) ETMOF17, (b) ETMOF18, (c) ETMOF19, (d) ETMOF20, (e) ETMOF21, (f) ETMOF22, (g) ETMOF23, (h) ETMOF24. 


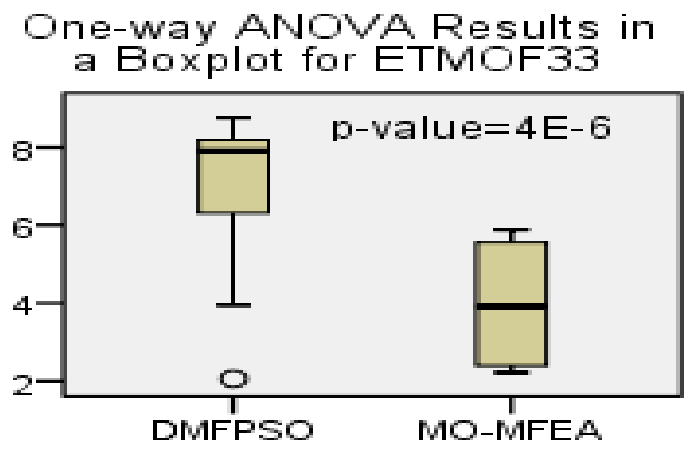

(a)

One-way ANOVA Results in a Boxplot for ETMOF34

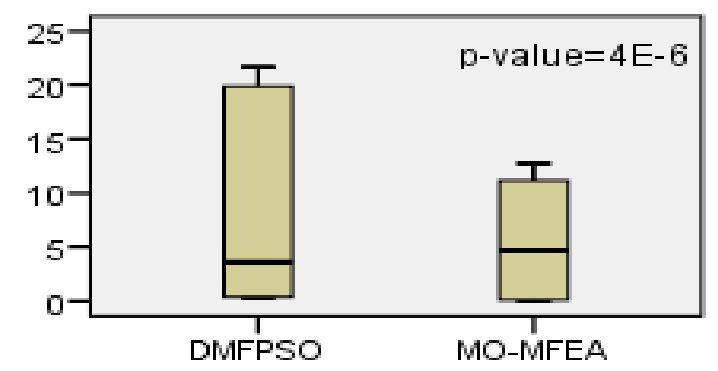

(b)

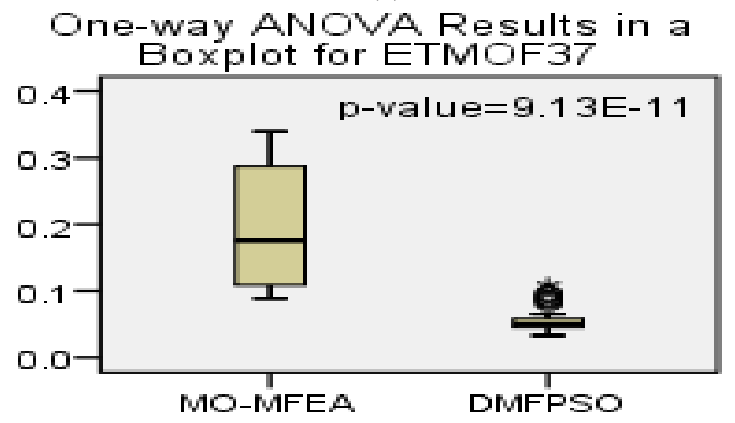

(e)

One-way ANOVA Results in a Boxplot for ETMOF 38

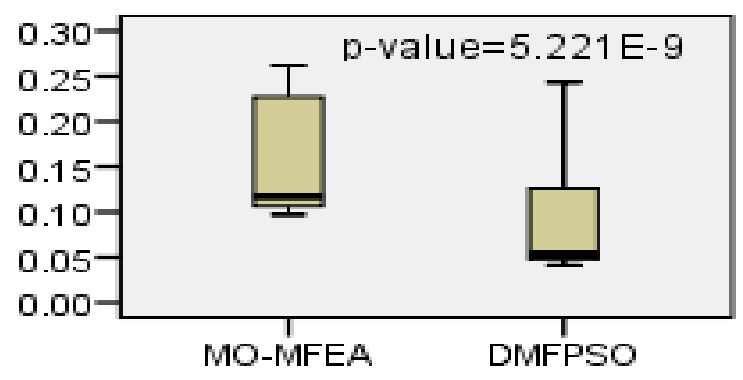

(f)
One-way ANOVA Results in a Boxplot for ETMOF35

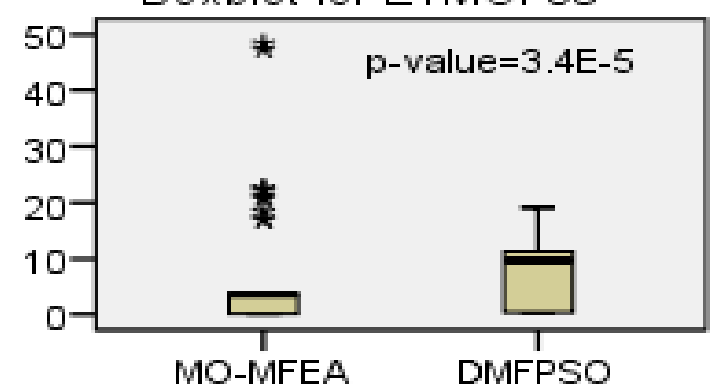

(c)

One-way ANOVA Results in a Boxpl ot for ETMOF36

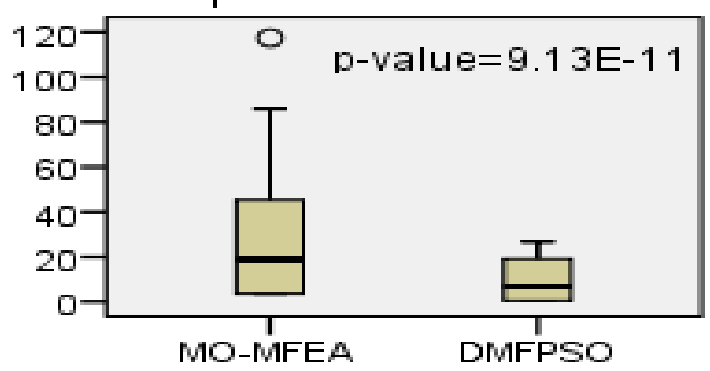

(d)

One-way ANOVA Results in a Boxplot for ETMOF39

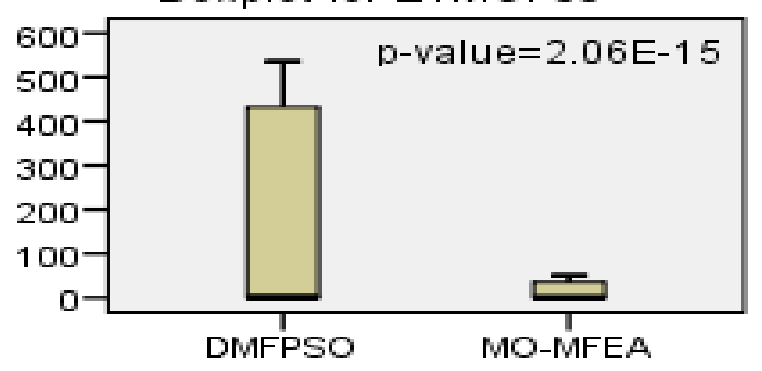

One-way ANOVA $(\mathrm{g})$ Results in a

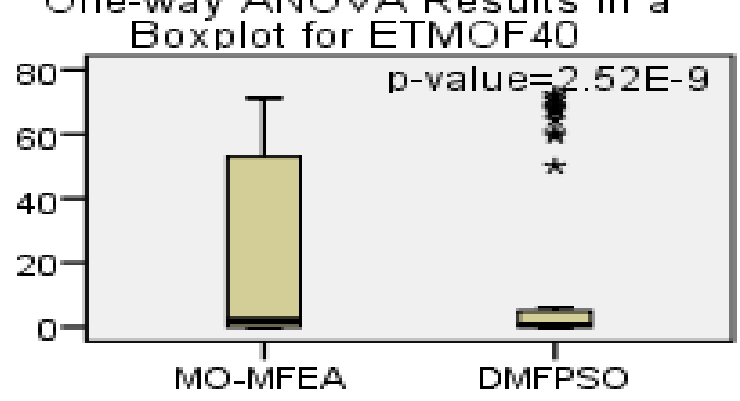

(h)

Fig. 9. One-way ANOVA Results in a Boxplot of DMFPSO and MO-MFEA over IGD of (a) ETMOF33, (b) ETMOF34, (c) ETMOF35, (d) ETMOF36, (e) ETMOF37, (f) ETMOF38, (g) ETMOF39, (h) ETMOF40.

Figure 8 demonstrates that DMFPSO is the best method to solve of majority of problems ETMOF17- ETMOF24, based on the average IGD value which is not statistically significant when the p-values less than 0.05 . In addition, Table 4 and Table 5 detail the MSS over IGD and MIGD respectively. Compared with MO-MFEA, DMFPSO got the smallest MSS value when solving 8 problems in C3 and 4 functions in C4. Furthermore, category C5 has 8 Dynamic Multi-Objective Optimization Problems with 2 or 3 tasks, and each task has 2 or 3 DMOPs executed simultaneously. Based on Figure 9, we can conclude that DMFPSO is a competitive system to the MO-MFEA system using IGD metric. Table 10 reports the IGD and MIGD values obtained through the 
comparison approaches. Also, Table 4 presents the MSS values on the IGD, and we can prove the effectiveness of the new proposal in solving ETMOF33, ETMOF35, ETMOF36, ETMOF37, ETMOF38. For three test beds only, which are: ETMOF34, ETMOF39 and ETMOF40, DMFPSO returned similar results to MO-MFEA.

As mentioned in [15], the MO-MFEA is a variant of the baseline Non-dominated Sorting Genetic Algorithm (NSGA- II) proposed by Deb et al.[41] in 2000. The main differences are investigated in the use of implicit parallelism, to attempt multitask as well as the use of an implicit genetic transfer mechanics like the binary crossover (SBX) operator. Compared with the MOMFEA system, the proposed method was the best due to the simplicity to manage multiple tasks using a distributed architecture of multiple sub-swarms. Each particle in the sub-swarm aims to optimize a specific task. In contrast, the multitasking management in MO-MFEA is more complicated due to the negative exchange of genetic material to create the skill factor of offspring close to the parents.

\section{Conclusion}

This paper proposed a new Distributed Multifactorial Particle Swarm Optimization algorithm (DMFPSO) for multi-task optimization. This new system starts with a global swarm of $\mathrm{N}$ particles. Then, one random skill factor is affected to each particle. DMFPSO was equipped with a set of sub-swarms constructed according to the number of the assigned skill factors. Therefore, each particle has one skill factor referred to optimized task. In more details, each sub-swarm was designed for a specific task. In addition, each particle could be assigned with two optimization profiles. DMFPSO method showed the advantages of using a couple of beta functions (Beta-1 and Beta-2) to update the velocity and position at each iteration. The first Beta-1 function was used to explore the search space and push particles closer to the optimal solution set. The second Beta-2 function was used for convergence enhancement. The proposed DMFPSO was tested on 36 benchmarks provided by CEC 2021 using IGD, MIGD, and MSS quality indicators. Compared with MO-MFEA, DMFPSO has proven to be the best method to solve a set of multi-task optimization problems. Each task can be expressed as; Multi-Objective Optimization Problem, Many-objective Optimization Problem, Large-scale Multi- Objective Optimization Problem, Many-task Optimization Problem and Dynamic Multi-Objective Optimization Problem. In this case study, both IGD and MIGD metrics are used the obtain the best, worst, mean, median, and the standard deviation values. However, MSS metric is used as a comprehensive criterion, and a smaller MSS value indicates that the overall performance of the DMFPSO algorithm on the test problem is better. In conclusion, there is no PSO based method designed for ETMO problems in the literature, and this is the main motivated of this study. For future works, it is recommended to investigate the impact of the beta profiles on the performances of DMFPOS of solving a set of multi-task optimization problems (ETMO) based on its specific characteristics. Future investigations will focus on extending the proposal with a focus on the test beds were the proposed method returned moderate results. Such with dynamic multi-objective optimization problems (ETMO34, 39, and 40) characterised by a time-varying Pareto Optimal Set (POS) from concave to convex shape. So, the main goal will be an additional dynamic processing strategy for solving DMOP through multi-task optimization. Also, a new investigation will be considered to assume a positive transfer knowledge between related tasks.

\section{Acknowledgment}

We deeply acknowledge Taif University for Supporting this study through Taif University Researchers Supporting Project number (TURSP-2020/327), Taif University, Taif, Saudi Arabia. The research leading to these results has received funding from the Ministry of Higher Education and Scientific Research of Tunisia under the grant agreement number LR11ES48. 
Appendices

Table 6. IGD and MIGD Results for Eight Multi-Objective Optimization Problems from ETMOF1 to ETMOF8.

\begin{tabular}{|c|c|c|c|c|c|c|c|c|c|c|c|c|}
\hline \multirow[t]{2}{*}{ Problems } & \multirow[t]{2}{*}{ QI } & \multirow[t]{2}{*}{ Task No. } & \multicolumn{5}{|c|}{ MO-MFEA } & \multicolumn{5}{|c|}{ DMFPSO } \\
\hline & & & Best & Worst & Mean & Median & Std. & Best & Worst & Mean & Median & Std \\
\hline \multirow{4}{*}{ ETMOF1 } & \multirow[t]{2}{*}{ IGD } & $\mathrm{T} 1$ & $6,9 \mathrm{E}-1$ & $4,6 \mathrm{E}-1$ & $5,82 \mathrm{E}-1$ & $5,47 \mathrm{E}-1$ & $6,2 \mathrm{E}-2$ & $5,2 \mathrm{E}-2$ & 2,38E-2 & 3,8E-2 & $4,71 \mathrm{E}-2$ & $6,95 \mathrm{E}-3$ \\
\hline & & $\mathrm{T} 2$ & $1,75 \mathrm{E} 0$ & $1,29 \mathrm{E} 0$ & $1,57 \mathrm{E} 0$ & $1,62 \mathrm{E} 0$ & $1,52 \mathrm{E}-1$ & $1,28 \mathrm{E}-1$ & 5,39E-2 & $9,44 \mathrm{E}-2$ & $9,78 \mathrm{E}-2$ & 1,57E-2 \\
\hline & \multirow[t]{2}{*}{ MIGD } & $\mathrm{T} 1$ & $1,41 \mathrm{E}-2$ & $7,63 \mathrm{E}-3$ & $1,18 \mathrm{E}-2$ & $1,27 \mathrm{E}-2$ & $1,55 \mathrm{E}-3$ & $4,92 \mathrm{E}-4$ & 2,39E-4 & $3,7 \mathrm{E}-4$ & $3,08 \mathrm{E}-4$ & $6,83 \mathrm{E}-5$ \\
\hline & & $\mathrm{T} 2$ & $3,62 \mathrm{E}-2$ & $2,68 \mathrm{E}-2$ & $3,19 \mathrm{E}-2$ & $3,02 \mathrm{E}-2$ & $2,6 \mathrm{E}-3$ & $1,24 \mathrm{E}-3$ & $5,43 E-4$ & 9,51E-4 & 1,13E-3 & 1,99E-4 \\
\hline \multirow{4}{*}{ ETMOF2 } & \multirow[t]{2}{*}{ IGD } & $\mathrm{T} 1$ & $1,75 \mathrm{E} 0$ & $1,3 \mathrm{E} 0$ & 1,55E0 & $1,48 \mathrm{E} 0$ & 1,1E-1 & $6,43 \mathrm{E} 0$ & 8,19E-2 & $3,75 \mathrm{E} 0$ & 1,73E-1 & $2,56 \mathrm{E} 0$ \\
\hline & & $\mathrm{T} 2$ & 7E0 & $4,75 \mathrm{E} 0$ & 6,08E0 & 6,08E0 & 4,87E-1 & $2,64 \mathrm{E} 1$ & 2,15E-1 & $1,45 \mathrm{E} 1$ & $2,12 \mathrm{E} 1$ & $1,08 \mathrm{E} 1$ \\
\hline & \multirow[t]{2}{*}{ MIGD } & $\mathrm{T} 1$ & $3,75 \mathrm{E}-2$ & $2,63 \mathrm{E}-2$ & $3,09 \mathrm{E}-2$ & $3,36 \mathrm{E}-2$ & $3 \mathrm{E}-3$ & $6,97 \mathrm{E}-2$ & $6,33 E-4$ & $4,73 \mathrm{E}-2$ & 1,05E-3 & $2,24 \mathrm{E}-2$ \\
\hline & & $\mathrm{T} 2$ & $1,4 \mathrm{E}-1$ & $9,94 \mathrm{E}-2$ & $1,21 \mathrm{E}-1$ & $9,94 \mathrm{E}-2$ & $1,15 \mathrm{E}-2$ & $2,85 \mathrm{E}-1$ & $3,26 \mathrm{E}-3$ & $1,79 \mathrm{E}-1$ & $2,59 \mathrm{E}-1$ & $8,58 \mathrm{E}-2$ \\
\hline \multirow{4}{*}{ ETMOF3 } & \multirow[t]{2}{*}{ IGD } & $\mathrm{T} 1$ & 1,96E0 & $1,28 \mathrm{E} 0$ & $1,62 \mathrm{E} 0$ & $1,28 \mathrm{E} 0$ & 1,87E-1 & $6,41 \mathrm{E} 0$ & 3,91E-2 & 3,58E-1 & $4,47 \mathrm{E}-2$ & $1,35 \mathrm{E} 0$ \\
\hline & & $\mathrm{T} 2$ & $7,74 \mathrm{E}-1$ & $5,5 \mathrm{E}-1$ & $6,49 \mathrm{E}-1$ & $5,86 \mathrm{E}-1$ & $5,42 \mathrm{E}-2$ & $3,22 \mathrm{E}-2$ & $1,87 \mathrm{E}-2$ & $2,48 \mathrm{E}-2$ & $2,03 E-2$ & $3,87 \mathrm{E}-3$ \\
\hline & \multirow{2}{*}{ MIGD } & T1 & $3,56 \mathrm{E}-2$ & $2,45 \mathrm{E}-2$ & $3,09 \mathrm{E}-2$ & $3,17 \mathrm{E}-2$ & $2,92 \mathrm{E}-3$ & $8,58 \mathrm{E}-4$ & $3,62 \mathrm{E}-4$ & 6,2E-4 & $6,25 \mathrm{E}-4$ & 1,5E-4 \\
\hline & & $\mathrm{T} 2$ & $1,54 \mathrm{E}-2$ & $1,15 \mathrm{E}-2$ & $1,29 \mathrm{E}-2$ & $1,34 \mathrm{E}-2$ & $1,02 \mathrm{E}-3$ & $4,74 \mathrm{E}-4$ & 2E-4 & $3,01 E-4$ & $2,36 \mathrm{E}-4$ & 7,37E-5 \\
\hline \multirow{4}{*}{ ETMOF4 } & \multirow[t]{2}{*}{ IGD } & $\mathrm{T} 1$ & 3,15E8 & $1,47 \mathrm{E} 8$ & 2,18E8 & $2,34 \mathrm{E} 8$ & 4,4E7 & $4,45 \mathrm{E} 8$ & 1,33E8 & $2,62 \mathrm{E} 8$ & $3,15 \mathrm{E} 8$ & $7,76 \mathrm{E} 7$ \\
\hline & & $\mathrm{T} 2$ & 7E7 & $1,44 \mathrm{E} 7$ & 3,86E7 & $5,94 \mathrm{E} 7$ & 1,67E7 & $1,98 \mathrm{E} 8$ & 1,19E7 & $5,11 \mathrm{E} 7$ & $3,3 \mathrm{E} 7$ & $4,32 \mathrm{E} 7$ \\
\hline & \multirow[t]{2}{*}{ MIGD } & $\mathrm{T} 1$ & $5,27 \mathrm{E} 6$ & 1,71E6 & 3,78E6 & 5,27E6 & $9,45 \mathrm{E} 5$ & 3,55E6 & 2,07E6 & 2,82E6 & 3,51E6 & 3,96E5 \\
\hline & & $\mathrm{T} 2$ & 1,45E6 & $3,2 \mathrm{E} 5$ & $7,65 \mathrm{E} 5$ & $6,49 \mathrm{E} 5$ & $3,01 \mathrm{E} 5$ & 1,04E6 & 1,17E5 & 4,47E5 & $4,8 \mathrm{E} 5$ & $2,43 E 5$ \\
\hline \multirow{4}{*}{ ETMOF5 } & \multirow[t]{2}{*}{ IGD } & $\mathrm{T} 1$ & 1,53E4 & 3,03E2 & $1,86 \mathrm{E3}$ & $8,24 \mathrm{E} 2$ & $3,16 \mathrm{E} 3$ & 4,06E7 & $9,99 \mathrm{E} 4$ & $1,16 \mathrm{E} 7$ & $2,47 \mathrm{E} 6$ & $1,27 \mathrm{E} 7$ \\
\hline & & $\mathrm{T} 2$ & $7,4 \mathrm{E} 2$ & $3,94 \mathrm{E} 2$ & $5,77 \mathrm{E} 2$ & $5,41 \mathrm{E} 2$ & $9,47 \mathrm{E} 1$ & 3,17E2 & 1,32E2 & 2,34E2 & 1,79E2 & 5,19E1 \\
\hline & \multirow[t]{2}{*}{ MIGD } & $\mathrm{T} 1$ & 6,88E1 & $4,78 \mathrm{E} 0$ & $2,24 \mathrm{E} 1$ & 1,59E1 & 1,58E1 & $9,1 \mathrm{E} 5$ & 4,44E1 & $1,99 \mathrm{E} 5$ & 4,44E1 & $2,21 \mathrm{E} 5$ \\
\hline & & $\mathrm{T} 2$ & $1,56 \mathrm{E} 1$ & $8,6 \mathrm{E} 0$ & $1,15 \mathrm{E} 1$ & $1,25 \mathrm{E} 1$ & $1,7 \mathrm{E} 0$ & 4,59E0 & 1,01E0 & $2,47 \mathrm{EO}$ & $1,72 \mathrm{E} 0$ & $8,16 \mathrm{E}-1$ \\
\hline \multirow{4}{*}{ ETMOF6 } & \multirow[t]{2}{*}{ IGD } & $\mathrm{T} 1$ & $4,95 \mathrm{E} 15$ & $1,14 \mathrm{E} 15$ & $2,73 \mathrm{E} 15$ & $2,92 \mathrm{E} 15$ & 1,1E15 & $3,87 \mathrm{E} 13$ & 6,66E12 & $2,11 \mathrm{E} 13$ & $1,47 \mathrm{E} 13$ & 9,24E12 \\
\hline & & $\mathrm{T} 2$ & 2,01E4 & $7,01 E 3$ & $1,46 \mathrm{E} 4$ & $1,79 \mathrm{E} 4$ & $3,65 \mathrm{E} 3$ & $3,13 \mathrm{E} 4$ & $1,17 \mathrm{E} 4$ & $2,35 \mathrm{E} 4$ & $2,56 \mathrm{E} 4$ & $4,87 \mathrm{E} 3$ \\
\hline & \multirow[t]{2}{*}{ MIGD } & $\mathrm{T} 1$ & $1,28 \mathrm{E} 14$ & $2,18 \mathrm{E} 13$ & 5,59E13 & $5,16 \mathrm{E} 13$ & $2,89 \mathrm{E} 13$ & 1,02E12 & 8,02E10 & 3,09E11 & $5,82 \mathrm{E} 11$ & 2,3E11 \\
\hline & & $\mathrm{T} 2$ & $4,26 \mathrm{E} 2$ & $1,47 \mathrm{E} 2$ & 2,9E2 & $2,59 \mathrm{E} 2$ & 6,53E1 & 3,35E2 & 7,53E1 & 2,13E2 & $1,93 \mathrm{E} 2$ & $7,1 \mathrm{E} 1$ \\
\hline & \multirow{3}{*}{ IGD } & $\mathrm{T} 1$ & $1,87 \mathrm{E} 1$ & $1,27 \mathrm{E} 1$ & $1,56 \mathrm{E} 1$ & $1,55 \mathrm{E} 1$ & $1,52 \mathrm{E} 0$ & 8,01E0 & $3,76 \mathrm{E} 0$ & 5,71E0 & $5,71 \mathrm{E} 0$ & $1,26 \mathrm{E} 0$ \\
\hline & & $\mathrm{T} 2$ & $1,92 \mathrm{E} 2$ & $1,51 \mathrm{E} 2$ & $1,66 \mathrm{E} 2$ & $1,63 \mathrm{E} 2$ & 1,22E1 & 8,86E1 & 3,7E1 & 6,08E1 & 7,51E1 & $1,26 \mathrm{E} 1$ \\
\hline ETMOF7 & & T3 & $9,36 \mathrm{E} 1$ & $6,35 \mathrm{E} 1$ & $7,83 \mathrm{E} 1$ & 6,93E1 & $8,19 \mathrm{E} 0$ & 3,97E1 & 1,69E1 & 2,86E1 & $2,32 \mathrm{E} 1$ & 5,81E0 \\
\hline & MIGD & $\mathrm{T} 1$ & $5,57 \mathrm{E}-1$ & $3,49 \mathrm{E}-1$ & $4,53 \mathrm{E}-1$ & $4,42 \mathrm{E}-1$ & $5,28 \mathrm{E}-2$ & 1,12E-1 & $2,89 \mathrm{E}-2$ & $5,15 \mathrm{E}-2$ & $4,86 \mathrm{E}-2$ & $1,76 \mathrm{E}-2$ \\
\hline & & $\mathrm{T} 2$ & $5,82 \mathrm{E} 0$ & $3,82 \mathrm{E} 0$ & 5,19E0 & $5,21 \mathrm{E} 0$ & $4,33 \mathrm{E}-1$ & $9,78 \mathrm{E}-1$ & $3,46 \mathrm{E}-1$ & $6,02 \mathrm{E}-1$ & 9,06E-1 & 1,49E-1 \\
\hline & & T3 & $2,76 \mathrm{E} 0$ & $1,66 \mathrm{E} 0$ & $2,37 \mathrm{E} 0$ & $2,76 \mathrm{E} 0$ & $3,2 \mathrm{E}-1$ & $5,44 \mathrm{E}-1$ & 1,22E-1 & $2,74 \mathrm{E}-1$ & 2,52E-1 & $1,05 \mathrm{E}-1$ \\
\hline & IGD & $\mathrm{T} 1$ & 3,33E3 & $6,27 \mathrm{E} 2$ & 1,89E3 & $1,46 \mathrm{E} 3$ & 7,49E2 & $5,75 \mathrm{E} 2$ & $3,66 \mathrm{E} 1$ & 2,17E2 & 9,23E1 & $1,5 \mathrm{E} 2$ \\
\hline & & $\mathrm{T} 2$ & $7,63 \mathrm{E}-1$ & $3,25 \mathrm{E}-1$ & $5,44 \mathrm{E}-1$ & $4,15 \mathrm{E}-1$ & $1,14 \mathrm{E}-1$ & $3,43 \mathrm{E}-1$ & 1,1E-1 & 1,92E-1 & 1,82E-1 & $6,05 E-2$ \\
\hline ETMOF8 & & $\mathrm{T} 3$ & $8,25 \mathrm{E}-1$ & $2,35 \mathrm{E}-1$ & $5,04 \mathrm{E}-1$ & $4,47 \mathrm{E}-1$ & $1,3 \mathrm{E}-1$ & $2,65 \mathrm{E}-1$ & $6,71 \mathrm{E}-2$ & 1,65E-1 & 8,09E-2 & $5,98 \mathrm{E}-2$ \\
\hline & MIGD & $\mathrm{T} 1$ & $8,92 \mathrm{E} 1$ & $1,96 \mathrm{E} 1$ & $5,29 \mathrm{E} 1$ & $5,69 \mathrm{E} 1$ & $1,85 \mathrm{E} 1$ & 7,36E0 & 5,33E-1 & 2,94E0 & 2,23E0 & 1,79E0 \\
\hline & & $\mathrm{T} 2$ & $2,16 \mathrm{E}-2$ & $8,1 \mathrm{E}-3$ & $1,46 \mathrm{E}-2$ & $9,94 \mathrm{E}-3$ & $3,55 \mathrm{E}-3$ & 3,33E-3 & $9,62 \mathrm{E}-4$ & 1,88E-3 & 2,01E-3 & $6,13 E-4$ \\
\hline & & T3 & $1,92 \mathrm{E}-2$ & $6,79 \mathrm{E}-3$ & $1,45 \mathrm{E}-2$ & $1,71 \mathrm{E}-2$ & $3,23 \mathrm{E}-3$ & 2,96E-3 & $7,15 \mathrm{E}-4$ & 1,53E-3 & 7,7E-4 & $5,17 \mathrm{E}-4$ \\
\hline
\end{tabular}


Table 7. IGD and MIGD Results for Eight Many-Objective Optimization Problems from ETMOF9 to ETMOF16.

\begin{tabular}{|c|c|c|c|c|c|c|c|c|c|c|c|c|}
\hline \multirow{2}{*}{ Problems } & \multirow[t]{2}{*}{ QI } & \multirow[t]{2}{*}{ Task No. } & \multicolumn{5}{|c|}{ MO-MFEA } & \multicolumn{5}{|c|}{ DMFPSO } \\
\hline & & & Best & Worst & Mean & Median & Std. & Best & Worst & Mean & Median & Std \\
\hline \multirow[t]{4}{*}{ ETMOF9 } & \multirow[t]{2}{*}{ IGD } & $\mathrm{T} 1$ & 1,29E6 & $1,68 \mathrm{E} 5$ & 5,09E5 & $3,53 \mathrm{E} 5$ & $2,73 \mathrm{E} 5$ & 9,85E4 & $2,84 \mathrm{E} 2$ & $1,48 \mathrm{E} 4$ & $1,58 \mathrm{E} 4$ & 2,32E4 \\
\hline & & $\mathrm{T} 2$ & $1,4 \mathrm{E} 15$ & $14 \mathrm{E} 14$ & $6,75 \mathrm{E} 14$ & $5,87 \mathrm{E} 14$ & $2,45 \mathrm{E} 14$ & 2,99E14 & $9,41 \mathrm{E} 12$ & 9E13 & $2,23 \mathrm{E} 13$ & 8,38E13 \\
\hline & \multirow[t]{2}{*}{ MIGD } & $\mathrm{T} 1$ & $1,83 \mathrm{E} 4$ & $1,42 \mathrm{E} 3$ & $6,88 \mathrm{E} 3$ & $1,54 \mathrm{E} 4$ & $4,5 \mathrm{E} 3$ & 1,79E3 & $2,22 \mathrm{E0}$ & $1,56 \mathrm{E} 2$ & $1,64 \mathrm{E} 2$ & $3,76 \mathrm{E} 2$ \\
\hline & & $\mathrm{T} 2$ & $2,92 \mathrm{E} 13$ & $9,8 \mathrm{E} 12$ & $1,7 \mathrm{E} 13$ & $1,99 \mathrm{E} 13$ & $5,73 \mathrm{E} 12$ & 3,94E12 & 1,7E11 & 9,9E11 & 4,99E11 & 9,57E11 \\
\hline \multirow[t]{4}{*}{ ETMOF10 } & \multirow[t]{2}{*}{ IGD } & $\mathrm{T} 1$ & $1,47 \mathrm{E} 0$ & $8,25 \mathrm{E}-1$ & $1,19 \mathrm{E} 0$ & $9,51 \mathrm{E}-1$ & $1,78 \mathrm{E}-1$ & $3,5 \mathrm{E}-1$ & 1,52E-1 & $2,36 \mathrm{E}-1$ & $2,57 \mathrm{E}-1$ & $4,88 \mathrm{E}-2$ \\
\hline & & $\mathrm{T} 2$ & $1,65 \mathrm{E} 1$ & $1,24 \mathrm{E} 1$ & 1,41E1 & $1,24 \mathrm{E} 1$ & $1,22 \mathrm{E} 0$ & $3,7 \mathrm{EO}$ & 3,07E0 & 3,45E0 & 3,51E0 & 1,9E-1 \\
\hline & \multirow[t]{2}{*}{ MIGD } & $\mathrm{T} 1$ & $2,78 \mathrm{E}-2$ & $1,62 \mathrm{E}-2$ & $2,4 \mathrm{E}-2$ & $2,73 \mathrm{E}-2$ & $3 \mathrm{E}-3$ & $3,48 \mathrm{E}-3$ & $1,62 \mathrm{E}-3$ & $2,28 \mathrm{E}-3$ & $1,65 \mathrm{E}-3$ & $5,43 E-4$ \\
\hline & & $\mathrm{T} 2$ & $3,26 \mathrm{E}-1$ & $2,44 \mathrm{E}-1$ & $2,88 \mathrm{E}-1$ & $2,86 \mathrm{E}-1$ & $1,97 \mathrm{E}-2$ & 4,1E-2 & 2,94E-2 & 3,52E-2 & 3,88E-2 & 3,08E-3 \\
\hline \multirow[t]{4}{*}{ ETMOF11 } & \multirow[t]{2}{*}{ IGD } & $\mathrm{T} 1$ & $2,1 \mathrm{E}-1$ & $5,25 \mathrm{E}-2$ & $1,48 \mathrm{E}-1$ & $2,1 \mathrm{E}-1$ & $4,07 \mathrm{E}-2$ & $2,73 \mathrm{E}-2$ & $6,42 \mathrm{E}-3$ & $1,59 \mathrm{E}-2$ & $1,66 \mathrm{E}-2$ & $5,54 \mathrm{E}-3$ \\
\hline & & $\mathrm{T} 2$ & $1,21 \mathrm{E} 0$ & $7,32 \mathrm{E}-1$ & $1,05 \mathrm{E} 0$ & $1,06 \mathrm{E} 0$ & $1,31 \mathrm{E}-1$ & 3,07E-1 & $1,07 \mathrm{E}-1$ & $1,77 \mathrm{E}-1$ & 1,74E-1 & $5,09 \mathrm{E}-2$ \\
\hline & \multirow[t]{2}{*}{ MIGD } & $\mathrm{T} 1$ & $5,14 \mathrm{E}-3$ & $8,83 \mathrm{E}-4$ & $3,34 \mathrm{E}-3$ & $4 \mathrm{E}-3$ & $1,01 \mathrm{E}-3$ & $2,13 E-4$ & $7,97 \mathrm{E}-5$ & $1,41 \mathrm{E}-4$ & $1,83 E-4$ & $4,43 E-5$ \\
\hline & & $\mathrm{T} 2$ & $2,28 \mathrm{E}-2$ & $1,67 \mathrm{E}-2$ & $1,98 \mathrm{E}-2$ & $2,06 \mathrm{E}-2$ & $1,76 \mathrm{E}-3$ & $2,63 \mathrm{E}-3$ & $8,95 \mathrm{E}-4$ & $1,75 \mathrm{E}-3$ & 1,99E-3 & $4,24 \mathrm{E}-4$ \\
\hline \multirow{6}{*}{ ETMOF12 } & \multirow[t]{3}{*}{ IGD } & $\mathrm{T} 1$ & $3,41 \mathrm{E}-1$ & $1,62 \mathrm{E}-1$ & $2,72 \mathrm{E}-1$ & $2,3 \mathrm{E}-1$ & $4,19 \mathrm{E}-2$ & $8,53 E-2$ & $3,47 \mathrm{E}-2$ & $5,48 \mathrm{E}-2$ & $4,68 \mathrm{E}-2$ & $1,21 \mathrm{E}-2$ \\
\hline & & $\mathrm{T} 2$ & $3,75 \mathrm{E}-1$ & $4,4 \mathrm{E}-2$ & $2,03 \mathrm{E}-1$ & $2,42 \mathrm{E}-1$ & $7,61 \mathrm{E}-2$ & $8,87 \mathrm{E}-2$ & $3,29 \mathrm{E}-2$ & $6,67 \mathrm{E}-2$ & $6,61 \mathrm{E}-2$ & $1,56 \mathrm{E}-2$ \\
\hline & & $\mathrm{T} 3$ & $6,23 \mathrm{E}-2$ & $1,2 \mathrm{E}-2$ & $3,74 \mathrm{E}-2$ & $3,28 \mathrm{E}-2$ & $1,29 \mathrm{E}-2$ & $2,1 \mathrm{E}-2$ & $6,55 \mathrm{E}-3$ & $1,07 \mathrm{E}-2$ & $1,17 \mathrm{E}-2$ & $3,45 \mathrm{E}-3$ \\
\hline & \multirow[t]{3}{*}{ MIGD } & $\mathrm{T} 1$ & $9,86 \mathrm{E}-3$ & $5,97 \mathrm{E}-3$ & $8,49 \mathrm{E}-3$ & $9,86 \mathrm{E}-3$ & $9,74 \mathrm{E}-4$ & 1,06E-3 & $3,77 \mathrm{E}-4$ & $6,6 \mathrm{E}-4$ & $6,54 \mathrm{E}-4$ & $1,83 E-4$ \\
\hline & & $\mathrm{T} 2$ & $9,97 \mathrm{E}-3$ & $2,29 \mathrm{E}-3$ & $6,71 \mathrm{E}-3$ & $9,54 \mathrm{E}-3$ & $1,94 \mathrm{E}-3$ & 1,11E-3 & $3,82 \mathrm{E}-4$ & $6,48 \mathrm{E}-4$ & $7,1 \mathrm{E}-4$ & 1,55E-4 \\
\hline & & T3 & $1,5 \mathrm{E}-3$ & $5,47 \mathrm{E}-4$ & $9,78 \mathrm{E}-4$ & $1,37 \mathrm{E}-3$ & $2,57 \mathrm{E}-4$ & $2,55 \mathrm{E}-4$ & $4,74 \mathrm{E}-5$ & $1,06 \mathrm{E}-4$ & 1,09E-4 & $4,15 \mathrm{E}-5$ \\
\hline \multirow{6}{*}{ ETMOF13 } & \multirow[t]{3}{*}{ IGD } & $\mathrm{T} 1$ & $2,25 \mathrm{E} 1$ & 1,67E1 & $1,92 \mathrm{E} 1$ & $1,73 \mathrm{E} 1$ & $1,58 \mathrm{E} 0$ & 1,31E1 & 8,08E0 & 1,01E1 & $8,7 \mathrm{EO}$ & $1,42 \mathrm{E} 0$ \\
\hline & & $\mathrm{T} 2$ & $1,53 \mathrm{E} 0$ & $9,76 \mathrm{E}-1$ & $1,25 \mathrm{E} 0$ & $1,25 \mathrm{E} 0$ & $1,23 \mathrm{E}-1$ & 3,22E-1 & 1,53E-1 & $2,28 \mathrm{E}-1$ & 1,98E-1 & $4,48 \mathrm{E}-2$ \\
\hline & & T3 & $1,28 \mathrm{E} 1$ & $8,03 \mathrm{E} 0$ & $1,09 \mathrm{E} 1$ & $1,28 \mathrm{E} 1$ & 1,04E0 & 2,89E0 & 1,49E0 & $2,15 \mathrm{E} 0$ & 2,81E0 & 4,38E-1 \\
\hline & \multirow[t]{3}{*}{ MIGD } & $\mathrm{T} 1$ & $6,68 \mathrm{E}-1$ & $5,24 \mathrm{E}-1$ & $5,94 \mathrm{E}-1$ & $5,64 \mathrm{E}-1$ & $4,43 \mathrm{E}-2$ & $1,92 \mathrm{E}-1$ & $6,3 \mathrm{E}-2$ & $9,51 \mathrm{E}-2$ & $9,17 \mathrm{E}-2$ & $2,43 E-2$ \\
\hline & & $\mathrm{T} 2$ & $4,55 \mathrm{E}-2$ & $3,23 \mathrm{E}-2$ & $3,9 \mathrm{E}-2$ & $3,97 \mathrm{E}-2$ & $3,5 \mathrm{E}-3$ & $3,45 \mathrm{E}-3$ & $1,4 \mathrm{E}-3$ & $2,18 \mathrm{E}-3$ & 1,99E-3 & $5,11 \mathrm{E}-4$ \\
\hline & & T3 & $4,02 \mathrm{E}-1$ & $2,87 \mathrm{E}-1$ & $3,44 \mathrm{E}-1$ & $3,45 \mathrm{E}-1$ & $3,25 \mathrm{E}-2$ & $3,16 \mathrm{E}-2$ & 1,36E-2 & $1,99 \mathrm{E}-2$ & $2,46 \mathrm{E}-2$ & 4,32E-3 \\
\hline \multirow{6}{*}{ ETMOF14 } & \multirow[t]{3}{*}{ IGD } & $\mathrm{T} 1$ & $1,33 \mathrm{E} 0$ & $7,32 \mathrm{E}-1$ & $1,04 \mathrm{E} 0$ & $9,81 \mathrm{E}-1$ & $1,55 \mathrm{E}-1$ & $3,87 \mathrm{E}-1$ & $1,98 \mathrm{E}-1$ & 2,91E-1 & 3,31E-1 & $5,5 \mathrm{E}-2$ \\
\hline & & $\mathrm{T} 2$ & $1,48 \mathrm{E}-1$ & $1,2 \mathrm{E}-1$ & $1,36 \mathrm{E}-1$ & $1,38 \mathrm{E}-1$ & $7,81 \mathrm{E}-3$ & 1,33E-1 & $6,67 \mathrm{E}-2$ & 1,02E-1 & 1E-1 & 1,59E-2 \\
\hline & & $\mathrm{T} 3$ & $4 \mathrm{E}-2$ & $3,15 \mathrm{E}-2$ & $3,53 \mathrm{E}-2$ & $3,4 \mathrm{E}-2$ & $2,01 \mathrm{E}-3$ & 1,88E-2 & $1,43 \mathrm{E}-2$ & $1,72 \mathrm{E}-2$ & $1,74 \mathrm{E}-2$ & 1,07E-3 \\
\hline & \multirow[t]{3}{*}{ MIGD } & $\mathrm{T} 1$ & $4,32 \mathrm{E}-2$ & $2,35 \mathrm{E}-2$ & $3,34 \mathrm{E}-2$ & $3,19 \mathrm{E}-2$ & $6,4 \mathrm{E}-3$ & $4,52 \mathrm{E}-3$ & $1,65 \mathrm{E}-3$ & $2,91 E-3$ & $3,74 E-3$ & $7,63 E-4$ \\
\hline & & $\mathrm{T} 2$ & $4,41 \mathrm{E}-3$ & $3,41 \mathrm{E}-3$ & $3,93 \mathrm{E}-3$ & $3,86 \mathrm{E}-3$ & $2,25 \mathrm{E}-4$ & $1,48 \mathrm{E}-3$ & $6,07 E-4$ & 1E-3 & $8,95 E-4$ & 1,84E-4 \\
\hline & & T3 & $1,18 \mathrm{E}-3$ & $9,13 \mathrm{E}-4$ & $1,04 \mathrm{E}-3$ & $1,04 \mathrm{E}-3$ & $6,74 \mathrm{E}-5$ & $2,64 \mathrm{E}-4$ & $1,19 \mathrm{E}-4$ & $1,83 E-4$ & $1,42 E-4$ & $3,4 \mathrm{E}-5$ \\
\hline ETMOF15 & IGD & $\mathrm{T} 1$ & $1,14 \mathrm{E} 0$ & $6,39 \mathrm{E}-1$ & $9,23 \mathrm{E}-1$ & $8,14 \mathrm{E}-1$ & $1,49 \mathrm{E}-1$ & $5,15 \mathrm{E}-2$ & $1,15 \mathrm{E}-2$ & $2,41 E-2$ & $1,51 \mathrm{E}-2$ & $1,04 \mathrm{E}-2$ \\
\hline & & $\mathrm{T} 2$ & $7,52 \mathrm{E}-1$ & $5,84 \mathrm{E}-1$ & $6,84 \mathrm{E}-1$ & $6,74 \mathrm{E}-1$ & $4,79 \mathrm{E}-2$ & 2E-1 & $1,08 \mathrm{E}-1$ & $1,4 \mathrm{E}-1$ & $1,27 \mathrm{E}-1$ & $2,46 \mathrm{E}-2$ \\
\hline & MIGD & $\mathrm{T} 1$ & $2,26 \mathrm{E}-2$ & $1,25 \mathrm{E}-2$ & $1,85 \mathrm{E}-2$ & $2,06 \mathrm{E}-2$ & $3,17 \mathrm{E}-3$ & $4,65 \mathrm{E}-4$ & $1,25 \mathrm{E}-4$ & $2,12 \mathrm{E}-4$ & $4,65 \mathrm{E}-4$ & 9,61E-5 \\
\hline & & $\mathrm{T} 2$ & $1,54 \mathrm{E}-2$ & $1,2 \mathrm{E}-2$ & $1,38 \mathrm{E}-2$ & $1,35 \mathrm{E}-2$ & $7,65 \mathrm{E}-4$ & $1,94 \mathrm{E}-3$ & $9,75 \mathrm{E}-4$ & $1,41 \mathrm{E}-3$ & $1,25 \mathrm{E}-3$ & 2,32E-4 \\
\hline ETMOF16 & IGD & $\mathrm{T} 1$ & $5,77 \mathrm{E} 1$ & $2,6 \mathrm{E} 0$ & $2,23 \mathrm{E} 1$ & $1,71 \mathrm{E} 1$ & $1,37 \mathrm{E} 1$ & $1,48 \mathrm{E} 0$ & $7,1 \mathrm{E}-2$ & 5,36E-1 & 7,1E-2 & 2,7E-1 \\
\hline & & $\mathrm{T} 2$ & $4,73 \mathrm{E} 2$ & $1,07 \mathrm{E} 2$ & $3,22 \mathrm{E} 2$ & $2,43 \mathrm{E} 2$ & $1,06 \mathrm{E} 2$ & 9,91E0 & $1,25 \mathrm{EO}$ & $2,78 \mathrm{E} 0$ & $1,25 \mathrm{EO}$ & $1,88 E 0$ \\
\hline & MIGD & $\mathrm{T} 1$ & $1,09 \mathrm{E} 0$ & $1,5 \mathrm{E}-1$ & $3,92 \mathrm{E}-1$ & $2,16 \mathrm{E}-1$ & $2,29 \mathrm{E}-1$ & 2,16E-2 & 1,71E-3 & $7,24 \mathrm{E}-3$ & $3,44 E-3$ & 5,31E-3 \\
\hline & & $\mathrm{T} 2$ & $9,55 \mathrm{E} 0$ & $3,94 \mathrm{E} 0$ & $6,19 \mathrm{E} 0$ & $6,74 \mathrm{E} 0$ & $1,45 \mathrm{E} 0$ & 5E-2 & $1,36 \mathrm{E}-2$ & $2,73 E-2$ & $2,35 \mathrm{E}-2$ & 1,19E-2 \\
\hline
\end{tabular}


Table 8. IGD and MIGD Results for Eight Large-Scale Multi-Objective Optimization Problems from ETMOF17 to ETMOF24.

\begin{tabular}{|c|c|c|c|c|c|c|c|c|c|c|c|c|}
\hline \multirow[t]{2}{*}{ Problems } & \multirow[t]{2}{*}{ QI } & \multirow[t]{2}{*}{ Task No. } & \multicolumn{5}{|c|}{ MO-MFEA } & \multicolumn{5}{|c|}{ DMFPSO } \\
\hline & & & Best & Worst & Mean & Median & Std. & Best & Worst & Mean & Median & Std \\
\hline \multirow[t]{4}{*}{ ETMOF17 } & \multirow[t]{2}{*}{ IGD } & $\mathrm{T} 1$ & $2,07 \mathrm{E} 1$ & $1,47 \mathrm{E} 1$ & $1,8 \mathrm{E} 1$ & $1,7 \mathrm{E} 1$ & $1,41 \mathrm{E} 0$ & $8,66 \mathrm{E} 0$ & 7,91E-1 & $1,96 \mathrm{EO}$ & $1,22 \mathrm{EO}$ & $1,76 \mathrm{EO}$ \\
\hline & & $\mathrm{T} 2$ & $1,69 \mathrm{E} 1$ & $1,45 \mathrm{E} 1$ & $1,57 \mathrm{E} 1$ & $1,53 \mathrm{E} 1$ & $6,49 \mathrm{E}-1$ & 1,08E1 & $5,6 \mathrm{E}-1$ & $1,51 \mathrm{EO}$ & $6,16 \mathrm{E}-1$ & 2,17E0 \\
\hline & \multirow[t]{2}{*}{ MIGD } & $\mathrm{T} 1$ & $4,29 \mathrm{E}-1$ & $3,29 \mathrm{E}-1$ & $3,73 \mathrm{E}-1$ & $3,76 \mathrm{E}-1$ & $2,93 \mathrm{E}-2$ & $1,7 \mathrm{E}-1$ & 8,36E-3 & $2,27 \mathrm{E}-2$ & 1,32E-2 & 3,36E-2 \\
\hline & & $\mathrm{T} 2$ & $3,48 \mathrm{E}-1$ & $2,84 \mathrm{E}-1$ & $3,2 \mathrm{E}-1$ & $3,33 \mathrm{E}-1$ & $1,83 \mathrm{E}-2$ & 1,53E-1 & $4,85 \mathrm{E}-3$ & $1,63 E-2$ & $7,6 \mathrm{E}-3$ & 3,08E-2 \\
\hline \multirow[t]{4}{*}{ ETMOF18 } & \multirow[t]{2}{*}{ IGD } & $\mathrm{T} 1$ & $7,36 \mathrm{E} 1$ & $6,68 \mathrm{E} 1$ & $6,98 \mathrm{E} 1$ & $7,06 \mathrm{E} 1$ & $1,65 \mathrm{E} 0$ & $4,76 \mathrm{E} 0$ & 3,11E0 & $4,1 \mathrm{E} 0$ & 3,62E0 & 3,99E-1 \\
\hline & & $\mathrm{T} 2$ & $2,8 \mathrm{E} 0$ & $2,66 \mathrm{E} 0$ & $2,72 \mathrm{E} 0$ & $2,7 \mathrm{E} 0$ & $3,48 \mathrm{E}-2$ & $6,85 \mathrm{E}-1$ & $5,23 \mathrm{E}-1$ & $6,16 \mathrm{E}-1$ & $5,62 \mathrm{E}-1$ & 3,79E-2 \\
\hline & \multirow[t]{2}{*}{ MIGD } & $\mathrm{T} 1$ & $1,48 \mathrm{E} 0$ & $1,28 \mathrm{E} 0$ & $1,41 \mathrm{E} 0$ & $1,28 \mathrm{E} 0$ & $4,43 \mathrm{E}-2$ & $6,25 \mathrm{E}-2$ & 3,13E-2 & $4,16 \mathrm{E}-2$ & $3,64 \mathrm{E}-2$ & 7,83E-3 \\
\hline & & $\mathrm{T} 2$ & $5,68 \mathrm{E}-2$ & $5,17 \mathrm{E}-2$ & $5,42 \mathrm{E}-2$ & $5,26 \mathrm{E}-2$ & $1,33 \mathrm{E}-3$ & 7,36E-3 & $5,53 \mathrm{E}-3$ & $6,33 E-3$ & $5,79 \mathrm{E}-3$ & $4,67 \mathrm{E}-4$ \\
\hline \multirow[t]{4}{*}{ ETMOF19 } & \multirow[t]{2}{*}{ IGD } & $\mathrm{T} 1$ & $1,29 \mathrm{E} 4$ & $1,84 \mathrm{E} 2$ & $2,82 \mathrm{E} 3$ & $5,85 \mathrm{E} 3$ & $2,83 \mathrm{E} 3$ & $5,99 \mathrm{E3}$ & $4,53 \mathrm{E} 0$ & $3,75 \mathrm{E} 2$ & 2,61E1 & $1,27 \mathrm{E} 3$ \\
\hline & & $\mathrm{T} 2$ & $5,97 \mathrm{E} 1$ & $5,38 \mathrm{E} 1$ & $5,68 \mathrm{E} 1$ & $5,58 \mathrm{E} 1$ & $1,64 \mathrm{E} 0$ & 4,38E1 & $2,64 \mathrm{E} 0$ & 1,03E1 & 1,71E1 & 1,12E1 \\
\hline & \multirow[t]{2}{*}{ MIGD } & $\mathrm{T} 1$ & 7,11E2 & $4,02 \mathrm{E} 0$ & 7,91E1 & $1,78 \mathrm{E} 1$ & $1,46 \mathrm{E} 2$ & $6,62 \mathrm{E} 3$ & $4,14 \mathrm{E}-2$ & $3,16 \mathrm{E} 2$ & 5,19E-1 & $1,41 \mathrm{E} 3$ \\
\hline & & $\mathrm{T} 2$ & $1,21 \mathrm{E} 0$ & $1,07 \mathrm{E} 0$ & 1,13E0 & $1,15 \mathrm{E} 0$ & $3,66 \mathrm{E}-2$ & $6,45 \mathrm{E}-1$ & 2,89E-2 & 1,11E-1 & $3,74 \mathrm{E}-2$ & 1,61E-1 \\
\hline \multirow{6}{*}{ ETMOF20 } & \multirow[t]{3}{*}{ IGD } & $\mathrm{T} 1$ & $6,28 \mathrm{E} 1$ & $5,25 \mathrm{E} 1$ & 5,9E1 & 5,93E1 & $2,66 \mathrm{E} 0$ & $1,66 \mathrm{E} 2$ & $1,22 \mathrm{E} 2$ & $1,43 \mathrm{E} 2$ & $1,42 \mathrm{E} 2$ & 1,19E1 \\
\hline & & $\mathrm{T} 2$ & 2,97E0 & 2,72E0 & $2,87 \mathrm{EO}$ & $2,88 \mathrm{EO}$ & $5,71 \mathrm{E}-2$ & $5,4 \mathrm{E} 0$ & $4,06 \mathrm{E} 0$ & $4,68 \mathrm{E} 0$ & $4,36 \mathrm{E} 0$ & $3,44 \mathrm{E}-1$ \\
\hline & & T3 & $8,25 \mathrm{E} 1$ & $7,21 \mathrm{E} 1$ & 7,84E1 & $7,75 \mathrm{E} 1$ & $2,17 \mathrm{E} 0$ & $2,11 \mathrm{E} 2$ & $1,42 \mathrm{E} 2$ & $1,82 \mathrm{E} 2$ & $1,84 \mathrm{E} 2$ & 1,64E1 \\
\hline & \multirow[t]{3}{*}{ MIGD } & $\mathrm{T} 1$ & 1,91E0 & $1,63 \mathrm{E} 0$ & $1,78 \mathrm{E} 0$ & $1,73 \mathrm{E} 0$ & $8,63 \mathrm{E}-2$ & 2E0 & 1,13E0 & $1,46 \mathrm{E} 0$ & 1,62E0 & 2,37E-1 \\
\hline & & $\mathrm{T} 2$ & $8,91 \mathrm{E}-2$ & $8,17 \mathrm{E}-2$ & $8,63 \mathrm{E}-2$ & $8,77 \mathrm{E}-2$ & $1,84 \mathrm{E}-3$ & 7,39E-2 & $3,35 \mathrm{E}-2$ & $5,02 \mathrm{E}-2$ & $4,44 \mathrm{E}-2$ & $9,85 \mathrm{E}-3$ \\
\hline & & $\mathrm{T} 3$ & $2,52 \mathrm{E} 0$ & $2,2 \mathrm{E} 0$ & $2,33 \mathrm{E} 0$ & $2,26 \mathrm{E} 0$ & $8,65 \mathrm{E}-2$ & $2,74 \mathrm{E} 0$ & 1,32E0 & 1,82E0 & 2,07E0 & $3,9 \mathrm{E}-1$ \\
\hline \multirow{6}{*}{ ETMOF21 } & \multirow[t]{3}{*}{ IGD } & $\mathrm{T} 1$ & $4,26 \mathrm{E} 3$ & $7,6 \mathrm{E} 1$ & $1,35 \mathrm{E} 3$ & $4,26 \mathrm{E} 3$ & $1,25 \mathrm{E} 3$ & $2,16 \mathrm{E} 5$ & 6,99E0 & $3,49 \mathrm{E} 4$ & $6,99 \mathrm{EO}$ & $5,12 \mathrm{E} 4$ \\
\hline & & $\mathrm{T} 2$ & $2,34 \mathrm{E} 3$ & $2,75 \mathrm{E} 1$ & $7,64 \mathrm{E} 2$ & $2,82 \mathrm{E} 2$ & $7,21 \mathrm{E} 2$ & $1,92 \mathrm{E} 5$ & 1,62E1 & $2,99 \mathrm{E} 4$ & 2,92E1 & $4,39 \mathrm{E} 4$ \\
\hline & & T3 & 1,44E1 & $8,49 \mathrm{E} 0$ & $1,18 \mathrm{E} 1$ & $1,27 \mathrm{E} 1$ & $1,88 \mathrm{E} 0$ & $1,68 \mathrm{E} 1$ & 9,38E-1 & $6,5 \mathrm{E} 0$ & 1,23E0 & $4,66 \mathrm{E} 0$ \\
\hline & \multirow[t]{3}{*}{ MIGD } & $\mathrm{T} 1$ & $1,14 \mathrm{E} 2$ & $8,13 \mathrm{E}-1$ & 2,92E1 & $3,69 \mathrm{E} 1$ & 2,85E1 & $2,86 \mathrm{E} 3$ & $9,09 E-2$ & $4,88 \mathrm{E} 2$ & $2,54 \mathrm{E} 0$ & $8,33 \mathrm{E} 2$ \\
\hline & & $\mathrm{T} 2$ & $1,55 \mathrm{E} 2$ & $6,57 \mathrm{E}-1$ & 3,67E1 & $3,29 \mathrm{E} 0$ & 3,61E1 & $4,09 \mathrm{E} 3$ & $2,66 \mathrm{E}-2$ & $4,5 \mathrm{E} 2$ & $2,54 \mathrm{E}-1$ & $9,07 \mathrm{E} 2$ \\
\hline & & T3 & $4,1 \mathrm{E}-1$ & $2,51 \mathrm{E}-1$ & $3,58 \mathrm{E}-1$ & $3,8 \mathrm{E}-1$ & $4,29 \mathrm{E}-2$ & $2,04 E-1$ & $6,03 E-3$ & $6,19 E-2$ & 1,1E-2 & 5,49E-2 \\
\hline \multirow{6}{*}{ ETMOF22 } & \multirow[t]{3}{*}{ IGD } & $\mathrm{T} 1$ & $8,5 \mathrm{E} 4$ & $3,39 \mathrm{E} 4$ & $5,75 \mathrm{E} 4$ & $6,34 \mathrm{E} 4$ & $1,1 \mathrm{E} 4$ & $3,05 \mathrm{E} 3$ & 1,42E2 & $6,86 \mathrm{E} 2$ & $4,78 \mathrm{E} 2$ & 6,29E2 \\
\hline & & $\mathrm{T} 2$ & $3,41 \mathrm{E} 5$ & $2,47 \mathrm{E} 5$ & 2,92E5 & 2,98E5 & $2,37 \mathrm{E} 4$ & 7,09E3 & 5,51E2 & $2,15 \mathrm{E} 3$ & 1,94E3 & 1,69E3 \\
\hline & & T3 & $4,77 \mathrm{E} 5$ & $3,48 \mathrm{E} 5$ & 4,18E5 & 4,54E5 & $3,6 \mathrm{E} 4$ & $2,47 \mathrm{E} 4$ & $1,3 \mathrm{E} 3$ & $4,07 \mathrm{E} 3$ & 2,52E3 & $4,86 \mathrm{E} 3$ \\
\hline & \multirow[t]{3}{*}{ MIGD } & $\mathrm{T} 1$ & $2,14 \mathrm{E} 3$ & $1,26 \mathrm{E} 3$ & 1,69E3 & 1,63E3 & $2,63 \mathrm{E} 2$ & $9,18 \mathrm{E} 2$ & 2,01E0 & $8,05 \mathrm{E} 1$ & 3,29E0 & 2,11E2 \\
\hline & & $\mathrm{T} 2$ & $1,04 \mathrm{E} 4$ & $7,48 \mathrm{E} 3$ & $8,88 \mathrm{E} 3$ & $8,61 \mathrm{E} 3$ & $6,5 \mathrm{E} 2$ & $9,61 \mathrm{E} 2$ & $7,61 \mathrm{E} 0$ & 1,01E2 & 1,64E1 & 2,12E2 \\
\hline & & T3 & $1,37 \mathrm{E} 4$ & $9,28 \mathrm{E} 3$ & $1,18 \mathrm{E} 4$ & $1,35 \mathrm{E} 4$ & $1,35 \mathrm{E} 3$ & 9,18E2 & 9,82E0 & 1,2E2 & 1,61E1 & 2,19E2 \\
\hline ETMOF23 & IGD & $\mathrm{T} 1$ & $7,52 \mathrm{E} 1$ & $6,69 \mathrm{E} 1$ & $7,06 \mathrm{E} 1$ & $7,03 \mathrm{E} 1$ & $1,67 \mathrm{E} 0$ & 3,42E1 & $4,75 \mathrm{EO}$ & $7,96 \mathrm{E0}$ & 6,52E0 & $6,17 \mathrm{E} 0$ \\
\hline & & $\mathrm{T} 2$ & $1,05 \mathrm{E} 6$ & $4,99 \mathrm{E} 5$ & $7,45 \mathrm{E} 5$ & $7,12 \mathrm{E} 5$ & $1,34 \mathrm{E} 5$ & $1,93 \mathrm{E} 5$ & $5,17 \mathrm{E} 3$ & $2,02 \mathrm{E} 4$ & $9,41 \mathrm{E3}$ & 3,99E4 \\
\hline & MIGD & $\mathrm{T} 1$ & $1,51 \mathrm{E} 0$ & $1,35 \mathrm{E} 0$ & $1,42 \mathrm{E} 0$ & $1,38 \mathrm{E} 0$ & $4,04 \mathrm{E}-2$ & $2,47 \mathrm{E}-1$ & $4,21 \mathrm{E}-2$ & 1,02E-1 & $2,02 E-1$ & 5,72E-2 \\
\hline & & $\mathrm{T} 2$ & $2,13 \mathrm{E} 4$ & $1,26 \mathrm{E} 4$ & $1,6 \mathrm{E} 4$ & $1,32 \mathrm{E} 4$ & $2,73 \mathrm{E} 3$ & $3,58 \mathrm{E} 3$ & 6,18E1 & $3,48 \mathrm{E} 2$ & 1,31E3 & 7,67E2 \\
\hline ETMOF24 & IGD & $\mathrm{T} 1$ & $1,1 \mathrm{E} 2$ & $9,95 \mathrm{E} 1$ & $1,05 \mathrm{E} 2$ & $1,03 \mathrm{E} 2$ & 2,64E0 & 9,74E1 & 2,12E1 & $3,25 \mathrm{E} 1$ & 2,38E1 & 2,06E1 \\
\hline & & $\mathrm{T} 2$ & $1,04 \mathrm{E} 4$ & $3,54 \mathrm{E} 2$ & 2,01E3 & 1,78E3 & $2,04 \mathrm{E} 3$ & 1,47E6 & 2,53E1 & $1,38 \mathrm{E} 5$ & 2,53E1 & 3,49E5 \\
\hline & MIGD & $\mathrm{T} 1$ & $2,19 \mathrm{E} 0$ & 2,01E0 & $2,08 \mathrm{E} 0$ & $2,05 \mathrm{E} 0$ & $4,83 \mathrm{E}-2$ & $7,14 \mathrm{E}-1$ & 2,03E-1 & 2,9E-1 & 2,73E-1 & $1,17 \mathrm{E}-1$ \\
\hline & & $\mathrm{T} 2$ & $1,86 \mathrm{E} 2$ & $3,75 \mathrm{E} 0$ & $4,68 \mathrm{E} 1$ & 5,63E0 & $5,58 \mathrm{E} 1$ & 4,39E3 & 2,96E0 & $3,01 \mathrm{E} 2$ & 6,04E0 & 9,73E2 \\
\hline
\end{tabular}


Table 9. IGD and MIGD Results for Eight Many-Task Optimization Problems from ETMOF25 to ETMOF28.

\begin{tabular}{|c|c|c|c|c|c|c|c|c|c|c|c|c|}
\hline \multirow[t]{2}{*}{ Problems } & \multirow[t]{2}{*}{ QI } & \multirow[t]{2}{*}{ Task No. } & \multicolumn{5}{|c|}{ MO-MFEA } & \multicolumn{5}{|c|}{ DMFPSO } \\
\hline & & & Best & Worst & Mean & Median & Std. & Best & Worst & Mean & Median & Std \\
\hline \multirow{10}{*}{ ETMOF25 } & \multirow{5}{*}{ IGD } & $\mathrm{T} 1$ & 1,99E0 & $1,38 \mathrm{E} 0$ & $1,72 \mathrm{E} 0$ & $1,9 \mathrm{EO}$ & $1,6 \mathrm{E}-1$ & $4,96 \mathrm{E} 0$ & 2,72E-1 & $2,19 \mathrm{E} 0$ & $2,58 \mathrm{E} 0$ & 1,64E0 \\
\hline & & $\mathrm{T} 2$ & $5,07 \mathrm{E}-1$ & $3,56 \mathrm{E}-1$ & 4,31E-1 & $4,06 \mathrm{E}-1$ & $4,27 \mathrm{E}-2$ & $1,27 \mathrm{E} 0$ & $5,14 \mathrm{E}-2$ & $5,27 \mathrm{E}-1$ & $1,12 \mathrm{E} 0$ & $4,21 \mathrm{E}-1$ \\
\hline & & T3 & 9,55E-2 & $7,51 \mathrm{E}-2$ & $8,44 E-2$ & 8,32E-2 & $5,99 \mathrm{E}-3$ & $2,38 \mathrm{E}-1$ & $2,68 \mathrm{E}-2$ & $1,18 \mathrm{E}-1$ & $2,04 \mathrm{E}-1$ & $7,61 \mathrm{E}-2$ \\
\hline & & $\mathrm{T} 4$ & $5,17 \mathrm{E}-1$ & $3,62 \mathrm{E}-1$ & 4,35E-1 & 4,11E-1 & 3,8E-2 & $1,3 \mathrm{E} 0$ & $1,26 \mathrm{E}-1$ & $6,76 \mathrm{E}-1$ & $1,17 \mathrm{E} 0$ & $4,67 \mathrm{E}-1$ \\
\hline & & T5 & $2,02 \mathrm{EO}$ & $1,42 \mathrm{E} 0$ & $1,7 \mathrm{EO}$ & $1,95 \mathrm{EO}$ & $1,61 \mathrm{E}-1$ & $4,84 \mathrm{E} 0$ & $3,28 \mathrm{E}-1$ & $2,23 \mathrm{E} 0$ & $4,84 \mathrm{E} 0$ & $1,52 \mathrm{E} 0$ \\
\hline & \multirow{5}{*}{ MIGD } & $\mathrm{T} 1$ & $9,67 \mathrm{E}-2$ & $6,59 \mathrm{E}-2$ & $8,38 \mathrm{E}-2$ & $8,14 \mathrm{E}-2$ & $8,24 \mathrm{E}-3$ & $5,75 \mathrm{E}-3$ & $2,29 \mathrm{E}-3$ & 3,57E-3 & $4,8 \mathrm{E}-3$ & $1,02 E-3$ \\
\hline & & $\mathrm{T} 2$ & $2,51 \mathrm{E}-2$ & $1,76 \mathrm{E}-2$ & $2,14 \mathrm{E}-2$ & $1,83 \mathrm{E}-2$ & $2,04 \mathrm{E}-3$ & $1,27 \mathrm{E}-3$ & $3,56 \mathrm{E}-4$ & $7,72 \mathrm{E}-4$ & $6,53 \mathrm{E}-4$ & 2,18E-4 \\
\hline & & T3 & $4,71 \mathrm{E}-3$ & $3,62 \mathrm{E}-3$ & $4,2 \mathrm{E}-3$ & $4,13 \mathrm{E}-3$ & $3,38 \mathrm{E}-4$ & $5 E-4$ & $2,05 E-4$ & 3,57E-4 & $2,75 \mathrm{E}-4$ & $7,84 \mathrm{E}-5$ \\
\hline & & $\mathrm{T} 4$ & $2,46 \mathrm{E}-2$ & $1,84 \mathrm{E}-2$ & $2,11 \mathrm{E}-2$ & $2,29 \mathrm{E}-2$ & $1,63 \mathrm{E}-3$ & $1,35 \mathrm{E}-3$ & $4,14 \mathrm{E}-4$ & $7,25 \mathrm{E}-4$ & $4,8 \mathrm{E}-4$ & $2,53 E-4$ \\
\hline & & T5 & $1,01 \mathrm{E}-1$ & $6,23 \mathrm{E}-2$ & $8,36 \mathrm{E}-2$ & $8,82 \mathrm{E}-2$ & $7,66 \mathrm{E}-3$ & $5,52 \mathrm{E}-3$ & $2,36 \mathrm{E}-3$ & $3,56 \mathrm{E}-3$ & $3,68 \mathrm{E}-3$ & $8,22 \mathrm{E}-4$ \\
\hline \multirow{20}{*}{ ETMOF26 } & \multirow{10}{*}{ IGD } & $\mathrm{T} 1$ & $2,29 \mathrm{E} 0$ & 1,49E0 & $1,89 \mathrm{E} 0$ & $1,91 \mathrm{E} 0$ & $1,98 \mathrm{E}-1$ & $1,64 \mathrm{E} 0$ & $7,6 \mathrm{E}-1$ & 1,03E0 & 1,02E0 & 1,77E-1 \\
\hline & & $\mathrm{T} 2$ & $3,11 \mathrm{E}-1$ & $2,07 \mathrm{E}-1$ & $2,71 \mathrm{E}-1$ & $2,89 \mathrm{E}-1$ & $3,11 \mathrm{E}-2$ & 2,51E-1 & $1,13 \mathrm{E}-1$ & 1,63E-1 & 1,91E-1 & $3,07 \mathrm{E}-2$ \\
\hline & & T3 & $1,11 \mathrm{E}-1$ & $7,59 \mathrm{E}-2$ & $9,26 \mathrm{E}-2$ & $1,11 \mathrm{E}-1$ & $9,74 \mathrm{E}-3$ & 1,38E-1 & $5,53 \mathrm{E}-2$ & $9,18 \mathrm{E}-2$ & 1,04E-1 & 2,34E-2 \\
\hline & & $\mathrm{T} 4$ & $2,32 \mathrm{E}-1$ & $1,46 \mathrm{E}-1$ & $1,94 \mathrm{E}-1$ & $1,81 \mathrm{E}-1$ & $2,41 \mathrm{E}-2$ & 1,32E-1 & $6,6 \mathrm{E}-2$ & $9,71 \mathrm{E}-2$ & 1,05E-1 & $1,7 \mathrm{E}-2$ \\
\hline & & T5 & $2,19 \mathrm{E} 0$ & $1,53 \mathrm{E} 0$ & $1,89 \mathrm{E} 0$ & $2,16 \mathrm{E} 0$ & $1,58 \mathrm{E}-1$ & $1,64 \mathrm{E} 0$ & $5,11 \mathrm{E}-1$ & $1,01 E 0$ & 1,1E0 & 2,59E-1 \\
\hline & & T6 & $1,25 \mathrm{E} 0$ & $6,06 \mathrm{E}-1$ & $9,25 \mathrm{E}-1$ & $1,04 \mathrm{E} 0$ & $1,36 \mathrm{E}-1$ & $6,81 \mathrm{E}-1$ & 3,3E-1 & 4,82E-1 & 5,63E-1 & 9,3E-2 \\
\hline & & $\mathrm{T} 7$ & $5,58 \mathrm{E}-1$ & $3,68 \mathrm{E}-1$ & $4,76 \mathrm{E}-1$ & $5,25 \mathrm{E}-1$ & $4,38 \mathrm{E}-2$ & $3,28 \mathrm{E}-1$ & $1,77 \mathrm{E}-1$ & $2,45 \mathrm{E}-1$ & 2,22E-1 & 4,32E-2 \\
\hline & & T8 & $8,84 \mathrm{E}-2$ & $5,06 \mathrm{E}-2$ & $6,53 \mathrm{E}-2$ & $7,38 \mathrm{E}-2$ & $8,8 E-3$ & $1,04 \mathrm{E}-1$ & $3,68 \mathrm{E}-2$ & $6,44 \mathrm{E}-2$ & $9,19 \mathrm{E}-2$ & $1,82 \mathrm{E}-2$ \\
\hline & & T9 & $5,9 \mathrm{E}-1$ & $3,64 \mathrm{E}-1$ & $4,85 \mathrm{E}-1$ & $5 \mathrm{E}-1$ & $4,9 \mathrm{E}-2$ & $3,21 \mathrm{E}-1$ & $1,48 \mathrm{E}-1$ & 2,15E-1 & 2,09E-1 & $4,79 \mathrm{E}-2$ \\
\hline & & $\mathrm{T} 10$ & $9,61 \mathrm{E}-1$ & $5,04 \mathrm{E}-1$ & $7,24 \mathrm{E}-1$ & $8,49 \mathrm{E}-1$ & $1,07 \mathrm{E}-1$ & 5,39E-1 & $2,37 \mathrm{E}-1$ & 3,59E-1 & $4,71 \mathrm{E}-1$ & $8,67 \mathrm{E}-2$ \\
\hline & \multirow{10}{*}{ MIGD } & $\mathrm{T} 1$ & $2,23 \mathrm{E}-1$ & $1,48 \mathrm{E}-1$ & $1,86 \mathrm{E}-1$ & $1,98 \mathrm{E}-1$ & $1,85 \mathrm{E}-2$ & $4,85 \mathrm{E}-2$ & 6,71E-3 & $2,15 \mathrm{E}-2$ & $1,84 \mathrm{E}-2$ & $9,27 \mathrm{E}-3$ \\
\hline & & $\mathrm{T} 2$ & $3,29 \mathrm{E}-2$ & $2,05 \mathrm{E}-2$ & $2,66 \mathrm{E}-2$ & $2,05 \mathrm{E}-2$ & $3,32 \mathrm{E}-3$ & $2,58 \mathrm{E}-2$ & 1,39E-3 & $4,78 \mathrm{E}-3$ & 2,08E-3 & $5,24 \mathrm{E}-3$ \\
\hline & & $\mathrm{T} 3$ & $1,06 \mathrm{E}-2$ & $7,33 \mathrm{E}-3$ & $9,22 \mathrm{E}-3$ & $8,75 \mathrm{E}-3$ & $7,06 \mathrm{E}-4$ & $1,2 \mathrm{E}-2$ & $7,46 \mathrm{E}-4$ & $3,47 \mathrm{E}-3$ & $4,51 \mathrm{E}-3$ & 2,72E-3 \\
\hline & & $\mathrm{T} 4$ & $2,42 \mathrm{E}-2$ & $1,43 \mathrm{E}-2$ & $1,87 \mathrm{E}-2$ & $1,87 \mathrm{E}-2$ & $2,4 \mathrm{E}-3$ & $1,65 \mathrm{E}-2$ & $8,47 \mathrm{E}-4$ & $2,73 \mathrm{E}-3$ & $2,58 \mathrm{E}-3$ & $3,27 \mathrm{E}-3$ \\
\hline & & T5 & $2,19 \mathrm{E}-1$ & $1,53 \mathrm{E}-1$ & $1,9 \mathrm{E}-1$ & $2,06 \mathrm{E}-1$ & $1,86 \mathrm{E}-2$ & $4,5 \mathrm{E}-2$ & $8,21 \mathrm{E}-3$ & $2,15 \mathrm{E}-2$ & $1,74 \mathrm{E}-2$ & 8,57E-3 \\
\hline & & T6 & $1,11 \mathrm{E}-1$ & $7,16 \mathrm{E}-2$ & $9,21 \mathrm{E}-2$ & $9,86 \mathrm{E}-2$ & $1,02 \mathrm{E}-2$ & $5,68 \mathrm{E}-2$ & $3,74 \mathrm{E}-3$ & $1,29 \mathrm{E}-2$ & $9,66 \mathrm{E}-3$ & 1,11E-2 \\
\hline & & $\mathrm{T} 7$ & $5,62 \mathrm{E}-2$ & $4,26 \mathrm{E}-2$ & $4,82 \mathrm{E}-2$ & $4,53 \mathrm{E}-2$ & $4,39 \mathrm{E}-3$ & $1,44 \mathrm{E}-2$ & 2E-3 & $5,49 \mathrm{E}-3$ & $5,67 \mathrm{E}-3$ & $3,13 E-3$ \\
\hline & & $\mathrm{T} 8$ & $7,1 \mathrm{E}-3$ & $5,31 \mathrm{E}-3$ & $6,28 \mathrm{E}-3$ & $6,67 \mathrm{E}-3$ & $5,39 \mathrm{E}-4$ & $3,28 \mathrm{E}-3$ & 4,51E-4 & $1,4 \mathrm{E}-3$ & $2,7 \mathrm{E}-3$ & $6,71 \mathrm{E}-4$ \\
\hline & & T9 & $5,72 \mathrm{E}-2$ & $4,1 \mathrm{E}-2$ & $4,82 \mathrm{E}-2$ & $5,3 \mathrm{E}-2$ & $3,48 \mathrm{E}-3$ & $2,75 \mathrm{E}-2$ & $1,93 \mathrm{E}-3$ & $6,41 \mathrm{E}-3$ & $2,95 \mathrm{E}-3$ & $6,12 \mathrm{E}-3$ \\
\hline & & $\mathrm{T} 10$ & $9,5 \mathrm{E}-2$ & $6,04 \mathrm{E}-2$ & $7,86 \mathrm{E}-2$ & $7,89 \mathrm{E}-2$ & $8,58 \mathrm{E}-3$ & $5,27 \mathrm{E}-2$ & $4 \mathrm{E}-3$ & $1,26 \mathrm{E}-2$ & $9,77 \mathrm{E}-3$ & 1,12E-2 \\
\hline \multirow{13}{*}{ ETMOF27 } & \multirow{10}{*}{ IGD } & $\mathrm{T} 1$ & 1,06E5 & $2,43 \mathrm{E} 4$ & $5,71 \mathrm{E} 4$ & $6,42 \mathrm{E} 4$ & $1,49 \mathrm{E} 4$ & $4,7 \mathrm{E} 4$ & 8,12E3 & $2,23 E 4$ & $1,76 \mathrm{E} 4$ & 9,72E3 \\
\hline & & $\mathrm{T} 2$ & $2,75 \mathrm{E}-1$ & $2,26 \mathrm{E}-1$ & $2,5 \mathrm{E}-1$ & 2,59E-1 & $1,27 \mathrm{E}-2$ & $3,62 \mathrm{E}-1$ & $2,22 \mathrm{E}-1$ & $2,94 \mathrm{E}-1$ & $2,69 \mathrm{E}-1$ & $3,46 \mathrm{E}-2$ \\
\hline & & T3 & 1,72E-1 & 1,36E-1 & $1,48 E-1$ & $1,42 \mathrm{E}-1$ & $8,23 E-3$ & $2,32 \mathrm{E}-1$ & $1,68 \mathrm{E}-1$ & $2,02 \mathrm{E}-1$ & $2,01 \mathrm{E}-1$ & $1,57 \mathrm{E}-2$ \\
\hline & & $\mathrm{T} 4$ & $2,16 \mathrm{E}-2$ & $1,56 \mathrm{E}-2$ & $1,84 \mathrm{E}-2$ & $1,79 \mathrm{E}-2$ & $1,64 \mathrm{E}-3$ & $3,63 \mathrm{E}-2$ & $1,81 \mathrm{E}-2$ & $2,73 \mathrm{E}-2$ & $2,5 \mathrm{E}-2$ & $4,94 \mathrm{E}-3$ \\
\hline & & T5 & $8,1 \mathrm{EO}$ & $4,98 \mathrm{E} 0$ & $6,65 \mathrm{E} 0$ & $7,75 \mathrm{E} 0$ & 8,88E-1 & $8,14 \mathrm{E} 0$ & $2,5 \mathrm{E} 0$ & $4,91 \mathrm{EO}$ & $5,56 \mathrm{E} 0$ & $1,43 \mathrm{E} 0$ \\
\hline & & T6 & 1,03E5 & $3,38 \mathrm{E} 4$ & $6,31 \mathrm{E} 4$ & $9,71 \mathrm{E} 4$ & $1,69 \mathrm{E} 4$ & $2,64 \mathrm{E} 5$ & $5,16 \mathrm{E} 3$ & $4,66 \mathrm{E} 4$ & $2,77 \mathrm{E} 4$ & $6,09 \mathrm{E} 4$ \\
\hline & & $\mathrm{T} 7$ & $6,54 \mathrm{E}-1$ & $5,77 \mathrm{E}-1$ & $6,17 \mathrm{E}-1$ & $6,37 \mathrm{E}-1$ & $2,02 \mathrm{E}-2$ & $6,13 E-1$ & $4,58 \mathrm{E}-1$ & 5,33E-1 & $5,47 \mathrm{E}-1$ & $4,78 \mathrm{E}-2$ \\
\hline & & T8 & 4,1E-1 & 3,39E-1 & 3,72E-1 & 3,69E-1 & $1,77 \mathrm{E}-2$ & $4,84 \mathrm{E}-1$ & $3,79 \mathrm{E}-1$ & $4,19 \mathrm{E}-1$ & $4,06 \mathrm{E}-1$ & $2,75 \mathrm{E}-2$ \\
\hline & & T9 & $4,37 E-2$ & $3,75 \mathrm{E}-2$ & 4,1E-2 & $4,21 \mathrm{E}-2$ & $1,55 \mathrm{E}-3$ & $4,59 \mathrm{E}-2$ & $3,88 \mathrm{E}-2$ & $4,26 \mathrm{E}-2$ & $4,26 \mathrm{E}-2$ & $1,71 \mathrm{E}-3$ \\
\hline & & T10 & $1,71 \mathrm{E} 1$ & $1,26 \mathrm{E} 1$ & 1,49E1 & $1,26 \mathrm{E} 1$ & 1,12E0 & 1,17E1 & 4,56E0 & 8,11E0 & 8,77E0 & $1,57 \mathrm{E} 0$ \\
\hline & & $\mathrm{T} 1$ & $1,05 E 4$ & $2,85 \mathrm{E} 3$ & $5,83 \mathrm{E} 3$ & $6,94 \mathrm{E3}$ & $1,85 \mathrm{E} 3$ & $1,68 \mathrm{E} 4$ & $1,11 \mathrm{E} 3$ & $7,15 \mathrm{E} 3$ & $9,83 \mathrm{E} 3$ & $5,34 \mathrm{E} 3$ \\
\hline & & $\mathrm{T} 2$ & $2,66 \mathrm{E}-2$ & $2,28 \mathrm{E}-2$ & $2,49 \mathrm{E}-2$ & 2,59E-2 & $9,95 \mathrm{E}-4$ & $4,41 \mathrm{E}-2$ & $7,08 \mathrm{E}-3$ & $2,8 \mathrm{E}-2$ & $3,33 \mathrm{E}-2$ & $1,06 \mathrm{E}-2$ \\
\hline & & T3 & $1,62 \mathrm{E}-2$ & $1,3 \mathrm{E}-2$ & $1,46 \mathrm{E}-2$ & 1,52E-2 & $8 E-4$ & $3,07 \mathrm{E}-2$ & $6,43 E-3$ & $1,84 \mathrm{E}-2$ & $1,81 \mathrm{E}-2$ & $6,91 \mathrm{E}-3$ \\
\hline
\end{tabular}




\begin{tabular}{|c|c|c|c|c|c|c|c|c|c|c|c|c|}
\hline & \multirow{7}{*}{ MIGD } & $\mathrm{T} 4$ & $2,27 \mathrm{E}-3$ & $1,5 \mathrm{E}-3$ & $1,8 \mathrm{E}-3$ & $1,78 \mathrm{E}-3$ & 1,89E-4 & $4,03 \mathrm{E}-3$ & 9,08E-4 & $2,42 \mathrm{E}-3$ & 1,72E-3 & $1,02 \mathrm{E}-3$ \\
\hline & & T5 & 8,61E-1 & $4,68 \mathrm{E}-1$ & $6,48 \mathrm{E}-1$ & $6,61 \mathrm{E}-1$ & $1,06 \mathrm{E}-1$ & $1,53 \mathrm{E} 0$ & 2,05E-1 & $6,5 \mathrm{E}-1$ & $5,16 \mathrm{E}-1$ & $3,87 \mathrm{E}-1$ \\
\hline & & T6 & $8,24 \mathrm{E} 3$ & $2,49 \mathrm{E} 3$ & 5,93E3 & $6,87 \mathrm{E} 3$ & $1,56 \mathrm{E3}$ & $2,61 \mathrm{E} 4$ & 9,28E1 & 7,37E3 & $2,75 \mathrm{E} 3$ & 7,01E3 \\
\hline & & $\mathrm{T} 7$ & $6,61 \mathrm{E}-2$ & $5,9 \mathrm{E}-2$ & $6,31 \mathrm{E}-2$ & $6,2 \mathrm{E}-2$ & $1,75 \mathrm{E}-3$ & $6,87 \mathrm{E}-2$ & $2,65 \mathrm{E}-2$ & $5,42 \mathrm{E}-2$ & $6,18 \mathrm{E}-2$ & $1,33 E-2$ \\
\hline & & T8 & 4,02E-2 & $3,49 \mathrm{E}-2$ & $3,77 \mathrm{E}-2$ & $3,8 \mathrm{E}-2$ & 1,39E-3 & $4,94 \mathrm{E}-2$ & $9,74 \mathrm{E}-3$ & 2,88E-2 & 2,71E-2 & $1,4 \mathrm{E}-2$ \\
\hline & & T9 & $4,41 \mathrm{E}-3$ & $3,98 \mathrm{E}-3$ & $4,2 \mathrm{E}-3$ & $3,98 \mathrm{E}-3$ & 1,01E-4 & $5,18 \mathrm{E}-3$ & $2,13 E-3$ & $4,08 \mathrm{E}-3$ & $4,42 \mathrm{E}-3$ & $1,16 \mathrm{E}-3$ \\
\hline & & $\mathrm{T} 10$ & $1,77 \mathrm{E} 0$ & $1,28 \mathrm{E} 0$ & $1,52 \mathrm{E} 0$ & 1,41E0 & $1,51 \mathrm{E}-1$ & 1,62E0 & 2,07E-1 & 8,63E-1 & 1,01E0 & $4,21 \mathrm{E}-1$ \\
\hline \multirow{40}{*}{ ETMOF28 } & \multirow{20}{*}{ IGD } & $\mathrm{T} 1$ & $1,52 \mathrm{E} 3$ & 7,79E2 & $1,08 \mathrm{E} 3$ & $1,14 \mathrm{E} 3$ & $1,55 \mathrm{E} 2$ & $1,26 \mathrm{E} 3$ & $5,77 \mathrm{E} 2$ & $9,68 \mathrm{E} 2$ & 1,02E3 & $1,97 \mathrm{E} 2$ \\
\hline & & $\mathrm{T} 2$ & $1,27 \mathrm{E} 5$ & $4,28 \mathrm{E} 4$ & $8,56 \mathrm{E} 4$ & $9,4 \mathrm{E} 4$ & $2,1 \mathrm{E} 4$ & $3,6 E 4$ & 2,07E4 & $2,95 \mathrm{E} 4$ & $2,6 \mathrm{E} 4$ & $5,6 \mathrm{E} 3$ \\
\hline & & T3 & $3,37 \mathrm{E}-1$ & $3,19 \mathrm{E}-1$ & $3,26 \mathrm{E}-1$ & $3,27 \mathrm{E}-1$ & 4,7E-3 & 3,36E-1 & 2,99E-1 & 3,2E-1 & $3,36 \mathrm{E}-1$ & $1,11 \mathrm{E}-2$ \\
\hline & & $\mathrm{T} 4$ & 8,27E-2 & $5,43 \mathrm{E}-2$ & $6,96 \mathrm{E}-2$ & $6,26 \mathrm{E}-2$ & $7,2 \mathrm{E}-3$ & $9,51 \mathrm{E}-2$ & 4,33E-2 & $5,53 \mathrm{E}-2$ & $7,74 \mathrm{E}-2$ & $1,42 \mathrm{E}-2$ \\
\hline & & T5 & $3,58 \mathrm{E} 2$ & $2,39 \mathrm{E} 2$ & $3,06 \mathrm{E} 2$ & 3,08E2 & $2,44 \mathrm{E} 1$ & $3,88 \mathrm{E} 2$ & $2,21 \mathrm{E} 2$ & $2,96 \mathrm{E} 2$ & $3,13 \mathrm{E} 2$ & $5,25 \mathrm{E} 1$ \\
\hline & & T6 & $3,17 \mathrm{E} 2$ & $9,77 \mathrm{E} 1$ & $2,07 \mathrm{E} 2$ & $1,42 \mathrm{E} 2$ & 6,82E1 & $3,43 \mathrm{E} 2$ & $5,21 \mathrm{E} 1$ & $1,79 \mathrm{E} 2$ & $1,98 \mathrm{E} 2$ & $9,54 \mathrm{E} 1$ \\
\hline & & $\mathrm{T} 7$ & 2,77E5 & $1,64 \mathrm{E} 5$ & $2,3 \mathrm{E} 5$ & $2,72 \mathrm{E} 5$ & $3,34 \mathrm{E} 4$ & $3,14 \mathrm{E} 5$ & $1,24 \mathrm{E} 5$ & 2,09E5 & 1,33E5 & $6,32 \mathrm{E} 4$ \\
\hline & & T8 & $1,97 \mathrm{E}-1$ & $1,83 \mathrm{E}-1$ & $1,93 \mathrm{E}-1$ & $1,92 \mathrm{E}-1$ & $3,02 \mathrm{E}-3$ & $1,95 \mathrm{E}-1$ & $1,79 \mathrm{E}-1$ & 1,86E-1 & 1,9E-1 & $4,4 \mathrm{E}-3$ \\
\hline & & T9 & $6,8 \mathrm{E}-2$ & $5,42 \mathrm{E}-2$ & $6,07 E-2$ & 6,52E-2 & 3,43E-3 & $7,53 \mathrm{E}-2$ & $5,01 \mathrm{E}-2$ & $6,2 \mathrm{E}-2$ & $7,53 \mathrm{E}-2$ & $1,05 \mathrm{E}-2$ \\
\hline & & $\mathrm{T} 10$ & $4,01 \mathrm{E} 2$ & $2,46 \mathrm{E} 2$ & $3,3 \mathrm{E} 2$ & $4,36 \mathrm{E} 1$ & $4,36 \mathrm{E} 1$ & 3,57E2 & 1,98E2 & $2,59 \mathrm{E} 2$ & 2,51E2 & 5,13E1 \\
\hline & & $\mathrm{T} 11$ & $5,51 \mathrm{E} 2$ & $3,71 \mathrm{E} 2$ & $4,45 \mathrm{E} 2$ & $4,45 \mathrm{E} 2$ & $5,03 \mathrm{E} 1$ & $4,75 \mathrm{E} 2$ & 3,17E2 & $3,97 \mathrm{E} 2$ & $3,17 \mathrm{E} 2$ & 5,38E1 \\
\hline & & $\mathrm{T} 12$ & $9,66 \mathrm{E} 4$ & $1,97 \mathrm{E} 4$ & $6,15 \mathrm{E} 4$ & $1,97 \mathrm{E} 4$ & $2,19 \mathrm{E} 4$ & $5,54 \mathrm{E} 4$ & $1,52 \mathrm{E} 4$ & $3,55 \mathrm{E} 4$ & $3,24 \mathrm{E} 4$ & $1,18 E 4$ \\
\hline & & $\mathrm{T} 13$ & 7,43E-1 & $7,03 \mathrm{E}-1$ & $7,3 \mathrm{E}-1$ & $7,39 \mathrm{E}-1$ & $1,11 \mathrm{E}-2$ & $7,57 \mathrm{E}-1$ & $6,09 \mathrm{E}-1$ & $7 E-1$ & 6,09E-1 & $4,24 \mathrm{E}-2$ \\
\hline & & T14 & $4,96 \mathrm{E}-2$ & $3,66 \mathrm{E}-2$ & $4,23 \mathrm{E}-2$ & $4,82 \mathrm{E}-2$ & $3,16 \mathrm{E}-3$ & 4,1E-2 & 2,52E-2 & 3,3E-2 & $3,44 \mathrm{E}-2$ & 4,32E-3 \\
\hline & & $\mathrm{T} 15$ & $3,92 \mathrm{E} 2$ & $2,83 \mathrm{E} 2$ & $3,38 \mathrm{E} 2$ & $2,57 \mathrm{E} 1$ & $2,57 \mathrm{E} 1$ & $3,47 \mathrm{E} 2$ & $1,92 \mathrm{E} 2$ & $2,68 \mathrm{E} 2$ & 2,71E2 & 4,58E1 \\
\hline & & $\mathrm{T} 16$ & $6,94 \mathrm{E} 2$ & $3,5 \mathrm{E} 2$ & $5,26 \mathrm{E} 2$ & $5,48 \mathrm{E} 2$ & $8,72 \mathrm{E} 1$ & $4,55 \mathrm{E} 2$ & $2,43 \mathrm{E} 2$ & $3,61 \mathrm{E} 2$ & 2,88E2 & 5,98E1 \\
\hline & & $\mathrm{T} 17$ & $1,6 \mathrm{E} 5$ & $7,2 \mathrm{E} 4$ & $1,09 \mathrm{E} 5$ & $1,47 \mathrm{E} 5$ & $1,74 \mathrm{E} 4$ & 1,17E5 & $5,43 E 4$ & $7,71 \mathrm{E} 4$ & $7,78 \mathrm{E} 4$ & $1,87 \mathrm{E} 4$ \\
\hline & & T18 & 1,78E-1 & $5,84 \mathrm{E}-2$ & $9,65 \mathrm{E}-2$ & $7,15 \mathrm{E}-2$ & $3,25 \mathrm{E}-2$ & $1,87 \mathrm{E}-1$ & $4,82 \mathrm{E}-2$ & $9,77 \mathrm{E}-2$ & $5,58 \mathrm{E}-2$ & 4,49E-2 \\
\hline & & T19 & $1,54 \mathrm{E}-1$ & $1,21 \mathrm{E}-1$ & $1,38 \mathrm{E}-1$ & $1,51 \mathrm{E}-1$ & $8,7 \mathrm{E}-3$ & 1,53E-1 & 1,04E-1 & $1,25 \mathrm{E}-1$ & $1,17 \mathrm{E}-1$ & $1,68 E-2$ \\
\hline & & T20 & $2,47 \mathrm{E} 2$ & $1,59 \mathrm{E} 2$ & $1,99 \mathrm{E} 2$ & $2,01 \mathrm{E} 2$ & $2,45 \mathrm{E} 1$ & 2,03E2 & $1,05 \mathrm{E} 2$ & 1,61E2 & 1,42E2 & $3,12 \mathrm{E} 1$ \\
\hline & \multirow{20}{*}{ MIGD } & $\mathrm{T} 1$ & $2,58 \mathrm{E} 2$ & $1,5 \mathrm{E} 2$ & $2,1 \mathrm{E} 2$ & $1,9 \mathrm{E} 2$ & 2,39E1 & $6,57 \mathrm{E} 1$ & 1,95E1 & $4,66 \mathrm{E} 1$ & $5,05 \mathrm{E} 1$ & $1,24 \mathrm{E} 1$ \\
\hline & & $\mathrm{T} 2$ & $8,62 \mathrm{E} 3$ & $1,6 \mathrm{E} 4$ & $1,13 \mathrm{E} 4$ & 4,34E3 & 4,34E3 & $5,57 \mathrm{E3}$ & $1,23 \mathrm{E} 3$ & $3,48 \mathrm{E} 3$ & $4,84 \mathrm{E} 3$ & $1,33 \mathrm{E} 3$ \\
\hline & & T3 & $6,73 \mathrm{E}-2$ & $6,36 \mathrm{E}-2$ & $6,51 \mathrm{E}-2$ & $6,52 \mathrm{E}-2$ & $9,2 \mathrm{E}-4$ & $1,66 \mathrm{E}-2$ & $7,91 \mathrm{E}-3$ & 1,43E-2 & $1,66 \mathrm{E}-2$ & $3,2 \mathrm{E}-3$ \\
\hline & & $\mathrm{T} 4$ & $2,07 \mathrm{E}-2$ & $1,08 \mathrm{E}-2$ & $1,41 \mathrm{E}-2$ & $1,38 \mathrm{E}-2$ & $2,07 \mathrm{E}-3$ & $4,17 \mathrm{E}-3$ & $9,78 \mathrm{E}-4$ & $2,67 \mathrm{E}-3$ & $2,39 \mathrm{E}-3$ & $1,07 E-3$ \\
\hline & & T5 & $7,18 \mathrm{E} 1$ & $5,04 \mathrm{E} 1$ & $6,03 \mathrm{E} 1$ & $5,04 \mathrm{E} 1$ & $6,34 \mathrm{E} 0$ & 2,08E1 & 7,87E0 & 1,21E1 & 7,87E0 & $3,81 \mathrm{EO}$ \\
\hline & & T6 & $6,1 \mathrm{E} 1$ & $1,88 \mathrm{E} 1$ & $3,69 \mathrm{E} 1$ & $5,15 \mathrm{E} 1$ & $1,14 \mathrm{E} 1$ & 1,37E1 & $1,72 \mathrm{E} 0$ & 6,9E0 & 1,72E0 & $3,29 \mathrm{E} 0$ \\
\hline & & $\mathrm{T} 7$ & $6,78 \mathrm{E} 4$ & $2,91 \mathrm{E} 4$ & $4,76 \mathrm{E} 4$ & $3,9 \mathrm{E} 4$ & $9,73 \mathrm{E} 3$ & $1,49 \mathrm{E} 4$ & $1,82 \mathrm{E} 3$ & $8,15 E 3$ & $1,24 \mathrm{E} 4$ & $4,73 \mathrm{E} 3$ \\
\hline & & T8 & $3,96 \mathrm{E}-2$ & $3,26 \mathrm{E}-2$ & $3,84 \mathrm{E}-2$ & $3,79 \mathrm{E}-2$ & $1,38 \mathrm{E}-3$ & $9,64 \mathrm{E}-3$ & $8,78 \mathrm{E}-3$ & 9,35E-3 & 9,59E-3 & $2,8 \mathrm{E}-4$ \\
\hline & & T9 & $1,37 \mathrm{E}-2$ & $1,04 \mathrm{E}-2$ & $1,23 \mathrm{E}-2$ & $1,19 \mathrm{E}-2$ & $7,95 \mathrm{E}-4$ & 3E-3 & $1,13 E-3$ & 2,36E-3 & $1,67 \mathrm{E}-3$ & $6,35 \mathrm{E}-4$ \\
\hline & & $\mathrm{T} 10$ & $9,41 \mathrm{E} 1$ & $4,97 \mathrm{E} 1$ & $7,09 \mathrm{E} 1$ & $6,16 \mathrm{E} 1$ & $1,16 \mathrm{E} 1$ & 1,61E1 & 2,8E0 & 1,01E1 & 1,52E1 & 4,33E0 \\
\hline & & T11 & $1,14 \mathrm{E} 2$ & $8,12 \mathrm{E} 1$ & $9,66 \mathrm{E} 1$ & $9,13 \mathrm{E} 1$ & $8,37 \mathrm{E} 0$ & 2,96E1 & 8,92E0 & 1,91E1 & 2,39E1 & 6,58E0 \\
\hline & & $\mathrm{T} 12$ & $1,77 \mathrm{E} 4$ & $5,79 \mathrm{E} 3$ & $1,19 \mathrm{E} 4$ & $1,08 \mathrm{E} 4$ & $3,66 \mathrm{E} 3$ & $3,84 \mathrm{E} 3$ & $1,18 \mathrm{E} 3$ & $2,37 \mathrm{E} 3$ & $1,95 \mathrm{E} 3$ & $1,13 \mathrm{E} 3$ \\
\hline & & T13 & $1,5 \mathrm{E}-1$ & $1,24 \mathrm{E}-1$ & $1,46 \mathrm{E}-1$ & $1,46 \mathrm{E}-1$ & $5,26 \mathrm{E}-3$ & $3,76 \mathrm{E}-2$ & $1,77 \mathrm{E}-2$ & $3,43 E-2$ & $3,68 \mathrm{E}-2$ & 5,9E-3 \\
\hline & & $\mathrm{T} 14$ & $9,12 \mathrm{E}-3$ & $7,17 \mathrm{E}-3$ & $8,08 \mathrm{E}-3$ & $7,85 \mathrm{E}-3$ & $5,03 \mathrm{E}-4$ & $2,12 \mathrm{E}-3$ & $4,48 \mathrm{E}-4$ & $1,44 \mathrm{E}-3$ & $1,57 \mathrm{E}-3$ & $4,57 \mathrm{E}-4$ \\
\hline & & $\mathrm{T} 15$ & $8,62 \mathrm{E} 1$ & $5,05 \mathrm{E} 1$ & $6,22 \mathrm{E} 1$ & $5,81 \mathrm{E} 1$ & $7,62 \mathrm{E} 0$ & 1,93E1 & 4,53E0 & 1,12E1 & 1,62E1 & $4,26 \mathrm{EO}$ \\
\hline & & $\mathrm{T} 16$ & $1,31 \mathrm{E} 2$ & $6,53 \mathrm{E} 1$ & $1,09 \mathrm{E} 2$ & $1,22 \mathrm{E} 2$ & $1,6 \mathrm{E} 1$ & 2,81E1 & 1,21E1 & $2,05 \mathrm{E} 1$ & 1,84E1 & $5,17 \mathrm{E} 0$ \\
\hline & & $\mathrm{T} 17$ & $3,54 \mathrm{E} 4$ & $9,34 \mathrm{E} 3$ & $2,01 \mathrm{E} 4$ & $1,58 \mathrm{E} 4$ & $5,71 \mathrm{E} 3$ & $7,66 \mathrm{E} 3$ & $1,32 \mathrm{E} 3$ & $4,3 \mathrm{E} 3$ & $4,49 \mathrm{E} 3$ & $1,85 \mathrm{E} 3$ \\
\hline & & T18 & $3,87 \mathrm{E}-2$ & $1,17 \mathrm{E}-2$ & $2,08 \mathrm{E}-2$ & $2,52 \mathrm{E}-2$ & $7,25 \mathrm{E}-3$ & $8,72 \mathrm{E}-3$ & $1,44 \mathrm{E}-3$ & $4,84 \mathrm{E}-3$ & $1,8 \mathrm{E}-3$ & $2,48 \mathrm{E}-3$ \\
\hline & & T19 & $3,16 \mathrm{E}-2$ & $1,93 \mathrm{E}-2$ & $2,71 \mathrm{E}-2$ & $2,64 \mathrm{E}-2$ & $2,63 \mathrm{E}-3$ & $7,35 \mathrm{E}-3$ & $5,66 \mathrm{E}-3$ & $6,5 \mathrm{E}-3$ & $6,41 \mathrm{E}-3$ & 6,72E-4 \\
\hline & & $\mathrm{T} 20$ & $4,96 \mathrm{E} 1$ & $3,1 \mathrm{E} 1$ & $4,03 \mathrm{E} 1$ & $3,52 \mathrm{E} 1$ & $4,58 \mathrm{E} 0$ & $8,48 \mathrm{E} 0$ & 1,98E0 & $4,74 \mathrm{E} 0$ & $2,55 \mathrm{E} 0$ & $2,54 \mathrm{E} 0$ \\
\hline
\end{tabular}


Table 10. IGD AND MIGD Results for Eight Dynamic Multi-Objective Optimization Problems from ETMOF33 to ETMOF40.

\begin{tabular}{|c|c|c|c|c|c|c|c|c|c|c|c|c|}
\hline \multirow[t]{2}{*}{ Problems } & \multirow[t]{2}{*}{ QI } & \multirow[t]{2}{*}{ Task No. } & \multicolumn{5}{|c|}{ IGD } & \multicolumn{5}{|c|}{ MIGD } \\
\hline & & & Best & Worst & Mean & Median & Std. & Best & Worst & Mean & Median & Std \\
\hline \multirow[t]{4}{*}{ ETMOF33 } & \multirow[t]{2}{*}{ IGD } & $\mathrm{T} 1$ & $2,48 \mathrm{E} 0$ & $2,21 \mathrm{EO}$ & 2,38E0 & 2,38E0 & 5,92E-2 & $8,32 \mathrm{E} 0$ & $7,81 \mathrm{E} 0$ & $8,04 \mathrm{E} 0$ & 7,99E0 & 1,49E-1 \\
\hline & & $\mathrm{T} 2$ & $5,88 \mathrm{EO}$ & $5,34 \mathrm{EO}$ & 5,57E0 & $5,56 \mathrm{EO}$ & 1,42E-1 & $8,76 \mathrm{E} 0$ & $2,06 \mathrm{E} 0$ & $6,36 \mathrm{E} 0$ & $7,56 \mathrm{E} 0$ & $1,72 \mathrm{E} 0$ \\
\hline & \multirow[t]{2}{*}{ MIGD } & $\mathrm{T} 1$ & 4,93E-2 & $4,5 \mathrm{E}-2$ & $4,75 \mathrm{E}-2$ & $4,78 \mathrm{E}-2$ & 1,23E-3 & $9,86 \mathrm{E}-2$ & $6,69 \mathrm{E}-2$ & $8,23 \mathrm{E}-2$ & $7,39 \mathrm{E}-2$ & $7,73 \mathrm{E}-3$ \\
\hline & & $\mathrm{T} 2$ & $1,14 \mathrm{E}-1$ & $1,07 \mathrm{E}-1$ & $1,1 \mathrm{E}-1$ & $1,11 \mathrm{E}-1$ & $2,3 \mathrm{E}-3$ & 9,83E-2 & $2,27 \mathrm{E}-2$ & $6,14 \mathrm{E}-2$ & $8,48 \mathrm{E}-2$ & $2,08 \mathrm{E}-2$ \\
\hline \multirow{4}{*}{ ETMOF34 } & \multirow{2}{*}{ IGD } & $\mathrm{T} 1$ & $1,4 \mathrm{E}-1$ & 4,57E-2 & $9,24 \mathrm{E}-2$ & $8,26 \mathrm{E}-2$ & $2,14 \mathrm{E}-2$ & $4,09 \mathrm{E}-1$ & $3,18 \mathrm{E}-1$ & $3,59 \mathrm{E}-1$ & $3,84 \mathrm{E}-1$ & $2,23 \mathrm{E}-2$ \\
\hline & & $\mathrm{T} 2$ & 1,28E1 & 9,23E0 & 1,12E1 & 1,01E1 & $7,82 \mathrm{E}-1$ & $2,17 \mathrm{E} 1$ & $6,73 \mathrm{E} 0$ & $1,64 \mathrm{E} 1$ & 2,04E1 & $5,48 \mathrm{E} 0$ \\
\hline & \multirow[t]{2}{*}{ MIGD } & $\mathrm{T} 1$ & 2,31E-3 & $1,4 \mathrm{E}-3$ & 1,77E-3 & $2,15 \mathrm{E}-3$ & 2,41E-4 & $4,77 \mathrm{E}-3$ & $2,69 \mathrm{E}-3$ & $3,63 \mathrm{E}-3$ & $3,32 \mathrm{E}-3$ & $4,63 \mathrm{E}-4$ \\
\hline & & $\mathrm{T} 2$ & $2,44 \mathrm{E}-1$ & $1,78 \mathrm{E}-1$ & $2,23 \mathrm{E}-1$ & $2,36 \mathrm{E}-1$ & $1,58 \mathrm{E}-2$ & 2,54E-1 & $6,08 \mathrm{E}-2$ & 1,62E-1 & $6,26 \mathrm{E}-2$ & $6,03 E-2$ \\
\hline \multirow[t]{4}{*}{ ETMOF35 } & \multirow[t]{2}{*}{ IGD } & $\mathrm{T} 1$ & 3,71E0 & 3,47E0 & 3,59E0 & $3,67 \mathrm{E} 0$ & $7,87 \mathrm{E}-2$ & $1,28 \mathrm{E} 1$ & $1,09 \mathrm{E} 1$ & $1,14 \mathrm{E} 1$ & $1,14 \mathrm{E} 1$ & $4,06 \mathrm{E}-1$ \\
\hline & & $\mathrm{T} 2$ & $4,84 \mathrm{E} 1$ & $1,69 \mathrm{E} 1$ & $2,46 \mathrm{E} 1$ & $1,85 \mathrm{E} 1$ & $8,63 \mathrm{E} 0$ & 1,91E1 & 5,51E0 & 9,18E0 & $7,40 \mathrm{E} 0$ & $2,84 \mathrm{E} 0$ \\
\hline & \multirow[t]{2}{*}{ MIGD } & $\mathrm{T} 1$ & $7,45 \mathrm{E}-2$ & 6,79E-2 & $7,14 \mathrm{E}-2$ & 7,32E-2 & 1,62E-3 & $1,55 \mathrm{E}-1$ & $8,66 \mathrm{E}-2$ & $1,13 \mathrm{E}-1$ & $1,24 \mathrm{E}-1$ & $1,45 \mathrm{E}-2$ \\
\hline & & $\mathrm{T} 2$ & $1,8 \mathrm{E} 0$ & $3,32 \mathrm{E}-1$ & $5,83 \mathrm{E}-1$ & $4,71 \mathrm{E}-1$ & $3,5 \mathrm{E}-1$ & 1,38E-1 & $5,63 \mathrm{E}-2$ & 9,11E-2 & 9,55E-2 & 2,39E-2 \\
\hline \multirow[t]{4}{*}{ ETMOF36 } & \multirow[t]{2}{*}{ IGD } & $\mathrm{T} 1$ & $3,88 \mathrm{E} 0$ & $3,56 \mathrm{E} 0$ & $3,69 \mathrm{E} 0$ & $3,88 \mathrm{E} 0$ & $7,81 \mathrm{E}-2$ & $7,25 \mathrm{E}-1$ & 2,09E-1 & 3,92E-1 & $3,95 \mathrm{E}-1$ & $1,33 E-1$ \\
\hline & & $\mathrm{T} 2$ & 1,17E2 & $3,38 \mathrm{E} 1$ & $5,36 \mathrm{E} 1$ & 3,39E1 & $1,95 \mathrm{E} 1$ & 2,67E1 & $1,26 \mathrm{E} 1$ & 1,85E1 & 1,92E1 & 3,70E0 \\
\hline & \multirow[t]{2}{*}{ MIGD } & T1 & $7,54 \mathrm{E}-2$ & $7,13 \mathrm{E}-2$ & $7,32 \mathrm{E}-2$ & $7,18 \mathrm{E}-2$ & $1,17 \mathrm{E}-3$ & 7,67E-3 & 1,92E-3 & $3,78 E-3$ & $5,73 E-3$ & $1,37 \mathrm{E}-3$ \\
\hline & & $\mathrm{T} 2$ & $2,21 \mathrm{E} 0$ & $6,41 \mathrm{E}-1$ & $1,08 \mathrm{E} 0$ & $1,46 \mathrm{E} 0$ & $4,55 \mathrm{E}-1$ & 3,14E-1 & 1,27E-1 & 1,82E-1 & 1,91E-1 & $4,17 E-2$ \\
\hline \multirow[t]{4}{*}{ ETMOF37 } & \multirow[t]{2}{*}{ IGD } & $\mathrm{T} 1$ & $3,4 \mathrm{E}-1$ & $2,01 \mathrm{E}-1$ & $2,87 \mathrm{E}-1$ & $2,67 \mathrm{E}-1$ & $3,24 \mathrm{E}-2$ & 1,09E-1 & 3,33E-2 & $6,25 \mathrm{E}-2$ & $9,64 \mathrm{E}-2$ & $2,29 \mathrm{E}-2$ \\
\hline & & $\mathrm{T} 2$ & $1,51 \mathrm{E}-1$ & $8,82 \mathrm{E}-2$ & $1,08 \mathrm{E}-1$ & $1,07 \mathrm{E}-1$ & $1,35 \mathrm{E}-2$ & $5,88 \mathrm{E}-2$ & $4,22 \mathrm{E}-2$ & 4,94E-2 & $4,65 \mathrm{E}-2$ & $4,89 \mathrm{E}-3$ \\
\hline & \multirow{2}{*}{ MIGD } & $\mathrm{T} 1$ & $6,81 \mathrm{E}-3$ & $4,58 \mathrm{E}-3$ & $5,6 \mathrm{E}-3$ & $6,29 \mathrm{E}-3$ & $5,73 \mathrm{E}-4$ & 1,76E-3 & $3,06 \mathrm{E}-4$ & 9,97E-4 & 1,39E-3 & 3,57E-4 \\
\hline & & $\mathrm{T} 2$ & $2,71 \mathrm{E}-3$ & $1,85 \mathrm{E}-3$ & $2,16 \mathrm{E}-3$ & $2,01 \mathrm{E}-3$ & $1,97 \mathrm{E}-4$ & $6,02 E-4$ & $3,46 \mathrm{E}-4$ & $4,69 \mathrm{E}-4$ & $4,06 \mathrm{E}-4$ & $6,65 \mathrm{E}-5$ \\
\hline \multirow[t]{4}{*}{ ETMOF38 } & \multirow[t]{2}{*}{ IGD } & $\mathrm{T} 1$ & $2,62 \mathrm{E}-1$ & $1,85 \mathrm{E}-1$ & $2,26 \mathrm{E}-1$ & $2,27 \mathrm{E}-1$ & $1,85 \mathrm{E}-2$ & 4,32E-1 & $5,86 \mathrm{E}-2$ & 1,78E-1 & $1,50 \mathrm{E}-1$ & $8,96 \mathrm{E}-2$ \\
\hline & & $\mathrm{T} 2$ & $1,21 \mathrm{E}-1$ & $9,75 \mathrm{E}-2$ & $1,08 \mathrm{E}-1$ & $1,04 \mathrm{E}-1$ & $6,09 \mathrm{E}-3$ & $5,34 \mathrm{E}-2$ & 4,13E-2 & $4,76 \mathrm{E}-2$ & $4,66 \mathrm{E}-2$ & $3,35 \mathrm{E}-3$ \\
\hline & \multirow[t]{2}{*}{ MIGD } & $\mathrm{T} 1$ & $5,13 \mathrm{E}-3$ & $3,83 \mathrm{E}-3$ & $4,62 \mathrm{E}-3$ & $4,31 \mathrm{E}-3$ & $3,56 \mathrm{E}-4$ & $7,13 \mathrm{E}-3$ & $8,5 \mathrm{E}-4$ & $1,98 \mathrm{E}-3$ & $1,45 \mathrm{E}-3$ & $1,33 E-3$ \\
\hline & & $\mathrm{T} 2$ & $2,52 \mathrm{E}-3$ & $1,8 \mathrm{E}-3$ & $2,19 \mathrm{E}-3$ & $2,04 \mathrm{E}-3$ & $1,76 \mathrm{E}-4$ & $7,3 \mathrm{E}-4$ & 3,9E-4 & $5,04 \mathrm{E}-4$ & $5,05 \mathrm{E}-4$ & $7,48 \mathrm{E}-5$ \\
\hline \multirow[t]{6}{*}{ ETMOF39 } & IGD & $\mathrm{T} 1$ & 3,23E-1 & 2,36E-1 & 2,81E-1 & 2,91E-1 & $2,62 \mathrm{E}-2$ & $1,23 \mathrm{E} 0$ & $1,04 \mathrm{E} 0$ & $1,12 \mathrm{E} 0$ & $1,11 \mathrm{E} 0$ & $4,25 \mathrm{E}-2$ \\
\hline & & $\mathrm{T} 2$ & 5,07E1 & 2,97E1 & 4,02E1 & 4,04E1 & $6,12 \mathrm{E} 0$ & $5,36 \mathrm{E} 2$ & $3,97 \mathrm{E} 2$ & $4,68 \mathrm{E} 2$ & $4,93 \mathrm{E} 2$ & $3,63 \mathrm{E} 1$ \\
\hline & & $\mathrm{T} 3$ & $1,04 \mathrm{E}-2$ & $8,24 E-3$ & $9,46 \mathrm{E}-3$ & 9,58E-3 & $5,31 \mathrm{E}-4$ & $2,14 \mathrm{E}-2$ & $1,95 \mathrm{E}-2$ & $2,01 \mathrm{E}-2$ & $1,98 \mathrm{E}-2$ & $5,77 \mathrm{E}-4$ \\
\hline & MIGD & $\mathrm{T} 1$ & $1,08 \mathrm{E}-2$ & $7,41 \mathrm{E}-3$ & 8,99E-3 & 9,35E-3 & $7,96 \mathrm{E}-4$ & $1,47 \mathrm{E}-2$ & $8,21 \mathrm{E}-3$ & $1,11 \mathrm{E}-2$ & $1,05 \mathrm{E}-2$ & $1,74 \mathrm{E}-3$ \\
\hline & & $\mathrm{T} 2$ & $1,43 E 0$ & $9,66 \mathrm{E}-1$ & $1,2 \mathrm{E} 0$ & 1,3E0 & $1,43 \mathrm{E}-1$ & $7,54 \mathrm{E} 0$ & $3,35 \mathrm{E} 0$ & $5 \mathrm{E} 0$ & $5,43 \mathrm{E} 0$ & $1,05 \mathrm{E} 0$ \\
\hline & & T3 & $3,64 \mathrm{E}-4$ & $2,56 \mathrm{E}-4$ & $2,92 \mathrm{E}-4$ & $3,23 \mathrm{E}-4$ & $2,7 \mathrm{E}-5$ & 2,79E-4 & 1,38E-4 & $1,96 \mathrm{E}-4$ & $1,93 \mathrm{E}-4$ & $3,77 \mathrm{E}-5$ \\
\hline ETMOF40 & IGD & $\mathrm{T} 1$ & 7,12E1 & $4,27 \mathrm{E} 1$ & $6,22 \mathrm{E} 1$ & 6,39E1 & 7,22E0 & $8,2 \mathrm{E} 1$ & $5,94 \mathrm{E} 1$ & $7,13 \mathrm{E} 1$ & $6,46 \mathrm{E} 1$ & $5,06 \mathrm{E} 0$ \\
\hline & & $\mathrm{T} 2$ & $5,75 \mathrm{E}-2$ & $6,63 \mathrm{E}-3$ & $1,74 \mathrm{E}-2$ & $1,28 \mathrm{E}-2$ & $1,08 \mathrm{E}-2$ & 9,27E-3 & $5,54 \mathrm{E}-3$ & $6,34 \mathrm{E}-3$ & $6,21 \mathrm{E}-3$ & $8,11 E-4$ \\
\hline & & T3 & 1,2E1 & $1,48 \mathrm{E} 0$ & $3,41 \mathrm{E} 0$ & $3,1 \mathrm{E} 0$ & $2,58 \mathrm{E} 0$ & 1,12E0 & $8,2 \mathrm{E}-1$ & 9,17E-1 & $8,21 \mathrm{E}-1$ & $7,99 \mathrm{E}-2$ \\
\hline & MIGD & T1 & $2,25 \mathrm{E} 0$ & $1,66 \mathrm{E} 0$ & $1,96 \mathrm{E} 0$ & $1,84 \mathrm{E} 0$ & $1,39 \mathrm{E}-1$ & 1E0 & $5,06 \mathrm{E}-1$ & 7,02E-1 & 6,41E-1 & 1,29E-1 \\
\hline & & $\mathrm{T} 2$ & $9,97 \mathrm{E}-4$ & $2,13 \mathrm{E}-4$ & $4,58 \mathrm{E}-4$ & $4,57 \mathrm{E}-4$ & $1,68 \mathrm{E}-4$ & 1,02E-4 & $4,66 \mathrm{E}-5$ & 6,57E-5 & $8,16 \mathrm{E}-5$ & $1,47 \mathrm{E}-5$ \\
\hline & & T3 & $1,93 \mathrm{E}-1$ & $4,62 \mathrm{E}-2$ & $9,57 \mathrm{E}-2$ & $1,6 \mathrm{E}-1$ & $4,34 \mathrm{E}-2$ & $1,26 \mathrm{E}-2$ & 6,87E-3 & 9,02E-3 & $7,85 \mathrm{E}-3$ & $1,51 \mathrm{E}-3$ \\
\hline
\end{tabular}




\section{References}

[1] A. Gupta, Y. S. Ong, and L. Feng, "Multifactorial Evolution: Toward Evolutionary Multitasking," IEEE Transactions on Evolutionary Computation, vol. 20, no. 3, pp. 343-357, Jun. 2016, doi: 10.1109/TEVC.2015.2458037.

[2] Y. S. Ong and A. Gupta, "Evolutionary Multitasking: A Computer Science View of Cognitive Multitasking," Cognitive Computation, vol. 8, no. 2, pp. 125-142, Apr. 2016, doi: 10.1007/s12559-016-9395-7.

[3] T. Zeugmann et al., "Particle Swarm Optimization," in Encyclopedia of Machine Learning, Boston, MA: Springer US, 2011, pp. 760-766. doi: 10.1007/978-0-387-30164-8_630.

[4] A. Aboud, N. Rokbani, S. Mirjalili, and A. Alimi, "A Distributed Bi-behaviors Crow Search Algorithm for Dynamic Multi-Objective Optimization and Many-Objective Optimization," Sep. 2021, doi: 10.36227/TECHRXIV.16607858.V2.

[5] K. Deb, A. Pratap, S. Agarwal, and T. Meyarivan, "A fast and elitist multiobjective genetic algorithm: NSGA-II," IEEE Transactions on Evolutionary Computation, vol. 6, no. 2, pp. 182-197, Apr. 2002, doi: 10.1109/4235.996017.

[6] Q. Zhang and H. Li, "MOEA/D: A multiobjective evolutionary algorithm based on decomposition," IEEE Transactions on Evolutionary Computation, vol. 11, no. 6, pp. 712-731, Dec. 2007, doi: 10.1109/TEVC.2007.892759.

[7] A. Aboud, R. Fdhila, and A. M. Alimi, "MOPSO for dynamic feature selection problem based big data fusion," in 2016 IEEE International Conference on Systems, Man, and Cybernetics, SMC 2016 - Conference Proceedings, Feb. 2017, pp. 3918-3923. doi: 10.1109/SMC.2016.7844846.

[8] A. Aboud, R. Fdhila, and A. M. Alimi, "Dynamic Multi Objective Particle Swarm Optimization Based on a New Environment Change Detection Strategy," in Lecture Notes in Computer Science (including subseries Lecture Notes in Artificial Intelligence and Lecture Notes in Bioinformatics), Nov. 2017, vol. 10637 LNCS, pp. 258-268. doi: 10.1007/978-3-319-70093-9_27.

[9] A. Aboud, R. Fdhila, A. Hussain, and A. M. Alimi, "A novel Dynamic Pareto bi-level MultiObjective Particle Swarm Optimization (DPb-MOPSO) algorithm," TechRxiv, Dec. 2020. doi: 10.36227/TECHRXIV.13325354.V1.

[10] M. Farina, K. Deb, and P. Amato, "Dynamic multiobjective optimization problems: Test cases, approximations, and applications," IEEE Transactions on Evolutionary Computation, vol. 8, no. 5, pp. 425-442, Oct. 2004, doi: 10.1109/TEVC.2004.831456.

[11] A. Aboud et al., "DPb-MOPSO: A Novel Dynamic Pareto bi-level Multi-Objective Particle Swarm Optimization Algorithm", doi: 10.36227/TECHRXIV.17207576.

[12] A. Gupta, J. Mańdziuk, and Y.-S. Ong, "Evolutionary multitasking in bi-level optimization," Complex \& Intelligent Systems 2016 1:1, vol. 1, no. 1, pp. 83-95, Feb. 2016, doi: 10.1007/S40747-016-0011-Y. 
[13] J. Lin, H.-L. Liu, K. C. Tan, and F. Gu, "An Effective Knowledge Transfer Approach for Multiobjective Multitasking Optimization," IEEE Transactions on Cybernetics, vol. 51, no. 6, pp. 3238-3248, Mar. 2020, doi: 10.1109/tcyb.2020.2969025.

[14] J. Ding, C. Yang, Y. Jin, and T. Chai, "Generalized Multitasking for Evolutionary Optimization of Expensive Problems," IEEE Transactions on Evolutionary Computation, vol. 23, no. 1, pp. 44-58, Feb. 2019, doi: 10.1109/TEVC.2017.2785351.

[15] A. Gupta, Y. S. Ong, L. Feng, and K. C. Tan, "Multiobjective Multifactorial Optimization in Evolutionary Multitasking," IEEE Transactions on Cybernetics, vol. 47, no. 7, pp. 1652-1665, Jul. 2017, doi: 10.1109/TCYB.2016.2554622.

[16] Y. Yuan, Y. S. Ong, A. Gupta, P. S. Tan, and H. Xu, "Evolutionary multitasking in permutationbased combinatorial optimization problems: Realization with TSP, QAP, LOP, and JSP," IEEE Region 10 Annual International Conference, Proceedings/TENCON, pp. 3157-3164, Feb. 2017, doi: 10.1109/TENCON.2016.7848632.

[17] K. C. Tan, L. Feng, and M. Jiang, "Evolutionary Transfer Optimization - A New Frontier in Evolutionary Computation Research," IEEE Computational Intelligence Magazine, vol. 16, no. 1, pp. 22-33, Feb. 2021, doi: 10.1109/MCl.2020.3039066.

[18] G. Li, Q. Lin, and W. Gao, "Multifactorial optimization via explicit multipopulation evolutionary framework," Information Sciences, vol. 512, pp. 1555-1570, Feb. 2020, doi: 10.1016/J.INS.2019.10.066.

[19] S. J. Pan and Q. Yang, "A survey on transfer learning," IEEE Transactions on Knowledge and Data Engineering, vol. 22, no. 10, pp. 1345-1359, 2010, doi: 10.1109/TKDE.2009.191.

[20] L. Shao, F. Zhu, and X. Li, "Transfer learning for visual categorization: A survey," IEEE Transactions on Neural Networks and Learning Systems, vol. 26, no. 5, pp. 1019-1034, May 2015, doi: 10.1109/TNNLS.2014.2330900.

[21] K. Weiss, T. M. Khoshgoftaar, and D. Wang, "A survey of transfer learning," Journal of Big Data 2016 3:1, vol. 3, no. 1, pp. 1-40, May 2016, doi: 10.1186/S40537-016-0043-6.

[22] A. M. Alimi, “BETA NEURO-FUZZY SYSTEMS," vol. 1, no. 1, pp. 23-41, 2003.

[23] L. Zhou et al., "Toward Adaptive Knowledge Transfer in Multifactorial Evolutionary Computation," IEEE Transactions on Cybernetics, vol. 51, no. 5, pp. 2563-2576, May 2021, doi: 10.1109/TCYB.2020.2974100.

[24] C. Yang, J. Ding, Y. Jin, and T. Chai, "Offline data-driven multiobjective optimization: Knowledge transfer between surrogates and generation of final solutions," IEEE Transactions on Evolutionary Computation, vol. 24, no. 3, pp. 409-423, Jun. 2020, doi: 10.1109/TEVC.2019.2925959.

[25] L. Zhou et al., "Solving dynamic vehicle routing problem via evolutionary search with learning capability," in 2017 IEEE Congress on Evolutionary Computation, CEC 2017 - Proceedings, Jul. 2017, pp. 890-896. doi: 10.1109/CEC.2017.7969403. 
[26] G. Ruan, L. L. Minku, S. Menzel, B. Sendhoff, and X. Yao, "When and How to Transfer Knowledge in Dynamic Multi-objective Optimization," 2019 IEEE Symposium Series on Computational Intelligence, SSCI 2019, pp. 2034-2041, Dec. 2019, doi: 10.1109/SSCI44817.2019.9002815.

[27] M. Jiang, Z. Wang, H. Hong, and G. G. Yen, "Knee Point-Based Imbalanced Transfer Learning for Dynamic Multiobjective Optimization," IEEE Transactions on Evolutionary Computation, vol. 25, no. 1, pp. 117-129, Feb. 2021, doi: 10.1109/TEVC.2020.3004027.

[28] M. Jiang, Z. Wang, L. Qiu, S. Guo, X. Gao, and K. C. Tan, "A Fast Dynamic Evolutionary Multiobjective Algorithm via Manifold Transfer Learning," IEEE Transactions on Cybernetics, vol. 51, no. 7, pp. 3417-3428, May 2020, doi: 10.1109/TCYB.2020.2989465.

[29] L. Feng, Y. S. Ong, S. Jiang, and A. Gupta, "Autoencoding evolutionary search with learning across heterogeneous problems," IEEE Transactions on Evolutionary Computation, vol. 21, no. 5, pp. 760-772, Oct. 2017, doi: 10.1109/TEVC.2017.2682274.

[30] Z. Liang, W. Liang, X. Xu, L. Liu, and Z. Zhu, "A Two stage Adaptive Knowledge Transfer Evolutionary Multi-tasking Based on Population Distribution for Multi/Many-Objective Optimization," Jan. 2020, Accessed: Jul. 25, 2021. [Online]. Available: https://arxiv.org/abs/2001.00810v3

[31] B. Da et al., "Evolutionary Multitasking for Single-objective Continuous Optimization: Benchmark Problems, Performance Metric, and Baseline Results," Jun. 2017, Accessed: Aug. 25, 2021. [Online]. Available: https://arxiv.org/abs/1706.03470v1

[32] Y. Yuan et al., "Evolutionary Multitasking for Multiobjective Continuous Optimization: Benchmark Problems, Performance Metrics and Baseline Results," Jun. 2017, Accessed: Aug. 25, 2021. [Online]. Available: https://arxiv.org/abs/1706.02766v1

[33] Z. J. Wang, Z. H. Zhan, S. Kwong, H. Jin, and J. Zhang, "Adaptive Granularity Learning Distributed Particle Swarm Optimization for Large-Scale Optimization," IEEE Transactions on Cybernetics, vol. 51, no. 3, pp. 1175-1188, Mar. 2021, doi: 10.1109/TCYB.2020.2977956.

[34] M. Jiang, Z. Huang, L. Qiu, W. Huang, and G. G. Yen, "Transfer Learning-Based Dynamic Multiobjective Optimization Algorithms," IEEE Transactions on Evolutionary Computation, vol. 22, no. 4, pp. 501-514, Aug. 2018, doi: 10.1109/TEVC.2017.2771451.

[35] A. Muruganantham, K. C. Tan, and P. Vadakkepat, "Solving the IEEE CEC 2015 Dynamic Benchmark Problems Using Kalman Filter Based Dynamic Multiobjective Evolutionary Algorithm," pp. 239-252, 2016, doi: 10.1007/978-3-319-27000-5_20.

[36] N. Rokbani, M. Slim, and A. M. Alimi, "The Beta distributed PSO, $\beta$-PSO, with application to Inverse Kinematics," Proceedings - 2021 IEEE 4th National Computing Colleges Conference, NCCC 2021, Mar. 2021, doi: 10.1109/NCCC49330.2021.9428811.

[37] J. J. Durillo and A. J. Nebro, "JMetal: A Java framework for multi-objective optimization," Advances in Engineering Software, vol. 42, no. 10, pp. 760-771, Oct. 2011, doi: 10.1016/j.advengsoft.2011.05.014. 
[38] P. A. N. Bosman and D. Thierens, "The balance between proximity and diversity in multiobjective evolutionary algorithms," IEEE Transactions on Evolutionary Computation, vol. 7, no. 2, pp. 174-188, Apr. 2003, doi: 10.1109/TEVC.2003.810761.

[39] S. Jiang and S. Yang, "Evolutionary Dynamic Multiobjective Optimization: Benchmarks and Algorithm Comparisons," IEEE Transactions on Cybernetics, vol. 47, no. 1, pp. 198-211, Jan. 2017, doi: 10.1109/TCYB.2015.2510698.

[40] M. Dordevic, "Statistical analysis of various hybridization of evolutionary algorithm for traveling salesman problem," in Proceedings of the IEEE International Conference on Industrial Technology, Feb. 2019, vol. 2019-February, pp. 899-904. doi: 10.1109/ICIT.2019.8755092.

[41] K. Deb, S. Agrawal, A. Pratap, and T. Meyarivan, "A Fast Elitist Non-dominated Sorting Genetic Algorithm for Multi-objective Optimization: NSGA-II," Lecture Notes in Computer Science (including subseries Lecture Notes in Artificial Intelligence and Lecture Notes in Bioinformatics), vol. 1917, pp. 849-858, 2000, doi: 10.1007/3-540-45356-3_83.

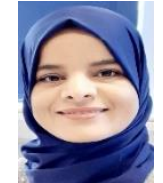

Ahlem Aboud She is currently a PhD student in computer science in ISITCom, University of Sousse in collaboration with REGIM-lab: REsearch Group on Intelligent Machines at ENIS Sfax, University of Sfax. She received his engineering degree in 2015 from the ISIMS Sfax. She is currently IEEE student member since October 2015. His research interests including: dynamic multi-objective optimization, many-objective optimization evolutionary computation, bio-inspired methods and machine learning.

Nizar Rokbani He is an Assit Prof of Industrial Computing with Institute of Applied Science and technology of Sousse, Tunisia Since 2014. He graduated in Electrical Engineering from the National Engineering School of Tunis, ENIT in 1995. He obtained a Master degree in industrial computing in 2003 from the National Engineering School of Sfax, ENIS, and a PHD in Electrical Engineering in 2013. His research interests include applications of intelligent techniques such as Swarm intelligence, computational intelligence, fuzzy logic, evolutionary algorithms to robotic systems and industrial processing. He funded several society chapters, including RAS and SMC 2009, and OES 2016, he is also the founding counselor of ISSAT Sousse Sb 2015, and Polytech Sousse $\mathrm{Sb}, 2016$. He is The IEEE RAS Tunisia Chair 2015-2018, the chapter was awarded: R8 Outstanding Society Chapter 2016, Best RAS Society Chapter award for 2017, and Outstanding Society chapter award of Tunisia Section for 2017.

Seyedalii Mirjalili is a Professor and the director of the Centre for Artificial Intelligence Research and Optimization at Torrens University Australia. He is internationally recognized for his advances in Swarm Intelligence and Optimization, including the first set of algorithms from a synthetic intelligence standpoint - a radical departure from how natural systems is typically understood - and a systematic design framework to reliably benchmark, evaluate, and propose computationally cheap robust optimization algorithms. Seyedali has published over 300 publications with over 35,000 citations and an $\mathrm{H}$-index of 65 . As the most cited researcher in Robust Optimization, he is in the list of $1 \%$ highly-cited researchers and named as one of the most influential researchers in the world by Web of Science. Seyedali is a senior member of IEEE and an associate

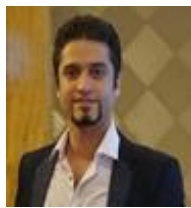
editor of several journals including Neurocomputing, Applied Soft Computing, Computers in Biology and Medicine, Advances in Engineering Software, Applied Intelligence, and IEEE Access. His research interests include Robust Optimization, Engineering Optimization, Multiobjective Optimization, Swarm Intelligence, Evolutionary Algorithms, and Artificial Neural Networks. He is working on the application of multi-objective and robust meta-heuristic optimization techniques as well. 
Dr Abdulrahman Qahtani is currently Assistant professor in computer science department at Taif University. Dr. Qahtani received his PhD from Southampton University in 2015. He has extensive experience in software engineering and development process in a distributed domain. His research focused on customization process across organizational boundaries. Recently, he applied machine learning algorithms on software engineering data to predict time and cost estimation for multi-client's projects.

Omar Almutiry received the PhD degree from the University of Southampton, UK, in 2017. Since 2018, he has been with the Applied Computer Science College, King Saud University, Saudi Arabia, where he is currently working as an Assistant Professor with the Department of Applied Computer Sciences. He is also assistant to the General Director of the Almuzahmiyah branch for academic affairs and development. His research areas include data science, health informatics, deep learning applications in healthcare and medical fields.

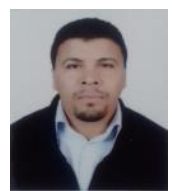

Habib Dhahri was born in Sidi Bouzid, Tunisia in 1975. He graduated in Computer Science in 2001, obtained his PhD in Computer Science in 2013 from the National Engineering School of Sfax (ENIS). He is now an assistant professor in Computer Science at the King Saud University. His area of interest includes computational intelligence, soft computing techniques and Machine Learning for Healthcare Data. He has authored and co-authored more than 30 publications in journals and conferences. He also serves as a reviewer for several international scientific journals.

Adel M. Alimi (S'91-M'96-SM'00) was born in Sfax, Tunisia, in 1966. He received the Degree in electrical engineering in 1990, the Ph.D. degree in electrical and computer engineering from the Polytechnic University of Montreal, Montr ' eal, QC, ' Canada, in 1995, and the HDR degree in electrical and computer engineering from the National Engineering School of Sfax, Sfax, in 2000. He is currently a Professor of electrical and computer engineering with the University of Sfax, Sfax. His current research interests include applications of intelligent methods (neural networks, fuzzy logic, and evolutionary algorithms) to pattern recognition, robotic systems, vision systems, industrial processes, intelligent pattern recognition, learning, analysis, and intelligent control of

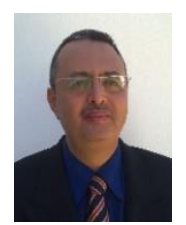
large-scale complex systems. Prof. Alimi is a member of IAPR, INNS, and PRS. He is a member and an Associate Editor of the Editorial Board of many international scientific journals, including Pattern Recognition Letters, Neurocomputing, Neural Processing Letters, International Journal of Image and Graphics, Neural Computing and Applications, International Journal of Robotics and Automation, and International Journal of Systems Science. He was a Guest Editor of several special issues of international journals, including Fuzzy Sets and Systems, Soft Computing, the Journal of Decision Systems, Integrated Computer-Aided Engineering, and Systems Analysis Modeling and Simulations. 